\author{
Universidade de São Paulo \\ Escola de Engenharia de São Carlos \\ Programa de Pós-Graduação em Engenharia Elétrica
}

Fabrício Bonfim Rodrigues de Oliveira

\title{
Redução de Perdas de Sistemas de Distribuição através do Dimensionamento Ótimo de Bancos de Capacitores via Entropia Cruzada
}



Fabrício Bonfim Rodrigues de Oliveira

\section{Redução de Perdas de Sistemas de Distribuição através do Dimensionamento Ótimo de Bancos de Capacitores via Entropia Cruzada}

Dissertação apresentada à Escola de Engenharia de São Carlos da Universidade de São Paulo, como parte dos requisitos para obtenção do título de Mestre em ciências, Programa de Engenharia Elétrica ${ }^{1}$.

Área de Concentração: Sistema Elétrico de Potência

Orientador: Prof. Dr. Eduardo Nobuhiro Asada 
AUTORIZO A REPRODUÇ̃̃O TOTAL OU PARCIAL DESTE TRABALHO, POR QUALQUER MEIO COONVENCIONAL OU ELETRÔNICO, PARA FINS DE ESTUDO E PESQUISA, DESDE QUE CITADA A FONTE.

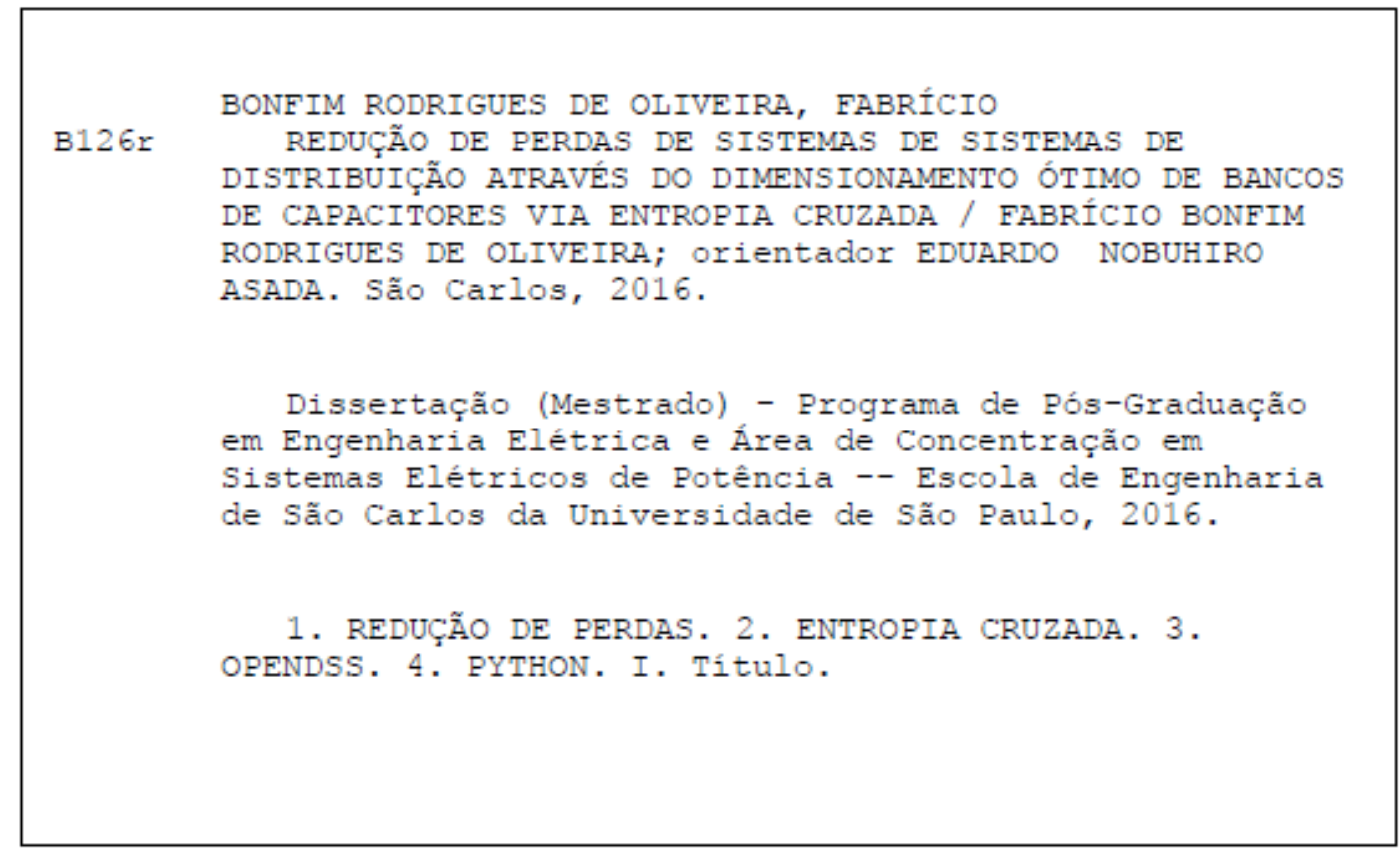




\section{FOLHA DE JULGAMENTO}

Candidato: Engenheiro FABRICIO BONFIM RODRIGUES DE OLIVEIRA.

Título da dissertaçāo: "Redução de perdas de sistemas de distribuição através do dimensionamento ótimo de bancos de capacitores via entropia cruzada".

Data da defesa: $21 / 11 / 2016$.

Comissão Julgadora:

Resultado:

Prof. Associado Eduardo Nobuhiro Asada (Orientador)

APROVAON

(Escola de Engenharia de São Carlos/EESC)

Prof. Dr. Rubén Augsuto Romero Lázaro

(Universidade Estadual Paulista "Júlio de Mesquita Filho"/UNESP" - Iha Solteira)

Profa. Dra. Fernanda Caseño Trindade Arioli

APROVADO

(Universidade Estadual de Campinas/UNICAMP)

Coordenador do Programa de Pós-Graduaçāo em Engenharia Elétrica: Prof. Associado Luis Fernando Costa Alberto

Presidente da Comissão de Pós-Graduação:

Prof. Associado Luis Fernando Costa Alberto 
Ao meu avô, Eng. Dr. Edward Bonfim. 


\section{Agradecimentos}

Primeiramente, agradeço a minha esposa Vanessa, aos meus pais Divino e Indiara e minha avó Edna por oferecerem essa oportunidade de ampliar meus conhecimentos e pelo apoio incondicional. Agradecimento especial, ao meu avô, Eng. Dr. Edward Bonfim, por ter sido, e sempre será, meu eterno mentor, sem seus conselhos nada do que me tornei hoje seria possível.

Agradeço, imensamente, o Professor Dr. Eduardo Asada por ter confiado em mim, acreditar que conseguiria realizar este trabalho. Pela paciência nos momentos mais difíceis da realização deste projeto. Agradeço ao Dr. Benvindo pelas sugestões e orientações, que sem elas ficaria muito mais difícil atingir o objetivo final.

Ao meu irmão Frederico pelo apoio, por estar sempre aconselhando e também por dividir os momentos de dificuldade.

Agradeço aos meus amigos Jason e Diego, por me ajudarem de todas as formas, ter dividido as dificuldades e alegrias deste momento. E todos os outros amigos e familiares que de alguma forma puderam contribuir com a realização deste trabalho.

Agradeço a todos os professores: Dr. José Carlos, Dr. Benvindo, Dr. Eduardo Werley, que contribuíram com seus conhecimentos ministrando disciplinas necessárias para cumprimento dos créditos. E a todos os colegas do grupo de trabalho LASEE.

Por fim, agradeço a Universidade de São Paulo, as agências de fomento CAPES e FAPESP (proc. 2014/27342-1) por terem disponibilizados as condições necessárias e de extrema importância, pois sem elas o desenvolvimento deste projeto de pesquisa não teria alcançado seu objetivo. 


\section{SUMÁRIO}

Resumo

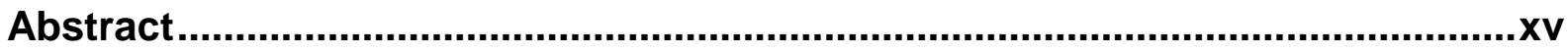

Lista de Siglas e Abreviaturas ...........................................................................

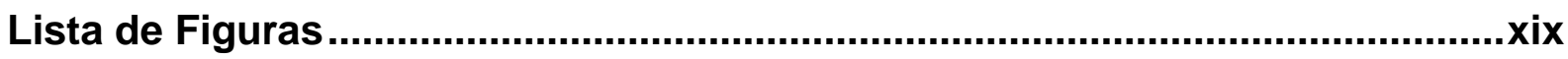

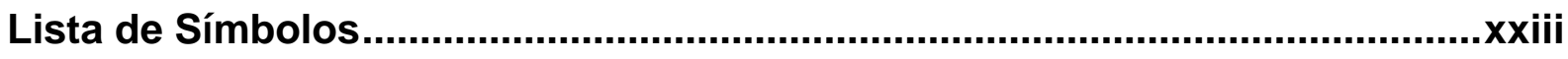

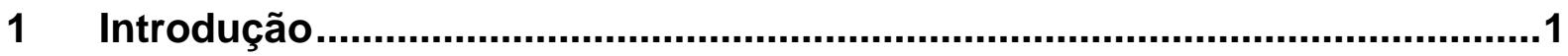

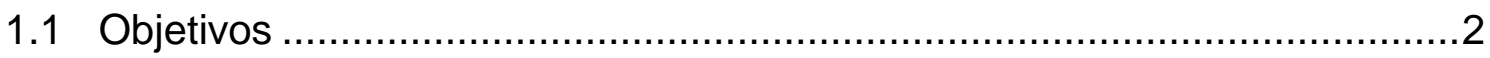

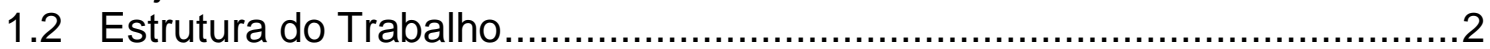

2 Métodos de Redução de Perdas em Sistemas de Distribuição de Energia

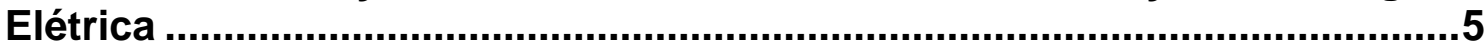

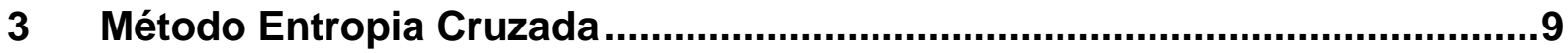

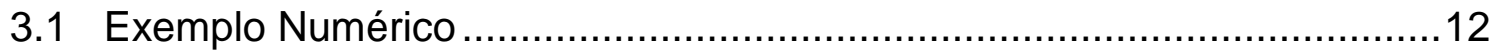

4 Metodologia da Abordagem de Solução ....................................................17

4.1 Formulação Matemática do Problema...................................................17

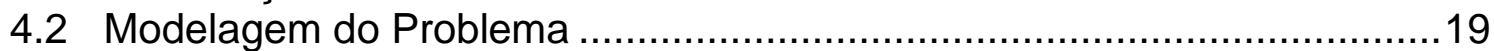

4.3 Implementação da Abordagem de Solução ……………………….......22

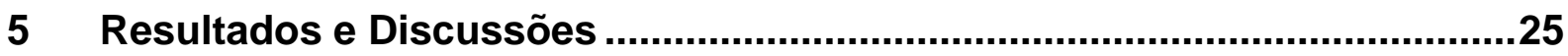

5.1 Sistema 36 barras balanceado .........................................................25

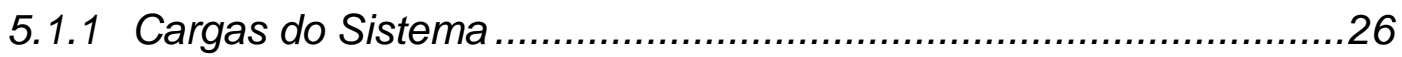

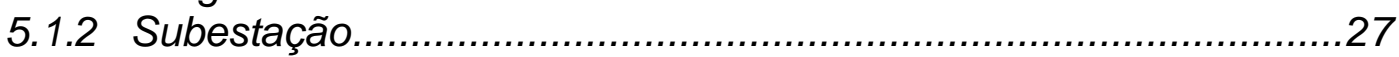

5.1.3 Geradores Distribuídos.......................................................2.

5.1.4 Bancos de Capacitores........................................................28

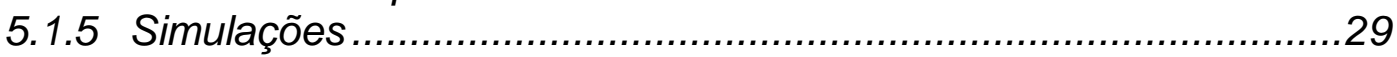

5.1.6 Bancos de Capacitores Fixos e Período de Maior Demanda-

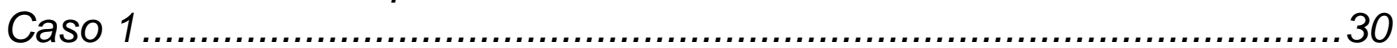

5.1.7 Bancos de Capacitores Ajustáveis e Período de Maior Demanda -

Caso 2 ................................................................................... 32

5.1.8 Bancos de Capacitores Fixos e Período de Menor Demanda-

Caso 3 .................................................................................. 37

5.1.9 Bancos de Capacitores Ajustáveis e Período de Menor Demanda -

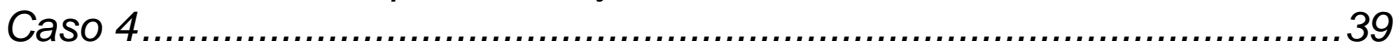

5.1.10 Discussão dos Casos 1 ao 4 .......................................................4 44

5.1.11 Seleção de $\mathrm{Ne}$ Nel para demais simulações .................................46

5.1.12 Simulação Geração Distribuída e Regulador de Tensão..................49

5.1.13 Sistema com curva de carga de 10 pontos..................................52

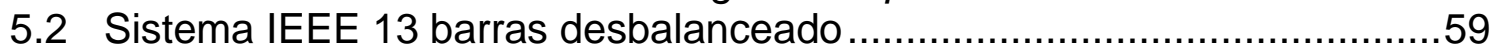

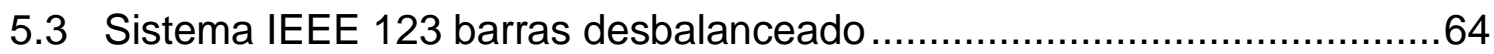

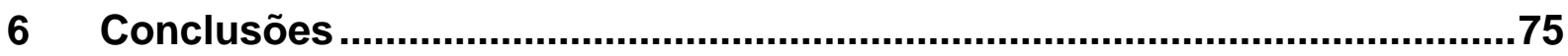

Referências Bibliográficas ...........................................................................77

Apêndice 
Software OpenDSS 


\section{Resumo}

Oliveira, F. B. R. Redução de Perdas de Sistemas de Distribuição através do Dimensionamento Ótimo de Bancos de Capacitores via Entropia Cruzada. Dissertação (Mestrado) - Escola de Engenharia de São Carlos, Universidade de São Paulo, São Carlos, 2016.

Os Sistemas de Distribuição são responsáveis pelo fornecimento da energia elétrica aos consumidores residenciais, industriais e comerciais com padrões de qualidade regulamentados pela Agência Nacional de Energia Elétrica (ANEEL). Assim, as concessionárias monitoram seu sistema para verificar o perfil de tensão na rede elétrica e as perdas técnicas do sistema. Este último critério de desempenho é extremamente relevante, pois representa o desperdício em energia e diminuição na capacidade de receita da empresa. Portanto, há interesse em fornecer a energia elétrica dentro das especificações regidas pela ANEEL e com as menores perdas elétricas possível. Contudo, técnicas como reconfiguração de linhas, recondutoramento, alocação de capacitores e geradores distribuídos são aplicadas. Em especial, a alocação de capacitores é uma técnica que visa identificar a quantidade, localização e tipo dos bancos de capacitores (BCs) que serão alocados no sistema com o intuito de minimizar as perdas, levando em consideração custos de implantação e operação. Para tal, métodos computacionais são utilizados para definir a melhor configuração dos BCs. As metaheurítiscas têm sido aplicadas na solução deste problema, cuja função objetivo é a minimização das perdas técnicas do sistema de distribuição. Desta forma, este trabalho tem o objetivo de propor uma abordagem de solução utilizando a metaheurística Entropia Cruzada implementada 
no software Python para redução das perdas de sistemas elétricos modelados no OpenDSS. A abordagem se mostrou uma importante ferramenta de análise de sistemas de distribuição, proporcionando resultados extremamente satisfatórios.

Palavras Chave: Entropia Cruzada, Redução de Perdas, OpenDSS, Python. 


\section{Abstract}

Oliveira, F. B. R. Losses Reduction of Distribution Systems through Optimal Dimensioning of Capacitor Banks via Cross Entropy. Dissertation (Master Degree) - School Engineering, University of São Paulo, São Carlos, 2016.

The distribution systems are responsible for providing electricity to residential, industrial and commercial consumers under quality standards regulated by the National Electric Energy Agency (ANEEL). Thus, utilities monitor the system to check the voltage profile in the grid and system technical losses. The latter quantity is an extremely important performance criterion, as it represents energy losses and decrease in revenue capacity of the company. Therefore, there is interest in providing electricity within specification stated by ANEEL with the lowest possible electrical losses. Techniques such as topology reconfiguration, reconductoring, allocation of capacitors and distributed generators are usually proposed in technical studies. Particularly, the allocation of capacitors is a technique that aims to identify the amount, location and type of capacitor banks (CBs), which are allocated in the system in order to minimize the losses, taking into consideration the implementation and operation costs. For this purpose, computational methods are used to determine the best configuration of CBs. Metaheuristics have been applied for the solution of this problem, with the objective to minimize the technical losses of distribution systems. This document shows the development of a solution method using the Cross Entropy metaheuristic implemented in Python programming language to reduce the losses of electrical systems modeled in OpenDSS program. The 
developed approach resulted in an important analysis tool for distribution systems, providing extremely satisfactory results.

Keywords: Cross Entropy, Loss Reduction, OpenDSS, Python. 


\section{Lista de Siglas e Abreviaturas}

SEP Sistema Elétrico de Potência

GD Geração Distribuída

BC Banco de Capacitor

EC Entropia Cruzada

mu Média dos valores da amostra

sigma Desvio padrão da amostra incial

$\mathrm{N} \quad$ Amostra inicial

Nel Amostra de elite 
xviii 


\section{Lista de Figuras}

Figura 3.1 - Algoritmo Genérico para Entropia Cruzada [24] ................................12

Figura 3.2 - Procedimento da Entropia Cruzada descrita pela função $f(x)$ [21] .......13

Figura 3.3 - Algoritmo Matlab de Otimização da função S [21].................................14

Figura 3.4 - Ilustração da evolução do algoritmo entropia cruzada. ........................15

Figura 4.1 - Fluxo de Potência entre as barras p e q [11] ......................................17

Figura 4.2 - Modelagem do método de entropia cruzada para dimensionamento

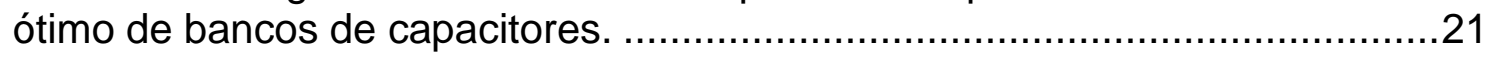

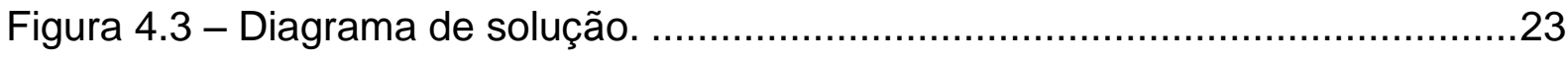

Figura 5.1 - Diagrama unifilar do Sistema Elétrico de 36 barras [26] ....................26

Figura 5.2 - Caso 2 para $\mathrm{N}=20, \mathrm{Nel}=4$, mu=1200 KVAr, sigma $=600 \mathrm{kVAr}$, erro $=50 \mathrm{kVAr}$, iterações $=9$ e Perdas Totais $=687,544 \mathrm{~kW}$.

Figura 5.3 - Caso 2 para $\mathrm{N}=40, \mathrm{Nel}=12$, mu=1200 KVAr, sigma $=600 \mathrm{kVAr}$, erro $=50 \mathrm{kVAr}$, iterações $=13$ e Perdas Totais $=681,369 \mathrm{~kW}$.

Figura 5.4 - Caso 4 para $\mathrm{N}=20$, $\mathrm{Nel}=4$, mu=1200 KVAr, sigma $=600 \mathrm{kVAr}$, erro $=50 \mathrm{kVAr}$, iterações $=11$ e Perdas Totais $=747,800 \mathrm{~kW}$.

Figura 5.5 - Caso 4 para $\mathrm{N}=40$, Nel=12, mu=1200 KVAr, sigma $=600 \mathrm{kVAr}$, erro $=50 \mathrm{kVAr}$, iterações $=13$ e Perdas Totais $=741,023 \mathrm{~kW}$.

Figura 5.6 - Consolidado de resultados.

Figura 5.7 - Média de Perdas Elétricas por Elitização. ..........................................48

Figura 5.8 - Média de Perdas Elétricas por Elitização. ..........................................48

Figura 5.9 - Comportamento algoritmo geração distribuída e regulador de tensão

Figura 5.10 - Carregamento x Perdas - Sistema 36 barras. ………......................54

Figura 5.11 - Tensão $(\mathrm{pu})$ nas barras por carregamento - Sistema 36 barras.........56

Figura 5.12 - Carregamento x Potência Reativa Total dos Bancos de Capacitores - Sistema 36 barras.

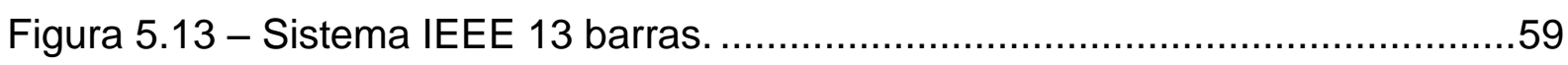

Figura 5.14 - Carregamento x Perdas - Sistema 13 barras. ...................................60 
Figura 5.15 - Carregamento x Potência Total Bancos de Capacitores - Sistema 13 barras.

Figura 5.16 - Tensão Fase-Neutro em pu - Carregamento 10\% - Sistema 13 barras.

Figura 5.17 - Sistema IEEE 123 barras.

Figura 5.18 - Comportamento Algoritmo Otimização para Sistema IEEE 123 barras.

Figura 5.19 - Identificação das tensões nas barras. Azul: barras com tensão acima de 1,02 pu. Verde: barras com tensão entre 1,0 e 1,02 pu. Vermelho: barras com tensão abaixo de 1,0 pu. 66

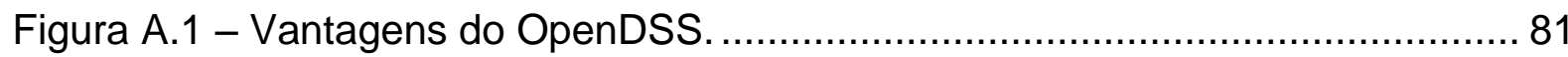

Figura A.2 - Aplicações do OpenDSS ................................................................ 82

Figura A.3 - Verificação da Interface Python-OpenDSS. ………............................ 83

Figura A.4 - Configuração comunicação Python-OpenDSS. ………………......... 84 


\section{Lista de Tabelas}

Tabela 5.1 - Cargas do Sistema Elétrico por período ...........................................27

Tabela 5.2 - Parâmetros da Subestação .........................................................27

Tabela 5.3 - Parâmetros dos Geradores ..........................................................28

Tabela 5.4 - Localização dos Bancos de Capacitores ............................................29

Tabela 5.5 - Tensões resultantes do cálculo de fluxo de carga para o caso 1.........31

Tabela 5.6 - Tensões resultantes do cálculo de fluxo de carga para $\mathrm{N}=20$, $\mathrm{Nel}=4, \mathrm{mu}=1200 \mathrm{KVAr}$, sigma $=600 \mathrm{kVAr}$, erro=50 kVAr, iterações=9 e Perdas Totais $=687,544 \mathrm{~kW}$.

Tabela 5.7 - Banco de Capacitores para $\mathrm{N}=20$, Nel=4, mu=1200 KVAr, sigma $=600 \mathrm{kVAr}$, erro $=50 \mathrm{kVAr}$, iterações $=9$ e Perdas Totais $=687,544$ $\mathrm{kW}$.......

Tabela 5.8 - Banco de Capacitores para $\mathrm{N}=40$, Nel=12, mu=1200 KVAr, sigma $=600 \mathrm{kVAr}$, erro $=50 \mathrm{kVAr}$, iterações $=9$ e Perdas Totais $=681,369$ $\mathrm{kW}$.......

Tabela 5.9 - Tensões resultantes do cálculo de fluxo de carga para $\mathrm{N}=40$, $\mathrm{Nel}=12, \mathrm{mu}=1200 \mathrm{KVAr}$, sigma=600 kVAr, erro=50 kVAr, iterações $=9 \mathrm{e}$ Perdas Totais $=681,369 \mathrm{~kW}$.

Tabela 5.10 - Banco de Capacitores para caso 3.................................................37

Tabela 5.11 - Tensões resultantes do cálculo de fluxo de carga do caso 3.

Tabela 5.12 - Tensões do cálculo de fluxo de carga para $\mathrm{N}=20$, Nel=4, $\mathrm{mu}=1200 \mathrm{KVAr}$, sigma $=600 \mathrm{kVAr}$, erro=50 kVAr, iterações=9 e Perdas Totais $=747,800 \mathrm{~kW}$

Tabela 5.13 - Banco de Capacitores para $\mathrm{N}=20$, Nel=4, mu=1200 KVAr, sigma $=600 \mathrm{kVAr}$, erro $=50 \mathrm{kVAr}$, iterações $=9$ e Perdas Totais $=747,800$ $\mathrm{kW}$.......

Tabela 5.14 - Banco de Capacitores para $\mathrm{N}=40$, Nel=12, mu=1200 KVAr, sigma $=600 \mathrm{kVAr}$, erro $=50 \mathrm{kVAr}$, iterações $=15$ e Perdas Totais $=741,023$ $\mathrm{kW}$.......

Tabela 5.15 - Tensões resultantes do cálculo de fluxo de carga para $\mathrm{N}=40$, $\mathrm{Nel}=12, \mathrm{~m}=1200 \mathrm{KVAr}$, sigma $=600 \mathrm{kVAr}$, erro=50 kVAr, iterações $=15 \mathrm{e}$ Perdas Totais $=741,023 \mathrm{~kW}$.

Tabela 5.16 - Resultados simulação taxas de elitização 10\%, 20 e 30\% .................47

Tabela 5.17 - Simulação geração distribuída e reguladores de tensão.....................50 
Tabela 5.18 - Perfil de tensão sem (V1) e com (V1') geração distribuída e reguladores de tensão....................................................................... 51

Tabela 5.19 - Curva de carga de 10 pontos por barra do sistema com valores percentuais do nível de carregamento. ...................................................... 53

Tabela 5.20 - Tensão $(\mathrm{pu})$ nas barras por carregamento - Sistema 36 barras........ 55

Tabela 5.21 - Bancos de capacitores por carregamento - Sistema 36 barras. ....... 58

Tabela 5.22 - Bancos de capacitores por carregamento - Sistema 13 barras. ........ 61

Tabela 5.23 - Tensão $(\mathrm{pu})$ nas barras por carregamento - Sistema 13 barras......... 63

Tabela 5.24 - Tensão fase-neutro e fase-fase para o sistema 123 barras............... 67 


\section{Lista de Símbolos}

\section{Conjuntos:}

$\Omega_{l} \quad$ Conjunto dos ramos.

$\Omega_{b} \quad$ Conjunto dos nós.

$\Omega_{a a} \quad$ Conjunto das chaves abertas.

$\Omega_{a f} \quad$ Conjunto das chaves fechadas.

$\Omega_{h} \quad$ Conjunto dos circuitos fictícios.

\section{Variáveis:}

$\begin{array}{ll}P_{i j} & \text { Fluxo de potência ativa no ramo } i j . \\ Q_{i j} & \text { Fluxo de potência reativa no ramo } i j . \\ I_{i j}^{s q r} & \text { Quadrado da magnitude do fluxo de corrente no ramo } i j . \\ P_{i}^{G} & \text { Geração de potência ativa no nó } i . \\ Q_{i}^{G} & \text { Geração de potência reativa no nó } i . \\ V_{i}^{s q r} & \text { Quadrado da magnitude de tensão no nó } i . \\ a_{i j} & \text { Variável auxiliar usado na modelagem no estado do ramo } i j . \\ H_{i j} & \text { Fluxo de potência artificial no ramo } i j . \\ H_{i}^{G} & \text { Geração de potência artificial no nó } i . \\ \vec{V}_{i} & \text { Fasor tensão no nó } i . \\ \vec{I}_{i j} & \text { Fasor corrente no ramo } i j . \\ I_{i j}^{2} & \text { Quadrado da magnitude da corrente no ramo } i j . \\ \theta_{i} & \text { Ângulo de fase da barra } i . \\ V_{i}^{2} & \text { Quadrado da magnitude de tensão no nó } i .\end{array}$




\section{Introdução}

O sistema de distribuição de energia é aquele que se confunde com a própria topografia das cidades, ramificado ao longo de ruas e avenidas para conectar fisicamente o sistema de transmissão, ou mesmo unidades geradoras de médio e pequeno porte, aos consumidores finais da energia elétrica [1]. A conexão, o atendimento e a entrega efetiva de energia elétrica ao consumidor do ambiente regulado ocorrem por parte das distribuidoras de energia. A energia distribuída, portanto, é a energia efetivamente entregue aos consumidores conectados à rede elétrica de uma determinada empresa de distribuição, podendo ser rede de tipo aérea (suportada por postes) ou de tipo subterrânea (com cabos ou fios localizados sob o solo, dentro de dutos subterrâneos). Do total da energia distribuída no Brasil, dentre as Distribuidoras associadas à Associação Brasileira de Distribuidores de Energia Elétrica (Abradee), o setor privado é responsável pela distribuição de, aproximadamente, $60 \%$ da energia, enquanto as empresas públicas se responsabilizam por, aproximadamente, $40 \%$ [1].

Pode-se dizer que o setor de distribuição é um dos mais regulados e fiscalizados do setor elétrico. A Agência Nacional de Energia Elétrica (ANEEL) edita Resoluções, Portarias e outras normas para o funcionamento adequado do setor de Distribuição, sendo muito rigorosa com sua fiscalização. Um exemplo são os Procedimentos de Distribuição (Prodist), o qual dispõe disciplinas, condições, responsabilidades e penalidades relativas à conexão, planejamento da expansão, 
operação e medição da energia elétrica. O Prodist, ainda, estabelece critérios e indicadores de qualidade para consumidores e produtores, distribuidores e agentes importadores e exportadores de energia [1].

Com o aumento das preocupações com os níveis de qualidade de energia estabelecidos pela ANEEL, o gerenciamento da potência reativa tem se tornado cada vez mais importante para as empresas fornecedoras de energia. No entanto, o crescimento das cargas longe dos centros geradores, as extensas linhas e as perdas técnicas e não técnicas resultam em variações de tensão nas barras, e assim comprometem a qualidade da energia elétrica fornecida. $O$ alto nível de potência reativa indutiva demandada nos sistemas de distribuição também causa problemas como a queda de tensão, o aumento das perdas, distorções no fator de potência e gastos com equipamentos mais robustos, causando dificuldades no controle da tensão [2].

\subsection{Objetivos}

Neste contexto, o presente trabalho tem por objetivo propor uma abordagem de solução utilizando técnica metaheurística para minimizar as perdas técnicas dos sistemas de distribuição pelo dimensionamento ótimo dos bancos de capacitores. Duas plataformas opensource OpenDSS e Python foram utilizadas e são explicadas no apêndice deste documento. A técnica Entropia Cruzada foi selecionada como algoritmo de otimização.

\subsection{Estrutura do Trabalho}

No Capítulo 2 é apresentado o levantamento bibliográfico dos métodos utilizados para redução das perdas elétricas em sistemas de distribuição de energia 
elétrica. No Capítulo 3 há a conceituação do método de entropia cruzada que será aplicado no algoritmo de otimização deste trabalho. No Capítulo 4, a formulação do problema e a abordagem de solução são descritas. Os resultados das simulações realizadas, bem como suas análises, são encontrados no Capítulo 5. Por fim, no Capítulo 6 têm-se a conclusão deste estudo e os trabalhos futuros que serão executados. 


\section{Métodos de Redução de Perdas em Sistemas de Distribuição de Energia Elétrica}

A crescente alta nos custos de distribuição devido ao aumento das perdas nos Sistemas de Distribuição motiva os engenheiros a melhorarem seus conhecimentos a respeito dos Sistemas de Energia Elétrica e aplicá-los na operação desses. Algumas formas básicas de redução das perdas no sistema podem ser citadas: recondutoramento, reconfiguração da rede e adição de bancos de capacitores ou gestão das cargas [3].

É sabido que as perdas no sistema de distribuição podem ser reduzidas diariamente, semanalmente e/ou sazonalmente através da reconfiguração do sistema tirando vantagens da diversidade de cargas. Cargas residenciais, industriais e comerciais diferem entre si e este comportamento pode ser observado em suas curvas de cargas. Quando possível, as cargas podem ser transferidas de um alimentador para outro com a finalidade de obter vantagem na redução de perdas do sistema pelas suas naturais diversidades, assim utilizando o sistema em sua total capacidade de operação. A reconfiguração manual é uma alternativa na redução das perdas, no entanto custos na capacitação de equipe especializada, combustível para transporte e tempo de manobra podem dificultar na obtenção do real benefício da reconfiguração [3]. Ainda, é possível melhorar o perfil de tensão e reduzir as perdas dos Sistemas de Distribuição através do ajuste adequado dos dispositivos de controle. 
Os bancos de capacitores (BC) são componentes cada vez mais aplicados nos sistemas de distribuição. Sua instalação torna-se frequentemente necessária, pois visa não só a redução das perdas ativas e reativas e melhoria nos perfis de tensão, mas também o controle do fluxo de potência, melhoria da estabilidade do sistema, redução do custo de operação dos sistemas, correção de fator de potência, compensação da potência reativa - produzida por cargas indutivas e pelas reatâncias das linhas, redução das cargas aparentes liberando capacidade para ligação de cargas adicionais e redução da componente atrasada da corrente [2][4]. Os benefícios reais obtidos com a instalação de capacitores em sistemas de distribuição dependem das características dos equipamentos e da forma como é feita essa instalação. Especificamente, dependem do número e tamanho dos capacitores, de sua localização, do tipo (fixos ou chaveados) e do esquema de controle utilizado. Muitas pesquisas já foram feitas no que tange à localização ótima de capacitores em sistemas de distribuição de energia balanceados [4].

A compensação por potência reativa tem sido estudada por muitos anos. Considerando esta como a função objetivo do problema, a minimização das perdas no sistema ou maximização da qualidade da tensão pode ser aplicadas, como mostrado em [5]. Neste âmbito, técnicas analíticas para otimizar a função objetivo perdas, como formulado em [6] através da reconfiguração da topologia do sistema, são utilizadas. Em contraste com estas técnicas, as metaheurísticas vêm se popularizando como alternativa eficiente de solução de problemas de otimização, possuindo o propósito de diminuir o exaustivo espaço de busca da solução para um conjunto factível de busca que possua a solução ótima do problema. O objetivo dessas técnicas é determinar a ótima localização, tamanho e número de capacitores alocados nos nós para atingir a máxima economia na implantação com a mínima 
perda [7]. A alocação combinada de GDs e BCs ao longo da rede pode ser aplicada para este fim, conforme realizado em [8]. Ainda, as condições de cargas devem ser levadas em consideração no tratamento do problema, com mostrado em [9][10][11].

As metaheurísiticas representam um conjunto de técnicas de otimização adaptadas para lidar com problemas complexos e que apresentam a característica da explosão combinatória. Essas técnicas foram desenvolvidas nas duas décadas passadas e são consideradas como as técnicas que devem apresentar maior evolução e utilização na resolução de problemas de otimização matemática complexa e que requerem tempo de processamento elevado [12].

A ideia fundamental de uma metaheurística consiste em analisar um espaço de busca considerado grande. Portanto, uma metaheurística é uma estratégia que especifica a forma em que deve ser realizada a busca de forma inteligente, isto é, a forma em que devem ser realizadas as transições através do espaço de busca partindo de um ponto inicial ou de um conjunto de pontos. Assim, a diferença entre as metaheurísticas é a estratégia usada por cada uma delas. A melhor metaheurística para determinado tipo de problema é aquela que encontra soluções de melhor qualidade para um número especificado de avaliações de espaço de busca [13]. Esses problemas são os seguintes:

1. Especificar uma forma de identificar ou representar um elemento do espaço de busca, isto é, uma proposta de solução do problema;

2. Especificar a forma de encontrar a função objetivo ou seu equivalente para cada proposta de solução;

3. Especificar a vizinhança da solução corrente; 
4. Especificar se a forma de realizar as transições de uma proposta de solução para outra deve ser realizada a partir de uma única referência ou de um conjunto de referências;

5. Se o processo de busca deve ser realizado através de soluções factíveis ou podem ser consideradas também soluções infactíveis no processo de busca. Ainda, pode-se citar importantes metaheurísitcas aplicadas para solução de problemas combinatórios, como a técnica Simulated Anneling idealizada por Metropolis e baseada no processo de construção de cristais perfeitos [14][15]; o Algoritmo Genético formulado usando os mecanismos da evolução e da genética natural [16]; e o método proposto em [17] e [18] por Fred Clover na década de 80, Busca Tabu, desenvolvido a partir do conceitos usados na inteligência artificial e, diferentemente, de outros métodos, não teve sua origem relacionada a processos de otimização biológicos ou físicos [15].

Este trabalho de pesquisa, como mencionado no Capítulo 1, possuiu por objetivo realizar o dimensionamento ótimo de bancos de capacitores para redução das perdas elétricas em sistemas de distribuição. Desta forma, a metaheurística entropia cruzada foi escolhida para compor o algoritmo de otimização que definiu a melhor configuração dos bancos de capacitores. A justificativa da seleção da técnica está na estrutura da metaheurística entropia cruzada, um algoritmo probabilístico baseado na densidade de probabilidade das variáveis do sistema. Além disto, foi de fácil implementação, possuiu aderência com a abordagem de solução e flexibilidade para se ajustar ao tamanho dos sistemas elétricos estudados e número de variáveis analisadas. 


\section{Método Entropia Cruzada}

Desenvolvido por Rubinstein em 1997, a entropia cruzada (EC) se demonstra eficiente para solução de problemas combinatórios complexos [19]. Pode ser dividido em duas fases:

1. Geração aleatória dos dados da amostra de acordo com específico mecanismo;

2. Atualização dos parâmetros do mecanismo para geração da melhor amostra na próxima iteração.

O método de entropia cruzada é uma abordagem para solução de problemas combinatórios, otimização de sistemas e simulação de ocorrências de eventos raros. Isto é, é aplicado em:

- Avaliação de riscos em projetos de expansão de linhas de transmissão, proporcionando identificação de cenários não favoráveis para o investimento [20].

- Planejamento ótimo da expansão da geração, levando em consideração o custo de investimento, demanda, viabilidade e segurança do projeto [21].

- Planejamento do "mix" no portfolio de fontes de energias renováveis com base no cenário econômico, político e ambiental [22].

A EC é uma adaptação do algoritmo de estimação de probabilidade de ocorrência de eventos raros em uma rede estocástica complexa. A melhor maneira de estimar essa probabilidade é encontrar a probabilidade da amostra de interesse, 
que é uma técnica de redução de variância, em que o sistema é simulado sob um conjunto diferente de parâmetros - ou, mais geralmente, uma probabilidade diferente de distribuição - de modo a fazer a ocorrência do evento raro mais provável [23].

Considere o problema de determinar a probabilidade, $\theta$, do evento raro $\Psi$ definido como a ocorrência de,

$$
S(X) \leq \gamma
$$

$S(X)$ é uma função desempenho de uma determinada amostra aleatória $X$ e $\gamma, \gamma \in \Re$, que representa o limiar da região de interesse do espaço amostral $X$ sob $f(; u) . X=\left(x_{1}, x_{2}, \ldots, x_{N}\right)$ é um vetor de $N$ números aleatórios pertencente a $X$.

A probabilidade $\theta$ pode ser expressa como,

$$
\theta=P_{u}\{S(X) \geq \gamma\}
$$

E a função teste $H(X)$ como,

$$
H(X)=I_{\{S(X) \geq \gamma\}}
$$

onde $I_{\{S(X) \geq \gamma\}}$, o operador Indicador, é definido como,

$$
I_{\{S(X) \geq \gamma\}}= \begin{cases}1 & \text { se } S(X) \geq \gamma \\ 0 & \text { se } S(X)<\gamma\end{cases}
$$

Utilizando simulação Monte Carlo convencional, $\theta$ pode ser estimada, em $f(; u)$, utilizando simulações por: 


$$
\theta=\frac{1}{N} \sum_{i=1}^{N} I_{\{S(X) \geq \gamma\}}
$$

No entanto, como o evento é raro, será necessário um elevado número de simulações e, consequentemente, alto esforço computacional para obter uma estimativa de $\theta$ com um coeficiente de variação dentro de uma tolerância aceitável. À medida que o evento $\theta$ torna-se mais raro, esse esforço será ainda maior. Desta forma, para tornar possível a simulação de eventos raros dentro de limites de tempo praticáveis, pode-se utilizar um estimador por meio de amostragem por importância, i.e., IS (Interest Sample).

Considere a sequência de números aleatórios $X=\left(x_{1}, x_{2}, \ldots, x_{N}\right)$ gerados em $X$ sob a função massa de probabilidade (pmf) $g$, sendo $g$ a função que associa cada possível ocorrência de uma variável aleatória uma probabilidade. Nessas condições $\theta$, será estimado através de IS por:

$$
\theta^{\prime}=L R\{\theta\}=\frac{1}{N} \sum_{i=1}^{N} I_{\{S(X) \geq \gamma\}} W(X)
$$

Onde,

$$
W(X)=\frac{f(X)}{g(X)}
$$

LR é o estimador utilizado para obter $\theta^{\prime}$ e o parâmetro $W(X)$ é denominado razão de verossimilhança. $O$ problema de estimar $\theta$ torna-se, então, determinar a pmf. Nesse sentido, como $\theta^{\prime}$ deve ser o mais próximo possível de $\theta$, deve-se obter uma função $g$ cuja distância estatística de $f$ seja mínima. Uma medida da distância 
estatística entre $f$ e $g$ pode ser obtida pela distância de Kullback-Leibler, também conhecida como Entropia Cruzada entre e $f$ e $g$.

Pode-se sintetizar os procedimentos da Entropia Cruzada através da descrição do algoritmo genérico retratado na Figura 3.1.

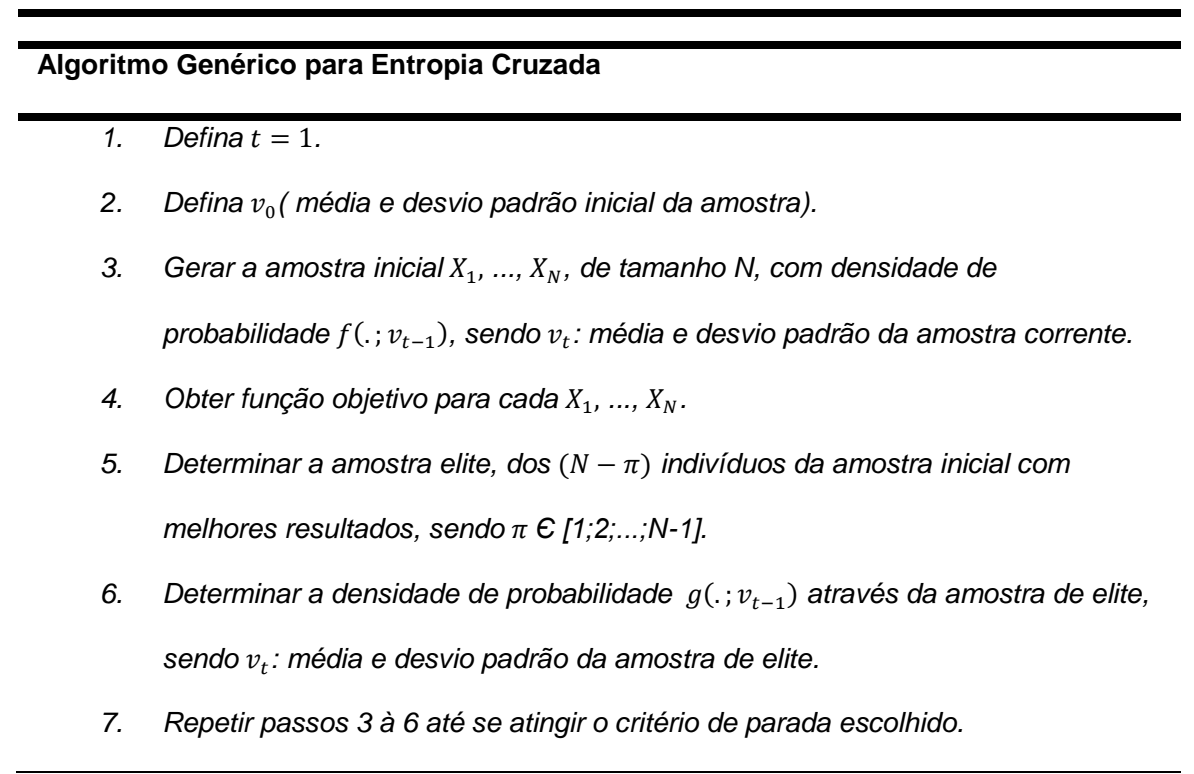

Figura 3.1 - Algoritmo Genérico para Entropia Cruzada [24].

\subsection{Exemplo Numérico}

Considere a otimização da função $S$ dada por [19]:

$$
S(x)=e^{-(x-2)^{2}}+0.8 e^{-(x+2)^{2}}, x \in \Re
$$

Como observado na Figura 3.2, $S$ tem máximo local em -2.00 e máximo global em 2.00. Considere ainda, que $f(x)$ seja a densidade de probabilidade da amostra corrente cuja média representa o valor de $x$ que maximiza a função $S$. Inicialmente $f(x)$ está definida por: 
- Média: $\mu_{0}=-6$;

- Desvio padrão: $\sigma_{0}=100$;

- Dimensão amostra de elite: $N^{\text {elite }}=10$;

- Dimensão amostra total: $N=100$;

- Critério de parada: $\varepsilon=0.05$.

O procedimento da Entropia Cruzada é comparado a "saltos" da densidade de probabilidade $f(x)$ da amostra de elite. Estes "saltos", como mostrado na Figura 3.2, são através da variação da média e desvio padrão, isto é, a medida que o algoritmo evolui, a média da amostra se aproxima do máximo global de $S(x)$, x igual a 2.00. Observa-se que o vetor $(\mu, \sigma)$ converge rapidamente para $(2.00,0.00)$.
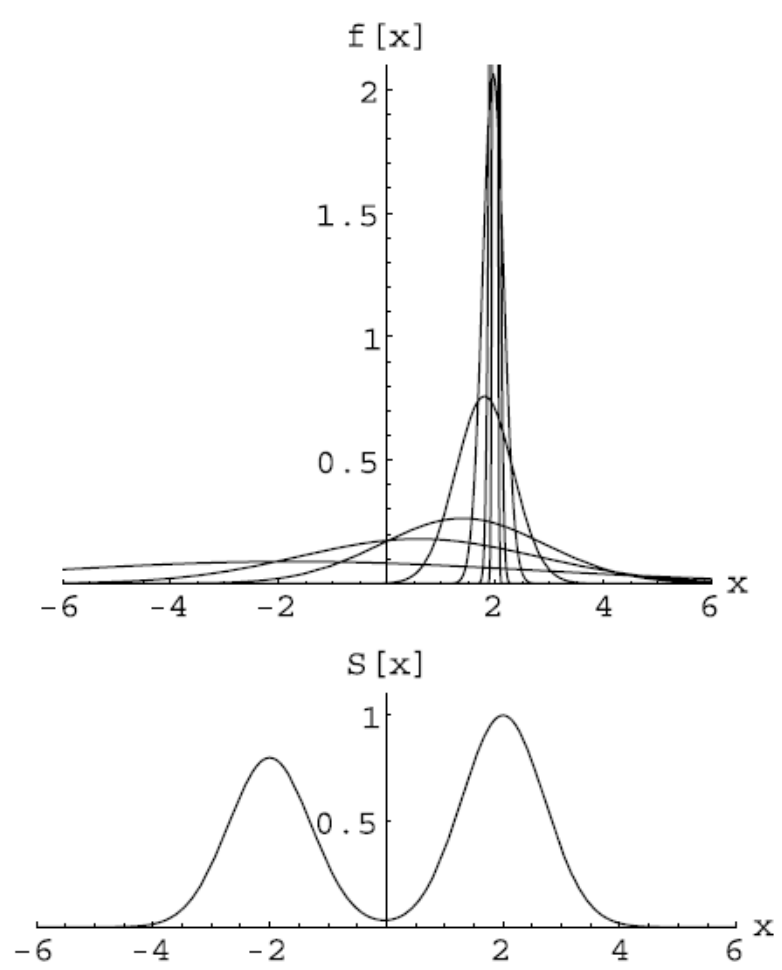

Figura 3.2 - Procedimento da Entropia Cruzada descrita pela função $f(x)$ [21].

Uma possível implementação em MATLAB para a otimização desta função é descrita na Figura 3.3 [21], Sendo: 
- $\boldsymbol{m u}$ a média;

- sigma o desvio padrão;

- No tamanho da amostra inicial;

- Nel o tamanho da amostra de elite;

- eps o critério de parada;

- $\quad \boldsymbol{x}$ a amostra inicial;

- SX a função objetivo;

- Xel a amostra de elite.

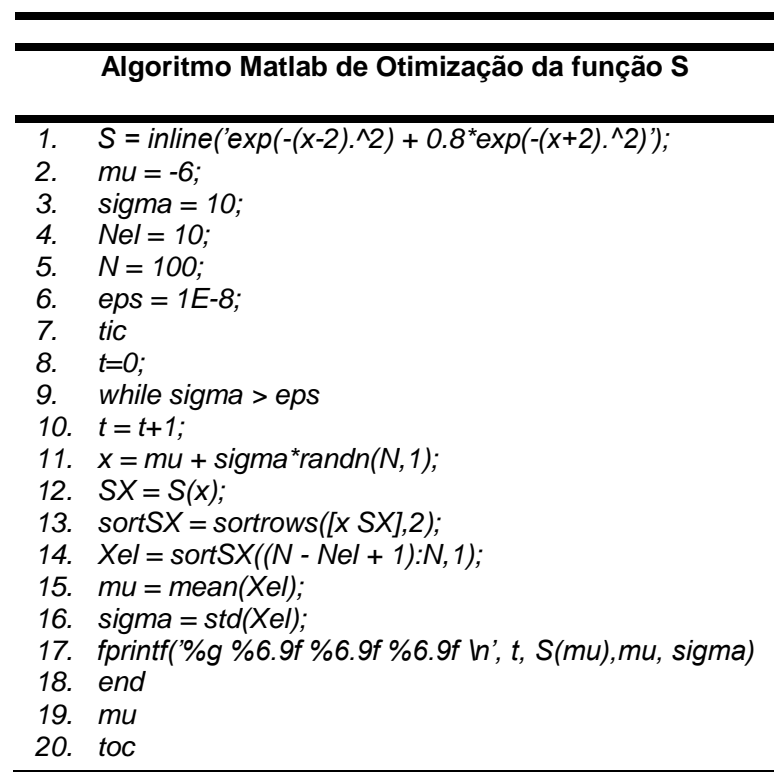

Figura 3.3 - Algoritmo Matlab de Otimização da função S [21].

Podemos ilustrar o método para melhor entendimento na Figura 3.4. A condição inicial é dada pela média e desvio padrão $(\mu, \sigma)$ que irão definir cada indivíduo $X_{N}$ da amostra inicial. Por sua vez, a função objetivo $f\left(X_{N}\right)$ é calculada e os melhores valores são ordenados de forma crescente. Por fim, a amostra de elite é composta pelos indivíduos $X_{N}$ com os melhores valores para a função objetivo, nesta 
nova amostra se obtém a média e desvio padrão. À medida que o algoritmo evolui, a média tenderá ao ponto ótimo do sistema e o desvio padrão ao critério de parada.

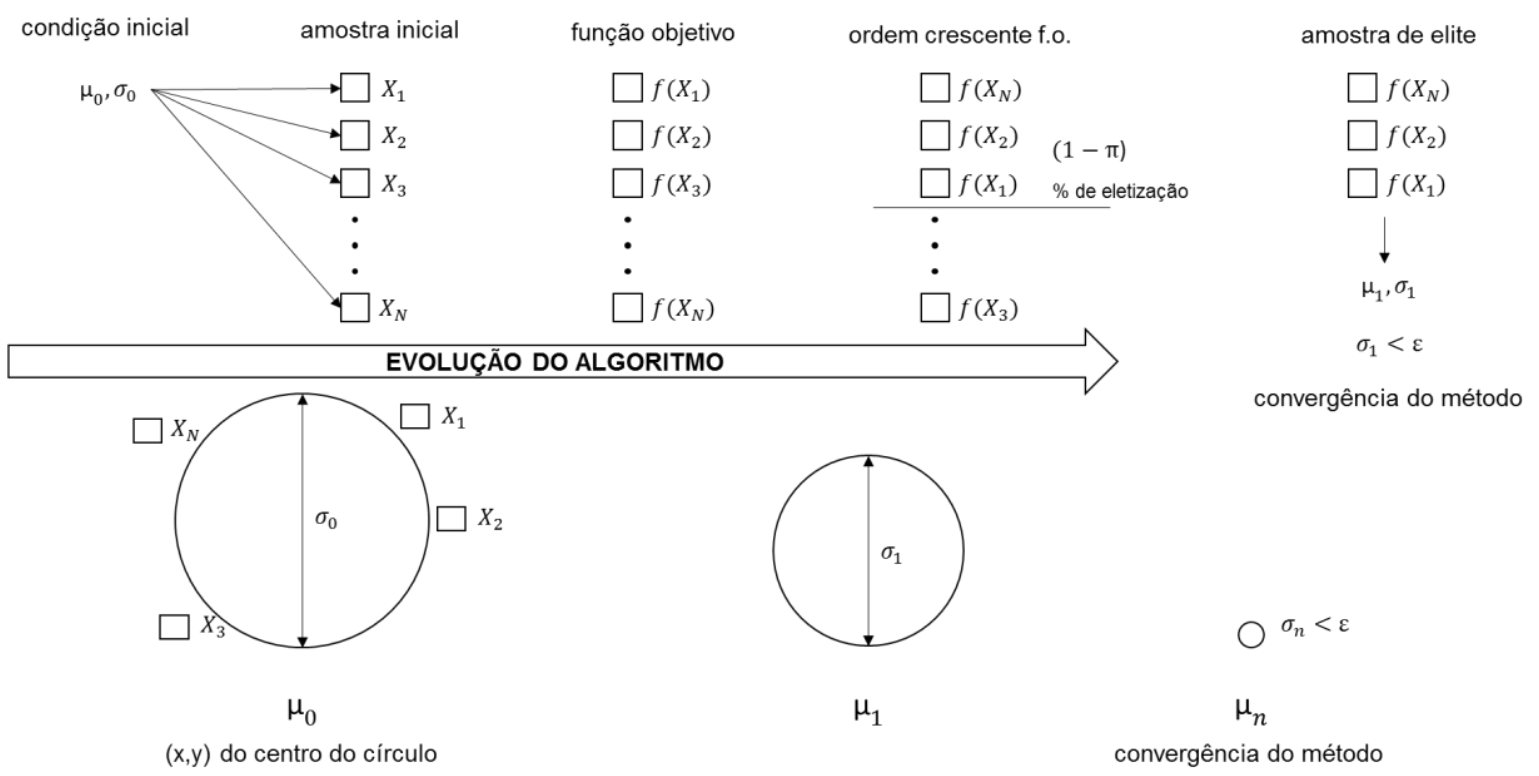

Figura 3.4 - Ilustração da evolução do algoritmo entropia cruzada.

No próximo Capítulo, serão descritas a formulação matemática do problema de redução de perdas em sistemas de distribuição, a abordagem de solução deste trabalho de pesquisa e a modelagem dos parâmetros da metaheurística entropia cruzada para o dimensionamento ótimo de bancos de capacitores. Além disto, serão apresentados os dois softwares utilizados, Phython e OpenDSS. 


\section{Metodologia da Abordagem de Solução}

\subsection{Formulação Matemática do Problema}

O problema de alocação e dimensionamento de bancos de capacitores é importante, pois seu projeto inadequado resulta em diminuição da eficiência do sistema, aumento dos custos de operação e das perdas do sistema [11]. Desta forma, este estudo propõe uma nova abordagem de solução para o problema de minimização das perdas técnicas $\left(P_{L}\right)$ dos Sistemas de Distribuição através do ajuste ótimo dos bancos de capacitores para cada período de carregamento [11].

Considere a linha conectada entre as barras $p$ e $q$ de um sistema de distribuição mostrado na Figura 4.1.

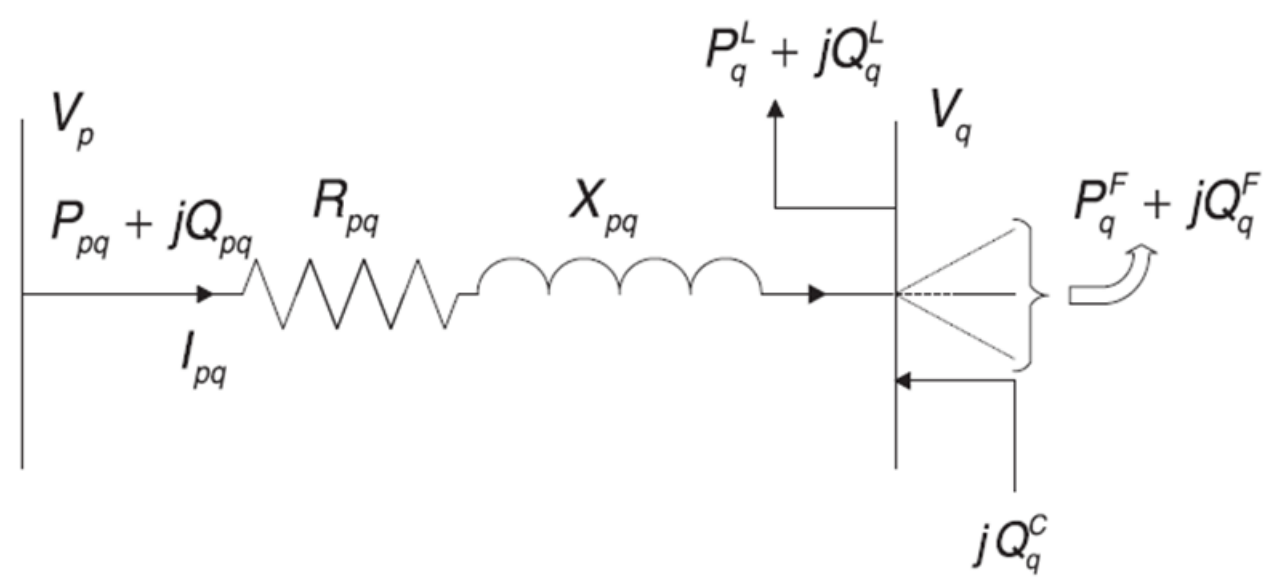

Figura 4.1 - Fluxo de Potência entre as barras p e q [11]. 
O Fluxo de Potência entre os nós $p$ e $q$ é dado por:

$$
\begin{gathered}
P_{p q}=P_{q}^{F}+P_{q}^{L}+\frac{R_{p q}}{V_{p}^{2}}\left(P_{p q}^{2}+Q_{p q}^{2}\right) \\
Q_{p q}=Q_{q}^{F}+Q_{q}^{L}+\frac{X_{p q}}{V_{p}^{2}}\left(P_{p q}^{2}+Q_{p q}^{2}\right)-Q_{q}^{C} \\
V_{q}^{2}=V_{p}^{2}-2\left(P_{p q} R_{p q}+Q_{p q} X_{p q}\right)+\frac{R_{p q}{ }^{2}+X_{p q}^{2}}{V_{p}^{2}}\left(P_{p q}^{2}+Q_{p q}^{2}\right)
\end{gathered}
$$

Sendo,

$$
P_{q}^{F}=\sum_{i, j=q} P_{i j} \text { e } Q_{q}^{F}=\sum_{i, j=q} Q_{i j}
$$

Onde $P_{p q}$ e $Q_{p q}$ são os fluxos de potência ativa e reativa entre $p$ e $q$. $Q_{q}^{C}$ é a injeção de potência reativa e $P_{q}^{L} e Q_{q}^{L}$ são potência ativa e reativa, respectivamente, demandada pela carga na barra $q . P_{q}^{F} e Q_{q}^{F}$ são a soma de potência ativa e reativa de todas as barras conectadas à barra $q$.

Ainda, a corrente entre $p$ e q é:

$$
I_{p q}=\sqrt{\frac{P_{p q}^{2}+Q_{p q}^{2}}{V_{p}^{2}}}
$$


Portanto, a função objetivo do problema em questão é dada matematicamente por:

$$
\operatorname{Min} P_{L}=\sum_{p, q \in S} I_{p q}^{2} R_{p q}
$$

\subsection{Modelagem do Problema}

Como mencionado nos Capítulos anteriores, deseja-se minimizar as perdas elétricas através do dimensionamento ótimo de bancos de capacitores já alocados previamente no sistema. Para tal, algumas considerações são necessárias para a modelagem adequado do problema:

1. A configuração dos bancos de capacitores $(\mathbf{B C O})$ é a variável do problema de minimização das perdas elétricas, caso dimensionamento ótimo seja alcançado, tem-se as menores perdas.

2. O tamanho da amostra inicial $\boldsymbol{N}$ é definido como a quantidade de valores $\boldsymbol{X}_{\boldsymbol{N}}$ em kVAr para cada banco de capacitor $\boldsymbol{C}_{\boldsymbol{N}}$.

3. O tamanho da amostra de elite $\mathbf{N e l}$ é definido como a quantidade de valores $\boldsymbol{X}_{\boldsymbol{N}}$ em kVAr para cada banco de capacitor $\boldsymbol{C}_{\boldsymbol{N}}$ que resultaram nas menores perdas elétricas.

4. A configuração inicial dos bancos de capacitores é dada pela média $\mu_{0}$.

5. O desvio padrão da configuração inicial é dado por $\boldsymbol{\sigma}_{\mathbf{0}}$.

6. A lei de geração dos possíveis valores $\boldsymbol{X}_{\boldsymbol{N}}$ em kVAr de um dado banco de capacitor $\boldsymbol{C}_{\boldsymbol{N}}$ é dada por $\mathbf{X}$, sendo este descrito pela soma 
entre a média $\mu$ dos valores $\boldsymbol{X}_{\boldsymbol{N}}$ de um banco de capacitor $\boldsymbol{C}_{\boldsymbol{N}}$ e o desvio padrão $\boldsymbol{\sigma}$ desta amostra. Matematicamente, temos: $\boldsymbol{X}=$ $\mu_{c N}+$ random. $\sigma_{c N}$.

7. O critério de parada do algoritmo é dado por $\varepsilon$, sendo este em kVAr. Caso o desvio padrão $\boldsymbol{\sigma}$ da amostra corrente seja menor que $\boldsymbol{\varepsilon}$, algoritmo convergiu.

Para ilustração do método descrito acima, considere-se um sistema elétrico com doze bancos de capacitores inicialmente de 1200 kVAr cada e já alocados nas barras.

Assim temos:

- Quantidade de bancos de capacitores, BCO igual a 12;

- Tamanho da amostra $C_{N}, N$ igual a 5;

- Tamanho da amostra de elite, $\mathrm{Nel}$ igual a 3;

- Valor inicial do banco de capacitor $C_{N}, \mu_{0}$ igual a 1200 kVAr;

- Desvio padrão do valor inicial do banco de capacitor $C_{N}, \sigma_{0}$ igual a 600 kVAr;

- Critério de parada $\varepsilon$ igual a 50 kVAr.

A Figura 4.2 mostra a modelagem citada. Inicialmente, todos os bancos de capacitores possuem valores iguais a $1200 \mathrm{kVAr}$. Em procedimentos temos:

1. Para cada banco, haverá geração de cinco ( $\boldsymbol{N}$ igual a 5$)$ valores de $X_{N}$, com base na lei de geração $X=\mu_{c N}+\operatorname{random} . \sigma_{c N}$;

2. As perdas elétricas serão obtidas para cada indivíduo, ou seja: $\left(X_{1}^{C 1}, X_{1}^{C 2}, X_{1}^{C 3}, \ldots, X_{1}^{C 12}\right) \rightarrow$ f.o.Perdas P $_{1}$

3. As perdas elétricas obtidas são colocadas em ordem crescente; 
4. As configurações de bancos de capacitores $X_{5}^{C n}, X_{3}^{C n} e X_{1}^{C n}$ que produziram as menores perdas elétricas são selecionadas;

5. As médias $\mu_{C n}$ e desvios padrão $\sigma_{C n}$ para cada banco de capacitor $C_{N}$ são calculados.

6. Caso todos os desvios padrão $\sigma_{C n}$ sejam menores que o critério de parada $\varepsilon$ igual a $50 \mathrm{kVAr}$, algoritmo convergiu.

$12 \mathrm{BCO}, \quad \mathrm{N}=5, \quad \mathrm{Nel}=3, \quad \mu_{0}=1200 \mathrm{kVAr}, \quad \sigma_{1}=600 \mathrm{kVAr}, \quad \varepsilon=50 \mathrm{kVAr}$

\begin{tabular}{|c|c|c|c|c|c|c|c|c|c|c|c|c|c|}
\hline \multirow{7}{*}{ amostra inicial } & \multicolumn{12}{|c|}{$\boldsymbol{X}=\mu_{c N}+$ random. $\sigma_{c N}$} & \multirow[b]{2}{*}{ f.o. } \\
\hline & $c_{1}$ & $c_{2}$ & $c_{3}$ & $C_{4}$ & $C_{5}$ & $c_{6}$ & $c_{7}$ & $C_{8}$ & $C_{9}$ & $c_{10}$ & $c_{11}$ & $c_{12}$ & \\
\hline & $X_{1}$ & $X_{1}$ & $X_{1}$ & $X_{1}$ & $X_{1}$ & $X_{1}$ & $X_{1}$ & $X_{1}$ & $X_{1}$ & $X_{1}$ & $X_{1}$ & $X_{1}$ & Perdas 1 \\
\hline & $X_{2}$ & $X_{2}$ & $X_{2}$ & $X_{2}$ & $X_{2}$ & $X_{2}$ & $X_{2}$ & $X_{2}$ & $X_{2}$ & $X_{2}$ & $X_{2}$ & $X_{2}$ & Perdas 2 \\
\hline & $X_{3}$ & $X_{3}$ & $X_{3}$ & $X_{3}$ & $X_{3}$ & $X_{3}$ & $X_{3}$ & $X_{3}$ & $X_{3}$ & $X_{3}$ & $X_{3}$ & $X_{3}$ & Perdas 3 \\
\hline & $X_{4}$ & $X_{4}$ & $X_{4}$ & $X_{4}$ & $X_{4}$ & $X_{4}$ & $X_{4}$ & $X_{4}$ & $X_{4}$ & $X_{4}$ & $X_{4}$ & $X_{4}$ & Perdas 4 \\
\hline & $X_{5}$ & $x_{5}$ & $x_{5}$ & $X_{5}$ & $X_{5}$ & $X_{5}$ & $X_{5}$ & $X_{5}$ & $x_{5}$ & $X_{5}$ & $X_{5}$ & $X_{5}$ & Perdas 5 \\
\hline \multirow{6}{*}{ ordem crescente de Perdas } & $c_{1}$ & $C_{2}$ & $C_{3}$ & $C_{4}$ & $C_{5}$ & $c_{6}$ & $C_{7}$ & $C_{8}$ & $C_{9}$ & $c_{10}$ & $c_{11}$ & $c_{12}$ & f.o. \\
\hline & $X_{5}$ & $X_{5}$ & $x_{5}$ & $x_{5}$ & $x_{5}$ & $x_{5}$ & $X_{5}$ & $X_{5}$ & $X_{5}$ & $X_{5}$ & $x_{5}$ & $X_{5}$ & Perdas 5 \\
\hline & $X_{3}$ & $X_{3}$ & $X_{3}$ & $X_{3}$ & $X_{3}$ & $X_{3}$ & $X_{3}$ & $X_{3}$ & $X_{3}$ & $X_{3}$ & $X_{3}$ & $X_{3}$ & Perdas 3 \\
\hline & $X_{1}$ & $X_{1}$ & $X_{1}$ & $X_{1}$ & $X_{1}$ & $X_{1}$ & $X_{1}$ & $X_{1}$ & $X_{1}$ & $X_{1}$ & $X_{1}$ & $X_{1}$ & Perdas 1 \\
\hline & $X_{4}$ & $X_{4}$ & $X_{4}$ & $X_{4}$ & $X_{4}$ & $X_{4}$ & $X_{4}$ & $X_{4}$ & $X_{4}$ & $X_{4}$ & $X_{4}$ & $X_{4}$ & Perdas 4 \\
\hline & $X_{2}$ & $X_{2}$ & $X_{2}$ & $X_{2}$ & $X_{2}$ & $X_{2}$ & $X_{2}$ & $X_{2}$ & $X_{2}$ & $X_{2}$ & $X_{2}$ & $X_{2}$ & Perdas 2 \\
\hline \multirow{5}{*}{ elitização 3/5 } & $c_{1}$ & $c_{2}$ & $c_{3}$ & $C_{4}$ & $C_{5}$ & $c_{6}$ & $C_{7}$ & $C_{8}$ & $C_{9}$ & $c_{10}$ & $c_{11}$ & $c_{12}$ & f.o. \\
\hline & $X_{5}$ & $X_{5}$ & $X_{5}$ & $x_{5}$ & $X_{5}$ & $X_{5}$ & $X_{5}$ & $X_{5}$ & $X_{5}$ & $X_{5}$ & $X_{5}$ & $X_{5}$ & Perdas 5 \\
\hline & $X_{3}$ & $X_{3}$ & $X_{3}$ & $X_{3}$ & $X_{3}$ & $X_{3}$ & $X_{3}$ & $X_{3}$ & $X_{3}$ & $X_{3}$ & $X_{3}$ & $X_{3}$ & Perdas 3 \\
\hline & $X_{1}$ & $X_{1}$ & $X_{1}$ & $X_{1}$ & $X_{1}$ & $X_{1}$ & $X_{1}$ & $X_{1}$ & $X_{1}$ & $X_{1}$ & $X_{1}$ & $X_{1}$ & \multirow[t]{2}{*}{ Perdas 1} \\
\hline & $\begin{array}{l}\mu_{c 1} \\
\sigma_{c 1}\end{array}$ & $\begin{array}{l}\mu_{c 2} \\
\sigma_{c 2}\end{array}$ & $\begin{array}{l}\mu_{c 3} \\
\sigma_{c 3}\end{array}$ & $\begin{array}{l}\mu_{c 4} \\
\sigma_{c 4}\end{array}$ & $\begin{array}{l}\mu_{c 5} \\
\sigma_{c 5}\end{array}$ & $\begin{array}{l}\mu_{c 6} \\
\sigma_{c 6}\end{array}$ & $\begin{array}{l}\mu_{\mu_{c 7}} \\
\sigma_{c 7}\end{array}$ & $\begin{array}{l}\mu_{c s} \\
\sigma_{c 8}\end{array}$ & $\begin{array}{l}\mu_{c \theta} \\
\sigma_{c \theta}\end{array}$ & $\begin{array}{l}\mu_{c 10} \\
\sigma_{c 10}\end{array}$ & \begin{tabular}{|l|}
$\mu_{c 11}$ \\
$\sigma_{c 11}$
\end{tabular} & $\begin{array}{l}\mu_{c 12} \\
\sigma_{c 12}\end{array}$ & \\
\hline
\end{tabular}

Figura 4.2 - Modelagem do método de entropia cruzada para dimensionamento ótimo de bancos de capacitores. 


\subsection{Implementação da Abordagem de Solução}

Para implementação do método de entropia cruzada e sistemas elétricos que foram analisados, se utilizou dois softwares:

1. No OpenDSS foram implementados os Sistemas Elétricos que serão descritos com mais detalhe no Capitulo 5. Esta ferramenta possui a estrutura COM Serve que permite sua comunicação externa com softwares, como MATLAB, Python, C++ e VB.

2. O software Python foi selecionado por ser uma plataforma opensource para implementação da metaheurística Entropia Cruzada.

A Figura 4.3 mostra o diagrama da estrutura proposta. Os sistemas elétricos foram modelados no OpenDSS, levando-se em consideração a quantidade de barras, localização dos bancos de capacitores e cargas, presença de geradores distribuídos e topologia da linha. Através da estrutura COM Serve, o software Python comunica-se com o OpenDSS para informar qual a configuração adequada dos bancos de capacitores. Após isto, o OpenDSS calcula a perda total do sistema e a envia ao Python para que o algoritmo de Entropia Cruzada verifique se o valor de perdas está de acordo com o critério de parada e critérios de desempenho (limites do perfil de tensão). Em caso afirmativo, o algoritmo é finalizado, e no caso contrário, um novo ajuste é calculado e repassado novamente ao OpenDSS. 


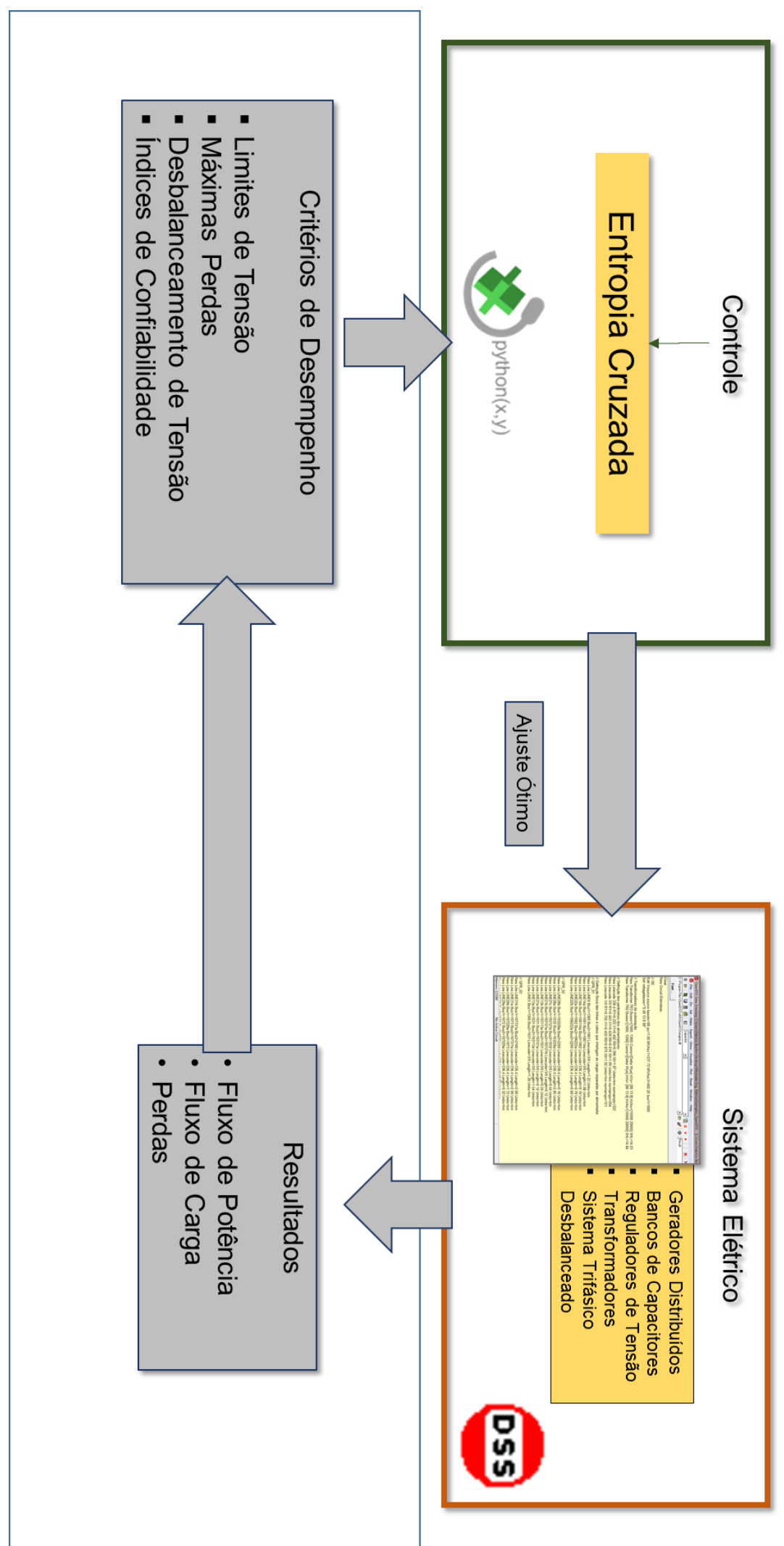

Figura 4.3 - Diagrama de solução. 


\section{Resultados e Discussões}

Nas próximas sessões serão mostrados os sistemas elétricos utilizados para simulações neste trabalho e os resultados obtidos com a metodologia descrita no Capítulo 4. Ressalta-se ainda que os testes realizados tiveram como objetivo avaliar a Metaheurística Entropia Cruzada e os Softwares de Análise OpenDSS e Python. Optou-se, para os testes, Sistemas Elétricos completos o suficiente para se perceber a influência de elementos externos à rede, como geradores distribuídos e banco de capacitores, na qualidade do perfil de tensão, no fluxo de potência e nas perdas totais do sistema.

\subsection{Sistema 36 barras balanceado}

O Sistema Elétrico [26] é composto por 36 barras mais o barramento infinito que representa a subestação de $13,8 \mathrm{kV}$, quatro transformadores, dois grupos de Geração Distribuída e doze bancos de capacitores. As cargas são trifásicas e balanceadas, estão distribuídas ao longo das barras do sistema e apresentam valores específicos para cada período analisado, maior e menor demanda, noite e madrugada, respectivamente. Na Figura 5.1, são representados, em diagrama unifilar, os elementos do sistema. 


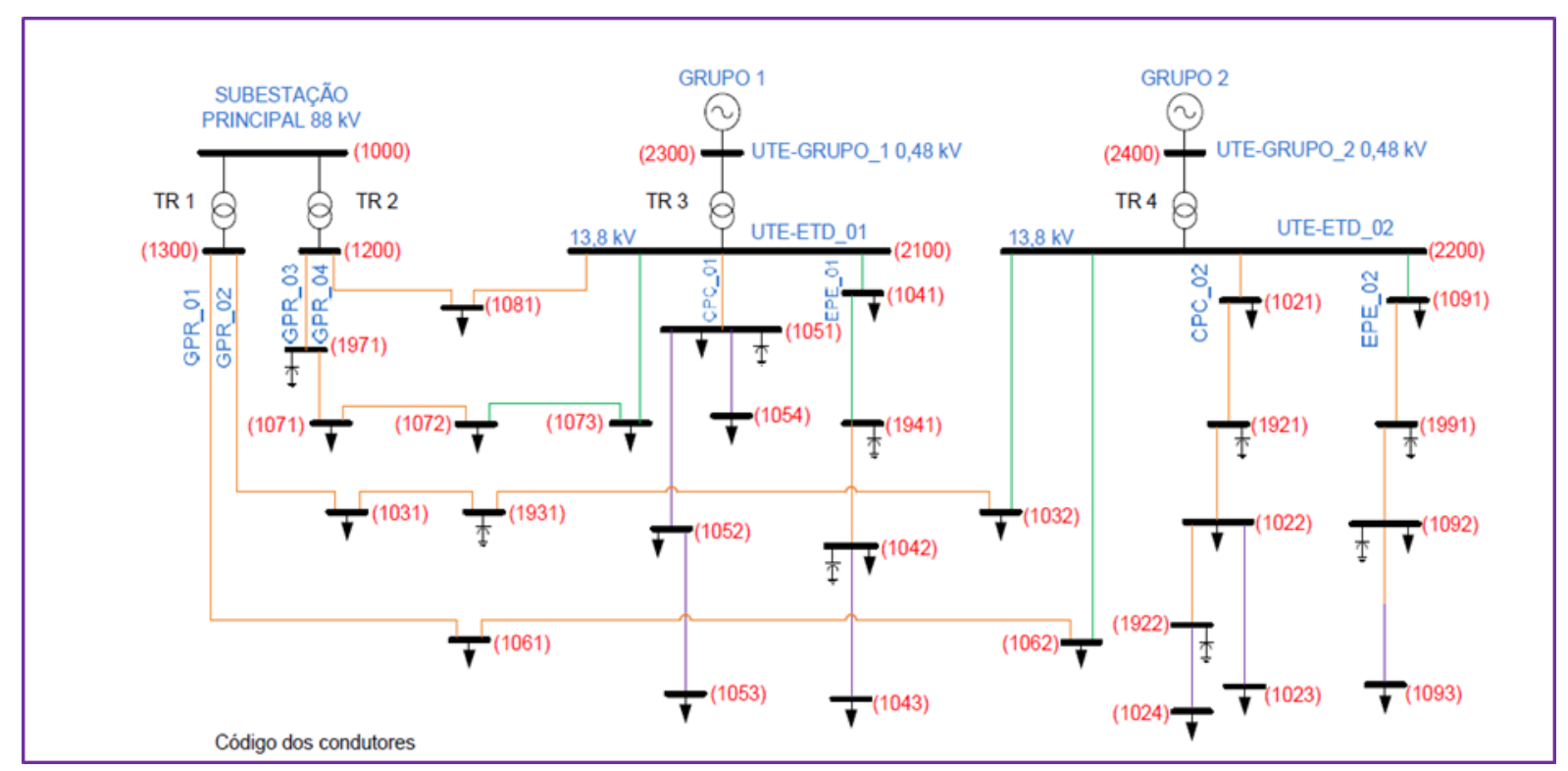

Figura 5.1 - Diagrama unifilar do Sistema Elétrico de 36 barras [26].

\subsubsection{Cargas do Sistema}

Como mencionado anteriormente, as cargas do sistema são trifásicas, balanceadas e apresentam valores específicos. Os valores para cada período e a barra em que uma carga específica se localiza no sistema são retratados na Tabela 5.1. 
Tabela 5.1 - Cargas do Sistema Elétrico por período

\begin{tabular}{|c|c|c|c|c|}
\hline \multirow[b]{3}{*}{ Barra } & \multicolumn{4}{|c|}{ Período de Carga do Sistema } \\
\hline & \multicolumn{2}{|c|}{ Noite (Maior Demanda) } & \multicolumn{2}{|c|}{ Madrugada (Menor Demanda) } \\
\hline & $\mathrm{kW}$ & kVAr & $\mathrm{kW}$ & $\mathrm{kVAr}$ \\
\hline 1031 & 30 & 10 & 20 & 10 \\
\hline 1032 & 620 & 200 & 300 & 100 \\
\hline 1061 & 200 & 100 & 10 & 0 \\
\hline 1062 & 130 & 40 & 60 & 20 \\
\hline 1071 & 210 & 70 & 110 & 40 \\
\hline 1072 & 790 & 260 & 370 & 120 \\
\hline 1073 & 90 & 30 & 50 & 20 \\
\hline 1081 & 910 & 300 & 440 & 150 \\
\hline 1021 & 260 & 90 & 140 & 50 \\
\hline 1022 & 1590 & 520 & 780 & 250 \\
\hline 1023 & 820 & 270 & 400 & 130 \\
\hline 1024 & 1990 & 65 & 980 & 320 \\
\hline 1041 & 340 & 110 & 170 & 60 \\
\hline 1042 & 2210 & 730 & 1090 & 360 \\
\hline 1043 & 1680 & 550 & 750 & 250 \\
\hline 1051 & 640 & 210 & 330 & 110 \\
\hline 1052 & 450 & 150 & 200 & 70 \\
\hline 1053 & 90 & 30 & 40 & 10 \\
\hline 1054 & 1030 & 340 & 470 & 150 \\
\hline 1091 & 2110 & 690 & 1030 & 340 \\
\hline 1092 & 2480 & 810 & 1230 & 400 \\
\hline 1093 & 330 & 110 & 180 & 60 \\
\hline
\end{tabular}

\subsubsection{Subestação}

O barramento infinito 1000 (Figura 4.1) representa a subestação do sistema com 88 kV de tensão nominal, 428,25 MVA e 237,72 MVA de potência trifásica e monofásica de curto-circuito, respectivamente, como mostrado na Tabela 5.2. Esta subestação está interligada a todas as cargas do sistema.

Tabela 5.2 - Parâmetros da Subestação

\begin{tabular}{|c|c|}
\hline & Parâmetros Subestação \\
\cline { 2 - 2 } & SP - B1000 \\
\hline Potência Monofásia de Curto-Circuito (MVA) & 237.72 \\
\hline Potência Trifásica de Curto-Circuito (MVA) & 482.25 \\
\hline Tensão Nominal (kV) & 88 \\
\hline
\end{tabular}




\subsubsection{Geradores Distribuídos}

Os geradores estão representados pelos grupos 1 e 2 conectados, respectivamente, às barras 2300 e 2400. Cada grupo possui 12 máquinas com potência nominal de 1,156 MVA e tensão nominal de 0,48 kV. Na saída de cada grupo há transformadores (TR3 e TR4, conforme Figura 5.1) de elevação de 0,48 kV para 13,8 kV - tensão nominal da linha. A Tabela 5.3 representa os parâmetros destes geradores.

Tabela 5.3 - Parâmetros dos Geradores

\begin{tabular}{|ccc|}
\hline & \multicolumn{2}{c|}{ Parâmetros Geradores } \\
\cline { 2 - 3 } & G1 - B2300 & G2 - B2400 \\
\hline Potência Nominal (MVA) & 1.156 & 1.156 \\
\hline Potência Nominal (MW) & 0.875 & 0.875 \\
\hline Número de Unidades & 12 & 12 \\
\hline Fator de Potência & 0.85 & 0.85 \\
\hline Tensão Nominal (kV) & 0.48 & 0.48 \\
\hline
\end{tabular}

\subsubsection{Bancos de Capacitores}

No caso de estudo há um total de 12 bancos de capacitores espalhados ao longo dos alimentadores. No primeiro momento, estes elementos são fixos e apresentam valores de 1200 kVAr. Na Tabela 5.4 pode se observar a localização destes bancos de capacitores no sistema. 
Tabela 5.4 - Localização dos Bancos de Capacitores

\begin{tabular}{|c|c|}
\hline & Capacitor \\
\cline { 2 - 2 } Barra & $\mathrm{kVAr}$ \\
\hline 1941 & 1200 \\
\hline 1042 & 1200 \\
\hline 1051 & 1200 \\
\hline 1991 & 1200 \\
\hline 1092 & 1200 \\
\hline 1931 & 1200 \\
\hline 1971 & 1200 \\
\hline 1921 & 1200 \\
\hline 1922 & 1200 \\
\hline 1073 & 1200 \\
\hline 1072 & 1200 \\
\hline 1061 & 1200 \\
\hline & \\
\hline
\end{tabular}

Estes valores para os $\mathrm{BC}$ são iniciais. Uma vez que se deseja realizar o ajuste ótimo destes BC para cada período de carga, como descrito no Capítulo 4, utilizou-se a Metaheurística Entropia Cruzada para identificar uma solução local adequada para este objetivo. Isto é, a Metaurística propôs qual a configuração, dada pela combinação dos valores dos $12 \mathrm{BC}$, para minimizar as perdas do Sistema Elétrico em cada período.

\subsubsection{Simulações}

O Sistema Elétrico foi implementado em código Python [22] e OpenDSS [23], como descrito. Os elementos subestação, cabos, barramentos, bancos de capacitores e geradores distribuídos foram declarados em código OpenDSS. O método de otimização Entropia Cruzada foi implementado em código Python. Uma vez definido os elementos fixos do Sistema Elétrico no OpenDSS, os parâmetros variáveis podem ser facilmente controlados no ambiente Python. Desta forma, há a 
automação das simulações desejadas com o artifício proposto pela interface PythonOpenDSS.

Após a implementação do sistema, este foi simulado nos sete casos de estudo abaixo:

1. Bancos de Capacitores fixos e período de maior demanda (Caso 1);

2. Bancos de Capacitores ajustáveis e período de maior demanda (Caso 2);

3. Bancos de Capacitores fixos e período de menor demanda (Caso 3);

4. Bancos de Capacitores ajustáveis e período de menor demanda (Caso 4);

5. Seleção de $\mathrm{N}$ e Nel para demais simulações (Caso 5);

6. Simulação Geração Distribuída e Regulador de Tensão (Caso 6);

7. Sistema com curva de carga de 10 pontos (Caso 7).

Em cada simulação, foi obtido o fluxo de carga, perdas totais e configuração proposta dos BCs.

\subsubsection{Bancos de Capacitores Fixos e Período de Maior Demanda - Caso 1}

A Tabela 5.5 mostra o fluxo de carga para o Caso 1, com valores para a tensão em $\mathrm{kV}$ e pu. De acordo com os limites de operação adequada regidos pela ANEEL, tensão no intervalo 0,93 e 1,05 pu, as barras do sistema, neste caso, violam esta zona de operação. Além disto, as perdas totais do sistema foram $\mathbf{1 4 7 0 , 5 0 ~ k W ~ e ~}$ a configuração dos Bancos de Capacitores é a mostrada na Tabela 5.4. 
Tabela 5.5 - Tensões resultantes do cálculo de fluxo de carga para o caso 1.

\begin{tabular}{|c|c|c|}
\hline Barra & $\mathrm{V} 1(\mathrm{kV})$ & V1 (pu) \\
\hline 1000 & 52.69 & 1.037 \\
\hline 1300 & 8.918 & 1.119 \\
\hline 1200 & 9.078 & 1.139 \\
\hline 2300 & 0.3384 & 1.221 \\
\hline 2400 & 0.3254 & 1.174 \\
\hline 2100 & 9.549 & 1.199 \\
\hline 2200 & 9.209 & 1.156 \\
\hline 1061 & 9.006 & 1.13 \\
\hline 1062 & 9.12 & 1.145 \\
\hline 1931 & 9.068 & 1.138 \\
\hline 1032 & 9.21 & 1.156 \\
\hline 1031 & 8.978 & 1.127 \\
\hline 1073 & 9.394 & 1.179 \\
\hline 1072 & 9.272 & 1.164 \\
\hline 1071 & 9.211 & 1.156 \\
\hline 1971 & 9.18 & 1.152 \\
\hline 1081 & 9.422 & 1.183 \\
\hline 1051 & 9.508 & 1.193 \\
\hline 1054 & 9.476 & 1.189 \\
\hline 1052 & 9.497 & 1.192 \\
\hline 1053 & 9.493 & 1.192 \\
\hline 1041 & 9.483 & 1.19 \\
\hline 1941 & 9.455 & 1.187 \\
\hline 1042 & 9.299 & 1.167 \\
\hline 1043 & 9.189 & 1.153 \\
\hline 1021 & 9.172 & 1.154 \\
\hline 1921 & 9.082 & 1.14 \\
\hline 1022 & 9.055 & 1.137 \\
\hline 1023 & 8.965 & 1.125 \\
\hline 1922 & 9.048 & 1.136 \\
\hline 1024 & 8.935 & 1.121 \\
\hline 1091 & 9.152 & 1.149 \\
\hline 1991 & 9.033 & 1.137 \\
\hline 1092 & 8.942 & 1.126 \\
\hline 1093 & 8.853 & 1.114 \\
\hline
\end{tabular}




\subsubsection{Bancos de Capacitores Ajustáveis e Período de Maior Demanda - Caso 2}

Neste caso é introduzido o módulo de otimização implementado em Python e representado pela Entropia Cruzada. Realizaram-se duas simulações, variando os parâmetros $\mathrm{N}$ (tamanho da amostra) e Nel (tamanho da amostra elite). A condição inicial dos Bancos de Capacitores, mu, é 1200 kVAr, o desvio padrão, sigma, é 600 kVAr e erro igual a 50 kVAr (parâmetros da metaheurística entropia cruzada).

Para $\mathrm{N}=20$ e $\mathrm{Nel}=4$, o algoritmo convergiu em 9 iterações e as perdas totais do sistema foram $687,544 \mathbf{k W}$, como se pode observar no comportamento da Entropia Cruzada na Figura 5.2.

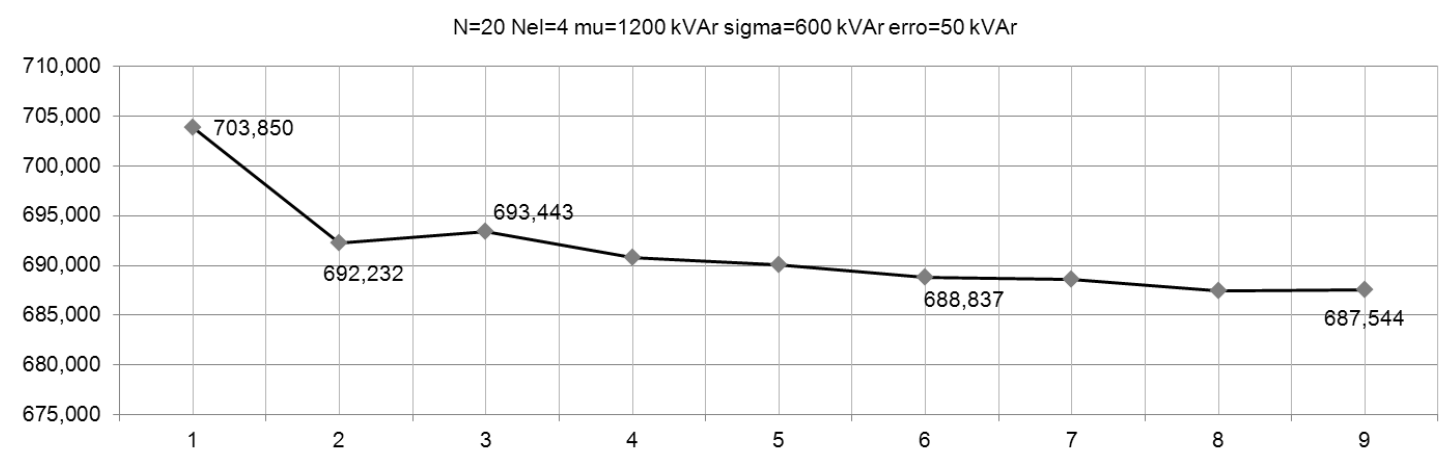

Figura 5.2 - Caso 2 para $\mathrm{N}=20, \mathrm{Nel}=4, \mathrm{mu}=1200 \mathrm{KVAr}$, sigma $=600 \mathrm{kVAr}$, erro=50 $\mathrm{kVAr}$, iterações $=9$ e Perdas Totais $=687,544 \mathrm{~kW}$.

A Tabela 5.6 mostra o Fluxo de Carga para esta simulação, com valores para a tensão em kV e pu. As barras do sistema estão na zona de operação adequada de operação. 
Tabela 5.6 - Tensões resultantes do cálculo de fluxo de carga para $N=20, N e l=4, m u=1200$

$K V A r$, sigma $=600 \mathrm{kVAr}$, erro $=50 \mathrm{kVAr}$, iterações $=9$ e Perdas Totais $=687,544 \mathrm{~kW}$.

\begin{tabular}{|c|c|c|}
\hline Barra & $\mathrm{V} 1(\mathrm{kV})$ & V1 (pu) \\
\hline 1000 & 50.76 & 0.9991 \\
\hline 1300 & 7.964 & 0.9995 \\
\hline 1200 & 7.893 & 0.9906 \\
\hline 2300 & 0.2765 & 0.9976 \\
\hline 2400 & 0.2763 & 0.9968 \\
\hline 2100 & 7.968 & 1.0000 \\
\hline 2200 & 7.921 & 0.9942 \\
\hline 1061 & 7.966 & 0.9999 \\
\hline 1062 & 7.938 & 0.9963 \\
\hline 1931 & 7.946 & 0.9973 \\
\hline 1032 & 8.017 & 1 \\
\hline 1031 & 7.956 & 0.9985 \\
\hline 1073 & 7.943 & 0.9969 \\
\hline 1072 & 7.92 & 0.9941 \\
\hline 1071 & 7.908 & 0.9925 \\
\hline 1971 & 7.903 & 0.992 \\
\hline 1081 & 7.931 & 0.9955 \\
\hline 1051 & 7.926 & 0.9949 \\
\hline 1054 & 7.897 & 0.9911 \\
\hline 1052 & 7.916 & 0.9935 \\
\hline 1053 & 7.913 & 0.9931 \\
\hline 1041 & 7.854 & 0.9858 \\
\hline 1941 & 7.796 & 0.9785 \\
\hline 1042 & 7.633 & 0.958 \\
\hline 1043 & 7.523 & 0.9442 \\
\hline 1021 & 7.752 & 0.973 \\
\hline 1921 & 7.676 & 0.9634 \\
\hline 1022 & 7.639 & 0.9588 \\
\hline 1023 & 7.547 & 0.9472 \\
\hline 1922 & 7.621 & 0.9565 \\
\hline 1024 & 7.504 & 0.9419 \\
\hline 1091 & 7.835 & 0.9833 \\
\hline 1991 & 7.756 & 0.9734 \\
\hline 1092 & 7.679 & 0.9637 \\
\hline 1093 & 7.602 & 0.9540 \\
\hline
\end{tabular}


Além disto, a configuração resultante dos Bancos de Capacitores é a mostrada na Tabela 5.7.

Tabela 5.7 - Banco de Capacitores para $\mathrm{N}=20, \mathrm{Nel}=4, \mathrm{mu}=1200 \mathrm{KVAr}$, sigma=600 kVAr, erro $=50 \mathrm{kVAr}$, iterações $=9$ e Perdas Totais $=687,544 \mathrm{~kW}$.

\begin{tabular}{|c|c|}
\hline & \multicolumn{2}{c|}{ Capacitor } \\
\cline { 2 - 2 } Barra & kVAr \\
\hline 1941 & 700 \\
\hline 1042 & 1200 \\
\hline 1051 & 1200 \\
\hline 1991 & 700 \\
\hline 1092 & 1100 \\
\hline 1931 & 600 \\
\hline 1971 & 0 \\
\hline 1921 & 0 \\
\hline 1922 & 0 \\
\hline 1073 & 400 \\
\hline 1072 & 500 \\
\hline 1061 & 1200 \\
\hline
\end{tabular}

Para $\mathrm{N}=40$ e $\mathrm{Nel}=12$, o algoritmo convergiu em 13 iterações e as perdas totais do sistema foram $681,369 \mathrm{~kW}$, como se pode observar no comportamento da Entropia Cruzada na Figura 5.3.

$\mathrm{N}=40 \mathrm{Nel}=12 \mathrm{mu}=1200 \mathrm{kVar}$ sigma $=600 \mathrm{kVAr}$ erro= $=50 \mathrm{kVAR}$

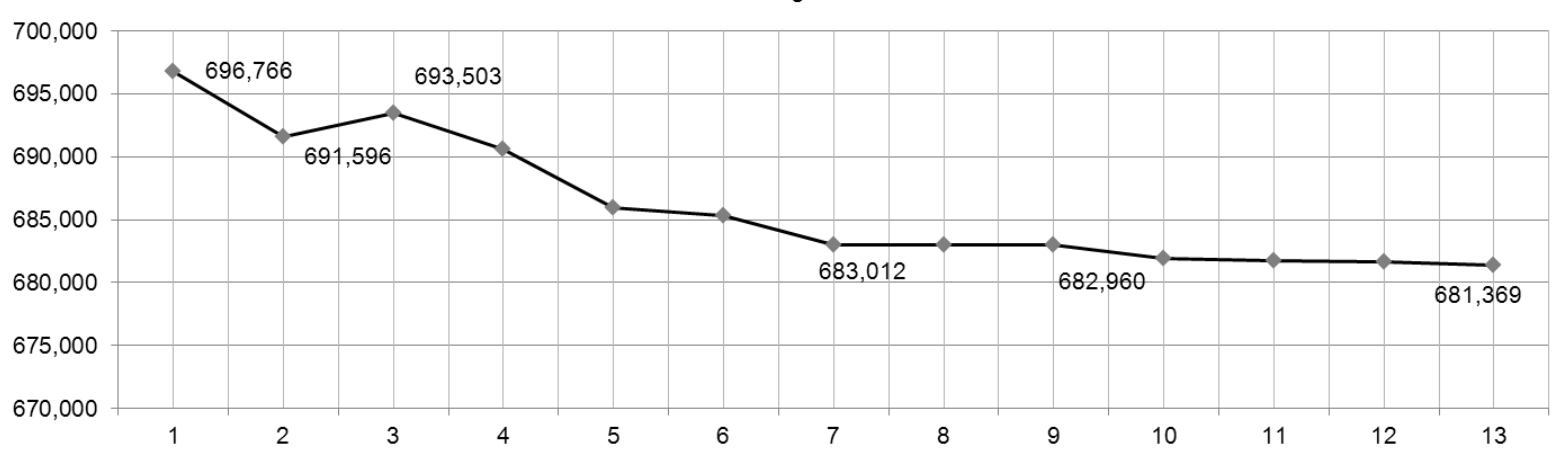

Figura 5.3 - Caso 2 para $\mathrm{N}=40, \mathrm{Nel}=12, \mathrm{mu}=1200 \mathrm{KVAr}$, sigma $=600 \mathrm{kVAr}$, erro=50 kVAr, iterações $=13$ e Perdas Totais $=681,369 \mathrm{~kW}$. 
A Tabela 5.9 mostra o Fluxo de Carga para esta simulação, com valores para a tensão em kV e pu. As barras do sistema estão na zona de operação adequada de operação. Além disto, a configuração dos Bancos de Capacitores é a mostrada na Tabela 5.8.

Tabela 5.8 - Banco de Capacitores para N=40, Nel=12, mu=1200 KVAr, sigma=600 kVAr, erro $=50 \mathrm{kVAr}$, iterações $=9$ e Perdas Totais $=681,369 \mathrm{~kW}$.

\begin{tabular}{|cc|}
\hline & Capacitor \\
\cline { 2 - 2 } Barra & kVAr \\
\hline 1941 & 700 \\
\hline 1042 & 1200 \\
\hline 1051 & 1200 \\
\hline 1991 & 1000 \\
\hline 1092 & 1000 \\
\hline 1931 & 200 \\
\hline 1971 & 200 \\
\hline 1921 & 0 \\
\hline 1922 & 0 \\
\hline 1073 & 200 \\
\hline 1072 & 0 \\
\hline 1061 & 100 \\
\hline & \\
\hline
\end{tabular}


36 Tabela 5.9 - Tensões resultantes do cálculo de fluxo de carga para $\mathrm{N}=40, \mathrm{Nel}=12$, $m u=1200 \mathrm{KVAr}$, sigma=600 kVAr, erro=50 kVAr, iterações $=9$ e Perdas Totais $=681,369 \mathrm{~kW}$.

\begin{tabular}{|c|c|c|}
\hline Barra & V1 (kV) & V1 (pu) \\
\hline 1000 & 50.69 & 0.9977 \\
\hline 1300 & 7.912 & 0.993 \\
\hline 1200 & 7.871 & 0.9879 \\
\hline 2300 & 0.2764 & 0.9973 \\
\hline 2400 & 0.2761 & 0.9963 \\
\hline 2100 & 7.954 & 0.9984 \\
\hline 2200 & 7.893 & 0.9907 \\
\hline 1061 & 7.903 & 0.9919 \\
\hline 1062 & 7.896 & 0.9911 \\
\hline 1931 & 7.894 & 0.9908 \\
\hline 1032 & 7.974 & 1 \\
\hline 1031 & 7.904 & 0.992 \\
\hline 1073 & 7.909 & 0.9927 \\
\hline 1072 & 7883 & 0.9895 \\
\hline 1071 & 7.878 & 0.9887 \\
\hline 1971 & 7.877 & 0.9886 \\
\hline 1081 & 7.916 & 0.9935 \\
\hline 1051 & 7.913 & 0.9932 \\
\hline 1054 & 7.883 & 0.9894 \\
\hline 1052 & 7.902 & 0.9918 \\
\hline 1053 & 7.899 & 0.9915 \\
\hline 1041 & 7.841 & 0.9841 \\
\hline 1941 & 7.783 & 0.9768 \\
\hline 1042 & 7.619 & 0.9563 \\
\hline 1043 & 7.509 & 0.9425 \\
\hline 1021 & 7.724 & 0.9699 \\
\hline 1921 & 7.648 & 0.9599 \\
\hline 1022 & 7.612 & 0.9554 \\
\hline 1023 & 7.520 & 0.9438 \\
\hline 1922 & 7.593 & 0.9531 \\
\hline 1024 & 7.477 & 0.9385 \\
\hline 1091 & 7.813 & 0.9806 \\
\hline 1991 & 7.734 & 0.9707 \\
\hline 1092 & 7.657 & 0.9610 \\
\hline 1093 & 7.580 & 0.9514 \\
\hline
\end{tabular}




\subsubsection{Bancos de Capacitores Fixos e Período de Menor Demanda - Caso 3}

A Tabela 5.11 mostra o Fluxo de Carga para o Caso 3, com valores para a tensão em kV e pu. De acordo com os limites de operação adequada regidos pela ANEEL, tensão no intervalo 0,93 e 1,05 pu, as barras do sistema, neste caso, violam esta zona de operação. Além disto, as perdas totais do sistema foram $\mathbf{2 6 8 1 , 2 0 ~ k W ~ e ~}$ a configuração dos Bancos de Capacitores é a mostrada na Tabela 5.10.

Tabela 5.10 - Banco de Capacitores para caso 3.

\begin{tabular}{|cc|}
\hline & Capacitor \\
\cline { 2 - 2 } Barra & kVAr \\
\hline 1941 & 1200 \\
\hline 1042 & 1200 \\
\hline 1051 & 1200 \\
\hline 1991 & 1200 \\
\hline 1092 & 1200 \\
\hline 1931 & 1200 \\
\hline 1971 & 1200 \\
\hline 1921 & 1200 \\
\hline 1922 & 1200 \\
\hline 1073 & 1200 \\
\hline 1072 & 1200 \\
\hline 1061 & 1200 \\
\hline & \\
\hline
\end{tabular}


Tabela 5.11 - Tensões resultantes do cálculo de fluxo de carga do caso 3.

\begin{tabular}{|c|c|c|}
\hline Barra & V1 (kV) & V1 (pu) \\
\hline 1000 & 54.05 & 1.064 \\
\hline 1300 & 9.555 & 1.199 \\
\hline 1200 & 9.771 & 1.226 \\
\hline 2300 & 0.3812 & 1.376 \\
\hline 2400 & 0.3649 & 1.317 \\
\hline 2100 & 10.68 & 1.341 \\
\hline 2200 & 10.25 & 1.286 \\
\hline 1061 & 9.763 & 1.225 \\
\hline 1062 & 10.06 & 1.263 \\
\hline 1931 & 9.921 & 1.245 \\
\hline 1032 & 10.160 & 1.2756 \\
\hline 1031 & 9.705 & 1.218 \\
\hline 1073 & 10.35 & 1.299 \\
\hline 1072 & 10.14 & 1.272 \\
\hline 1071 & 10.02 & 1.257 \\
\hline 1971 & 9.954 & 1.249 \\
\hline 1081 & 10.47 & 1.313 \\
\hline 1051 & 10.68 & 1.34 \\
\hline 1054 & 10.66 & 1.338 \\
\hline 1052 & 10.67 & 1.34 \\
\hline 1053 & 10.67 & 1.339 \\
\hline 1041 & 10.73 & 1.347 \\
\hline 1941 & 10.77 & 1.351 \\
\hline 1042 & 10.71 & 1.345 \\
\hline 1043 & 10.66 & 1.338 \\
\hline 1021 & 10.33 & 1.296 \\
\hline 1921 & 10.23 & 1.284 \\
\hline 1022 & 10.22 & 1.283 \\
\hline 1023 & 10.17 & 1.276 \\
\hline 1922 & 10.22 & 1.283 \\
\hline 1024 & 10.14 & 1.273 \\
\hline 1091 & 10.27 & 1.288 \\
\hline 1991 & 10.16 & 1.275 \\
\hline 1092 & 10.06 & 1.262 \\
\hline 1093 & 9.96 & 1.249 \\
\hline
\end{tabular}




\subsubsection{Bancos de Capacitores Ajustáveis e Período de Menor Demanda - Caso 4}

Neste caso, como no Caso 2, é introduzido o módulo de otimização implementado em Python e representado pela Entropia Cruzada. Realizaram-se duas simulações, variando os parâmetros N (tamanho da amostra) e Nel (tamanho da amostra elite). A condição inicial dos Bancos de Capacitores, mu, é 1200 kVAr, o desvio padrão, sigma, é 600 kVAr e erro igual a 50 kVAr.

Para $\mathrm{N}=20$ e $\mathrm{Nel}=4$, o algoritmo convergiu em 11 iterações e as perdas totais do sistema foram $\mathbf{7 4 7 , 8 0 0 ~} \mathbf{k W}$, como se pode observar no comportamento da Entropia Cruzada na Figura 5.4.

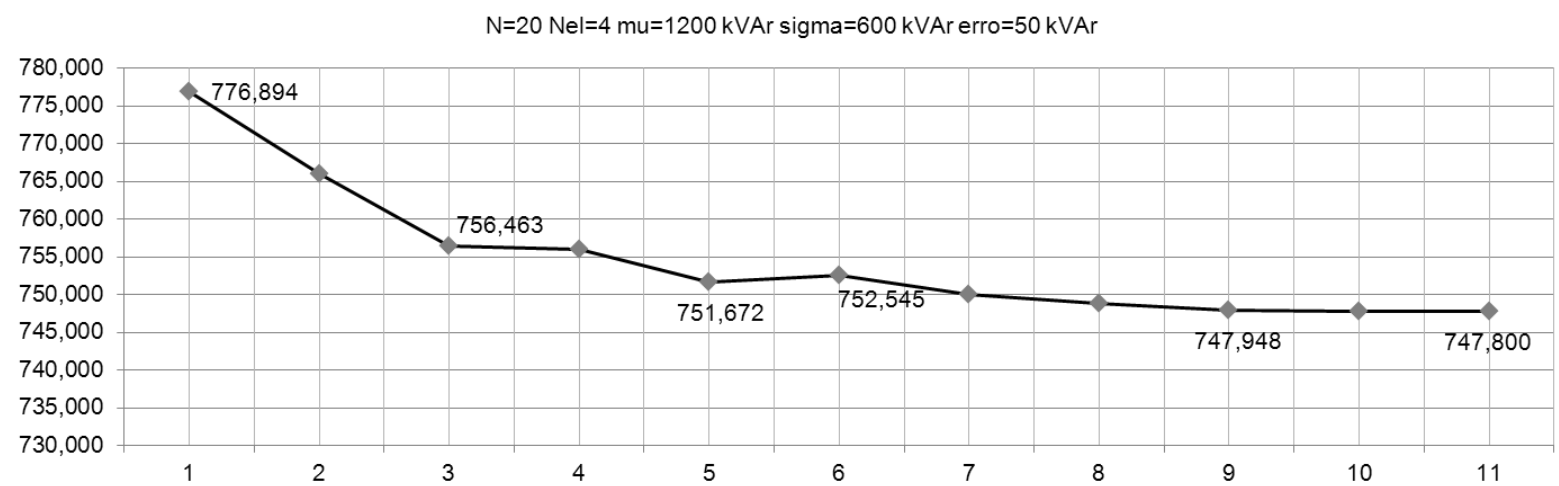

Figura 5.4 - Caso 4 para $\mathrm{N}=20, \mathrm{Nel}=4, \mathrm{mu}=1200 \mathrm{KVAr}$, sigma $=600 \mathrm{kVAr}$, erro=50 $\mathrm{kVAr}$, iterações $=11$ e Perdas Totais $=747,800 \mathrm{~kW}$.

A Tabela 5.12 mostra o Fluxo de Carga para esta simulação, com valores para a tensão em kV e pu. As barras do sistema estão na zona de operação adequada de operação. 
40 Tabela 5.12 - Tensões do cálculo de fluxo de carga para $\mathrm{N}=20, \mathrm{Nel}=4, \mathrm{mu}=1200$ KVAr, sigma $=600 \mathrm{kVAr}$, erro $=50 \mathrm{kVAr}$, iterações $=9$ e Perdas Totais $=747,800 \mathrm{~kW}$.

\begin{tabular}{|c|c|c|}
\hline Barra & $\mathrm{V} 1(\mathrm{kV})$ & $\mathrm{V} 1(\mathrm{pu})$ \\
\hline 1000 & 50.7 & 0.9979 \\
\hline 1300 & 7.854 & 0.9858 \\
\hline 1200 & 7.811 & 0.9803 \\
\hline 2300 & 0.2768 & 0.9989 \\
\hline 2400 & 0.2766 & 0.998 \\
\hline 2100 & 8.031 & 1.008 \\
\hline 2200 & 7.981 & 1.002 \\
\hline 1061 & 7.909 & 0.9927 \\
\hline 1062 & 7.971 & 1 \\
\hline 1931 & 7.944 & 0.9971 \\
\hline 1032 & 8.050 & 1.01 \\
\hline 1031 & 7.891 & 0.9904 \\
\hline 1073 & 7.979 & 1.001 \\
\hline 1072 & 7.93 & 0.9953 \\
\hline 1071 & 7.886 & 0.9898 \\
\hline 1971 & 7.865 & 0.9871 \\
\hline 1081 & 7.97 & 1 \\
\hline 1051 & 8.022 & 1.007 \\
\hline 1054 & 8.009 & 1.005 \\
\hline 1052 & 8.017 & 1.006 \\
\hline 1053 & 8.016 & 1.006 \\
\hline 1041 & 8.098 & 1.016 \\
\hline 1941 & 8.018 & 1.006 \\
\hline 1042 & 7.998 & 1.004 \\
\hline 1043 & 7.993 & 1.003 \\
\hline 1021 & 7.942 & 0.996 \\
\hline 1921 & 7.864 & 0.987 \\
\hline 1022 & 7.967 & 1 \\
\hline 1023 & 7.897 & 0.9912 \\
\hline 1922 & 7.852 & 0.9855 \\
\hline 1024 & 7.832 & 0.9831 \\
\hline 1091 & 7.821 & 0.9816 \\
\hline 1991 & 7.742 & 0.9717 \\
\hline 1092 & 7.665 & 0.9620 \\
\hline 1093 & 7.588 & 0.9524 \\
\hline
\end{tabular}


Além disto, a configuração dos Bancos de Capacitores é a mostrada na Tabela 5.13.

Tabela 5.13 - Banco de Capacitores para $\mathrm{N}=20, \mathrm{Nel}=4, \mathrm{mu}=1200 \mathrm{KVAr}$, sigma=600 kVAr, erro $=50 \mathrm{kVAr}$, iterações $=9$ e Perdas Totais $=747,800 \mathrm{~kW}$.

\begin{tabular}{|cc|}
\hline & Capacitor \\
\cline { 2 - 2 } Barra & kVAr \\
\hline 1941 & 600 \\
\hline 1042 & 600 \\
\hline 1051 & 1000 \\
\hline 1991 & 500 \\
\hline 1092 & 800 \\
\hline 1931 & 500 \\
\hline 1971 & 0 \\
\hline 1921 & 0 \\
\hline 1922 & 0 \\
\hline 1073 & 800 \\
\hline 1072 & 400 \\
\hline 1061 & 800 \\
\hline & \\
\hline
\end{tabular}

Para $\mathrm{N}=40$ e $\mathrm{Nel}=12$, o algoritmo convergiu em 15 iterações e as perdas totais do sistema foram $\mathbf{7 4 1 , 0 2 3} \mathbf{k W}$, como se pode observar no comportamento da Entropia Cruzada na Figura 5.5.

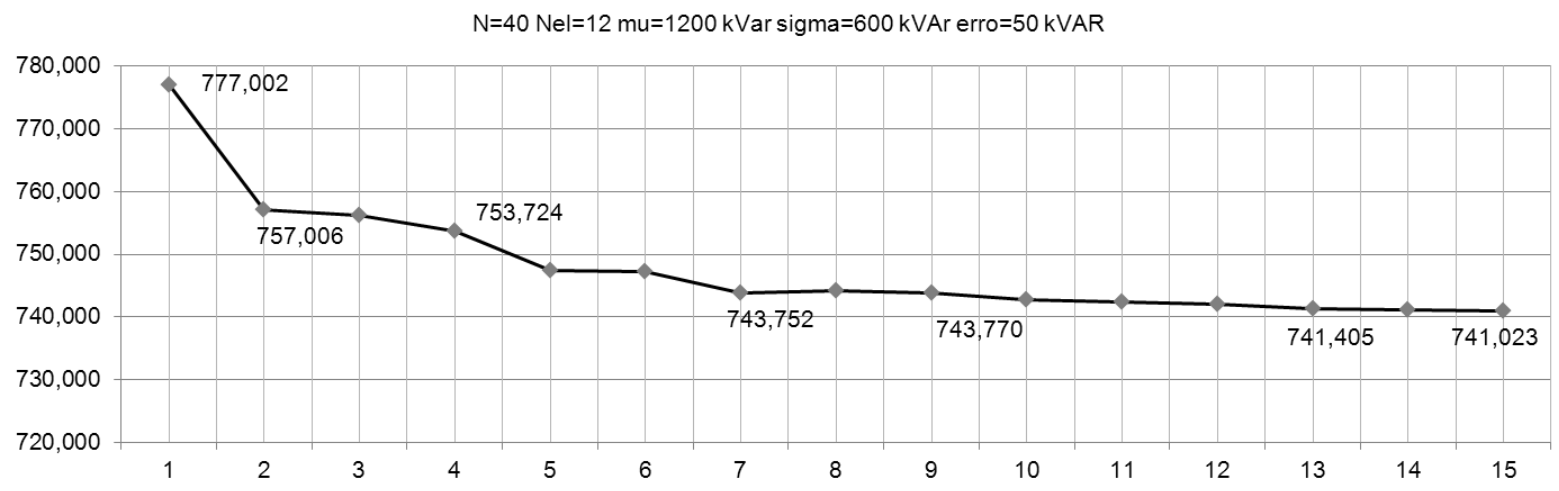

Figura 5.5 - Caso 4 para $\mathrm{N}=40, \mathrm{Nel}=12, \mathrm{mu}=1200 \mathrm{KVAr}$, sigma $=600 \mathrm{kVAr}$, erro $=50 \mathrm{kVAr}$, iterações $=13$ e Perdas Totais $=741,023 \mathrm{~kW}$. 
A Tabela 5.15 mostra o Fluxo de Carga para esta simulação, com valores para a tensão em kV e pu. As barras do sistema estão na zona de operação adequada de operação. Além disto, a configuração dos Bancos de Capacitores é a mostrada na Tabela 5.14.

Tabela 5.14 - Banco de Capacitores para $\mathrm{N}=40$, Nel=12, mu=1200 KVAr, sigma=600 kVAr, erro $=50 \mathrm{kVAr}$, iterações $=15$ e Perdas Totais $=741,023 \mathrm{~kW}$.

\begin{tabular}{|cc|}
\hline & Capacitor \\
\cline { 2 - 2 } Barra & kVAr \\
\hline 1941 & 600 \\
\hline 1042 & 600 \\
\hline 1051 & 1100 \\
\hline 1991 & 700 \\
\hline 1092 & 600 \\
\hline 1931 & 200 \\
\hline 1971 & 100 \\
\hline 1921 & 0 \\
\hline 1922 & 0 \\
\hline 1073 & 300 \\
\hline 1072 & 100 \\
\hline 1061 & 0 \\
\hline & \\
\hline
\end{tabular}


Tabela 5.15 - Tensões resultantes do cálculo de fluxo de carga para $\mathrm{N}=40, \mathrm{Nel}=12$,

$u m=1200 \mathrm{KVAr}$, sigma $=600 \mathrm{kVAr}$, erro=50 kVAr, iterações $=15$ e Perdas Totais $=741,023 \mathrm{~kW}$.

\begin{tabular}{|c|c|c|}
\hline Barra & $\mathrm{V} 1(\mathrm{kV})$ & V1 (pu) \\
\hline 1000 & 50.64 & 0.9967 \\
\hline 1300 & 7.812 & 0.9805 \\
\hline 2300 & 0.2767 & 0.9985 \\
\hline 2400 & 0.2764 & 0.9975 \\
\hline 2100 & 8.035 & 1.0085 \\
\hline 2200 & 7.956 & 0.9986 \\
\hline 1061 & 7.859 & 0.9864 \\
\hline 1062 & 7.936 & 0.9961 \\
\hline 1931 & 7.902 & 0.9918 \\
\hline 1032 & 7.92 & 0.9941 \\
\hline 1031 & 7.849 & 0.9851 \\
\hline 1073 & 7.934 & 0.9959 \\
\hline 1072 & 7.888 & 0.99 \\
\hline 1071 & 7.851 & 0.9854 \\
\hline 1971 & 7.832 & 0.983 \\
\hline 1081 & 7.952 & 0.9981 \\
\hline 1051 & 8.009 & 1.005 \\
\hline 1054 & 7.996 & 1.004 \\
\hline 1052 & 8.004 & 1.005 \\
\hline 1053 & 8.003 & 1.004 \\
\hline 1041 & 7.983 & 1.002 \\
\hline 1941 & 7.903 & 0.9919 \\
\hline 1042 & 7.824 & 0.9820 \\
\hline 1043 & 7.848 & 0.985 \\
\hline 1021 & 7.943 & 0.9969 \\
\hline 1921 & 7.827 & 0.9823 \\
\hline 1022 & 7.807 & 0.9799 \\
\hline 1023 & 7.728 & 0.9701 \\
\hline 1922 & 7.796 & 0.9785 \\
\hline 1091 & 7.928 & 0.9951 \\
\hline 1024 & 7.718 & 0.9687 \\
\hline 1091 & 7.876 & 0.9886 \\
\hline 1991 & 7.797 & 0.9787 \\
\hline 1092 & 7.719 & 0.9689 \\
\hline 1093 & 7.642 & 0.9592 \\
\hline
\end{tabular}




\subsubsection{Discussão dos Casos 1 ao 4}

Os casos de estudo se dividiram em dois grupos. Caso 1 e 2 consideram o carregamento na maior demanda, enquanto que os Casos 3 e 4 analisam o período de menor demanda da carga. Por sua vez, estes grupos são subdivididos em simulações com bancos de capacitores fixos (Casos 1 e 3 ) e capacitores chaveados (Casos 2 e 4). Nos Casos 2 e 4, o algoritmo de Entropia Cruzada está presente, ou seja, ocorre minimização da função objetivo perdas do sistema elétrico. A Figura 5.6 resume as simulações que foram realizadas.

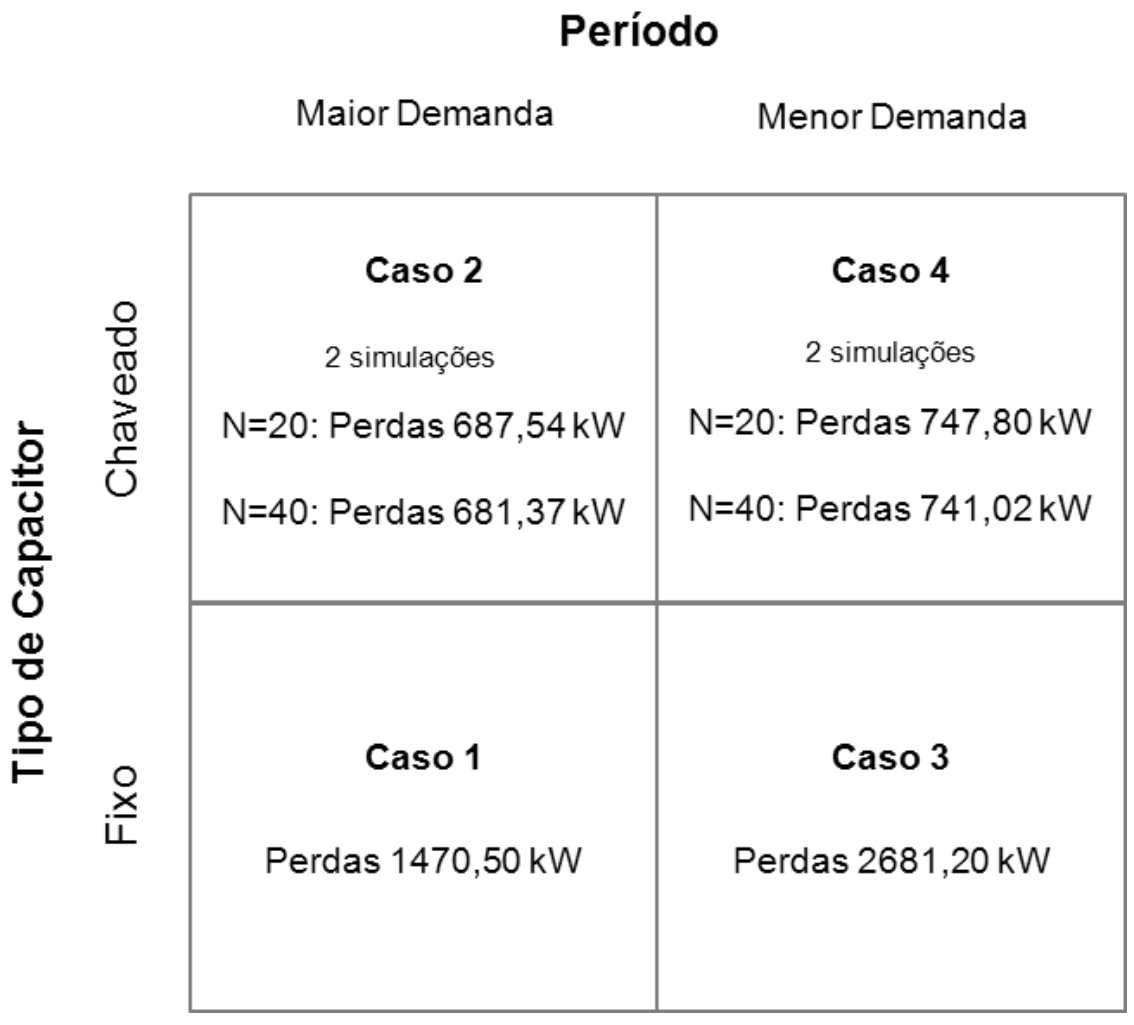

Figura 5.6 - Consolidado de resultados.

Como pode ser observado na Figura 5.6, quando é acoplado ao OpenDSS o método de otimização Entropia Cruzada, há diminuição significativa nas perdas totais do sistema, ou seja, há aproximadamente $72 \%$ de queda no seu valor (comparação entre Caso 3 e Caso 4 para $\mathrm{N}$ igual a 40). Além disto, nos casos onde 
os capacitores são chaveados, as tensões da rede elétrica permanecem dentro do limite de operação adequada, como visto nas Tabelas 5.6, 5.9, 5.12 e 5.15. Observa-se, também, que há uma relação entre tamanho da amostra $\mathrm{N}$ com o valor de perdas obtido, o que deve ser melhor analisado considerando o tamanho da amostra de elite em cada simulação.

Para este sistema de 36 barras, o algoritmo teve o mínimo de 9 iterações (Figura 4.2) e o máximo de 15 iterações (Figura 4.5). O tempo computacional em todas simulações foi de aproximadamente 1 minuto o que é justificado pelo critério de parada de 50 kVAr. Isto é, os bancos de capacitores podem apresentar valores múltiplos de 100 kVAr, dentro da faixa de variação 0 a 1200 kVAr, assim o desvio padrão da amostra de convergência deve possuir sigma menor ou igual a $50 \mathrm{kVAr}$ para que o algoritmo finalize. Com critério de parada de 50 kVAr, os "saltos" do algoritmo são maiores e chegam rapidamente ao ótimo local do problema, o que levaria um tempo maior caso os bancos de capacitores possuíssem faixa de variação contínua e o critério de parada fosse 0,001, por exemplo.

Por fim, é importante explicar os resultados não esperados obtidos, onde as perdas no período de menor demanda, em todas as simulações, foram maiores do que o período de maior demanda. O motivo para isto se baseia na presença exacerbada de bancos de capacitores (12 BCO) que no estado de alívio de carga (menor demanda) tornam o sistema capacitivo, de tal forma, que a potência reativa injetada na linha de distribuição é mais do que o necessário para compensação energética. Uma solução simples, para sanar este problema, seria a retirada dos bancos de capacitores C8 e C9 e o ajuste do valor de mu de 1200 kVAr para 600 kVAr. 


\subsubsection{Seleção de $\mathrm{N}$ e Nel para demais simulações}

Conforme observado nos casos de estudos citados nas seções anteriores, os resultados para perdas elétricas e fluxo de carga são sensíveis a relação tamanho da amostra (N) e amostra de elite (Nel). Com o propósito de obter o melhor ajuste nos parâmetros do sistema de otimização, realizaram-se simulações para taxas de elitização de $10 \%$, $20 \%$ e $30 \%$.

Desta forma, na Tabela 5.16 mostram-se todos resultados alcançados e nas Figuras 5.7 e 5.8 a sumarização dos mesmos. Para taxa de elitização de 10\%, o algoritmo convergiu mais rápido (média de 8 iterações) e obtiveram-se menores perdas (433 kW na relação $\mathrm{N}$ igual a 50 e Nel igual a 5). No entanto, na taxa de elitização de $20 \%$ a média de perdas elétricas foi menor (440 kW). Por fim, em 30\% de elitização, os valores foram intermediários em relação às duas outras taxas. Como o tempo de todas as simulações foi menor do que 1 minuto, optou-se por escolher a taxa de elitização de $20 \%$, tamanho da amostra N igual a 50 e amostra de elite igual a 10, conforme destacado em amarelo na Tabela 5.16 e nas Figuras 5.7 e 5.8. Acrescenta-se, que, exceto na simulação 1 , os valores para os capacitores 8 e 9 são sempre iguais a $0 \mathrm{kVAr}$. 
Tabela 5.16 - Resultados simulação taxas de elitização 10\%, 20 e 30\%

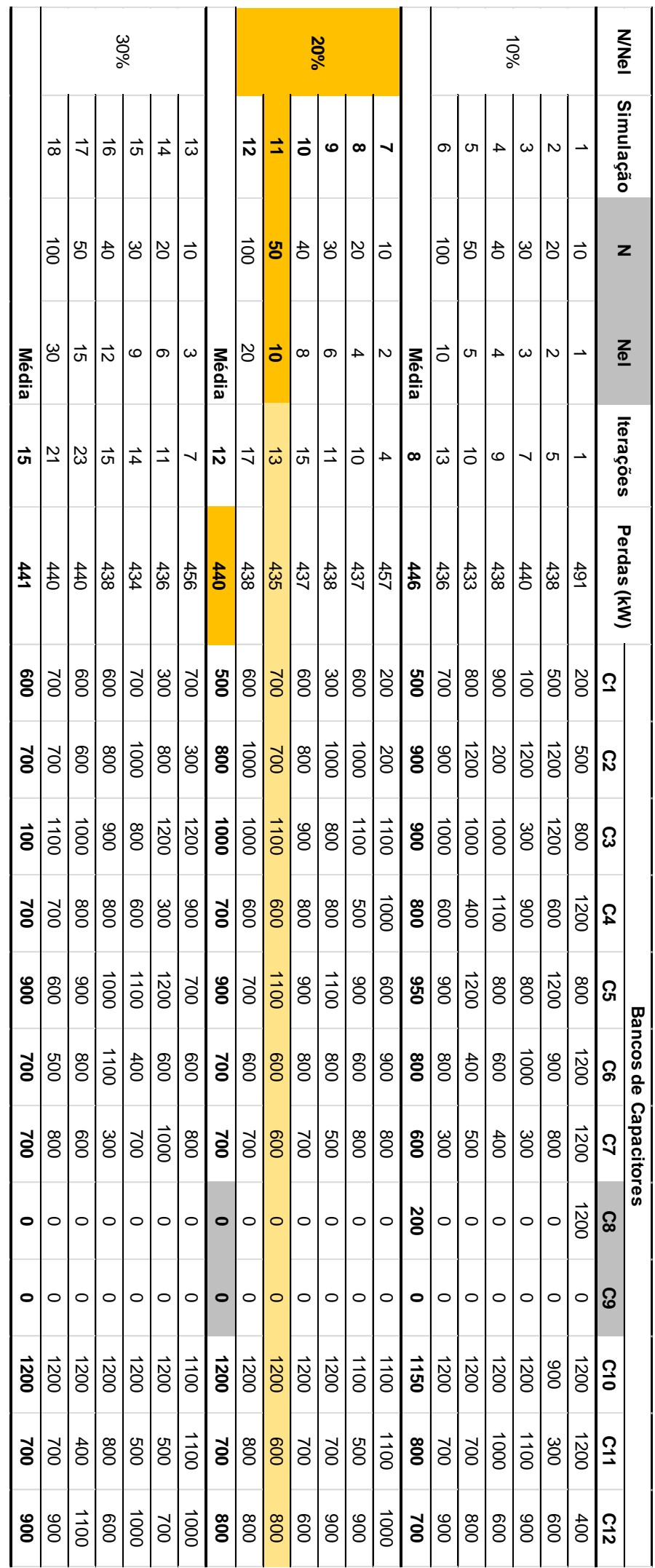




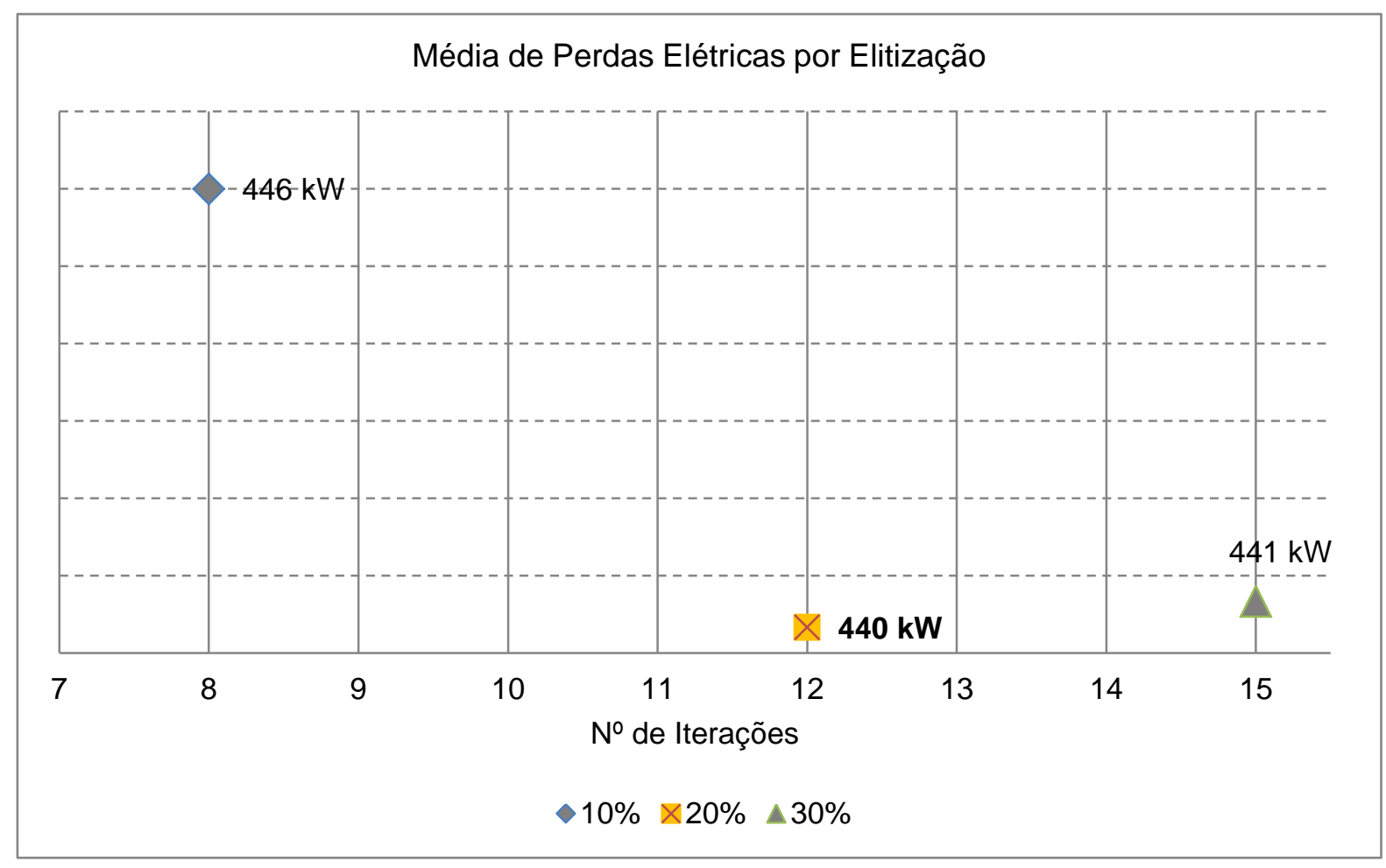

Figura 5.7- Média de Perdas Elétricas por Elitização.

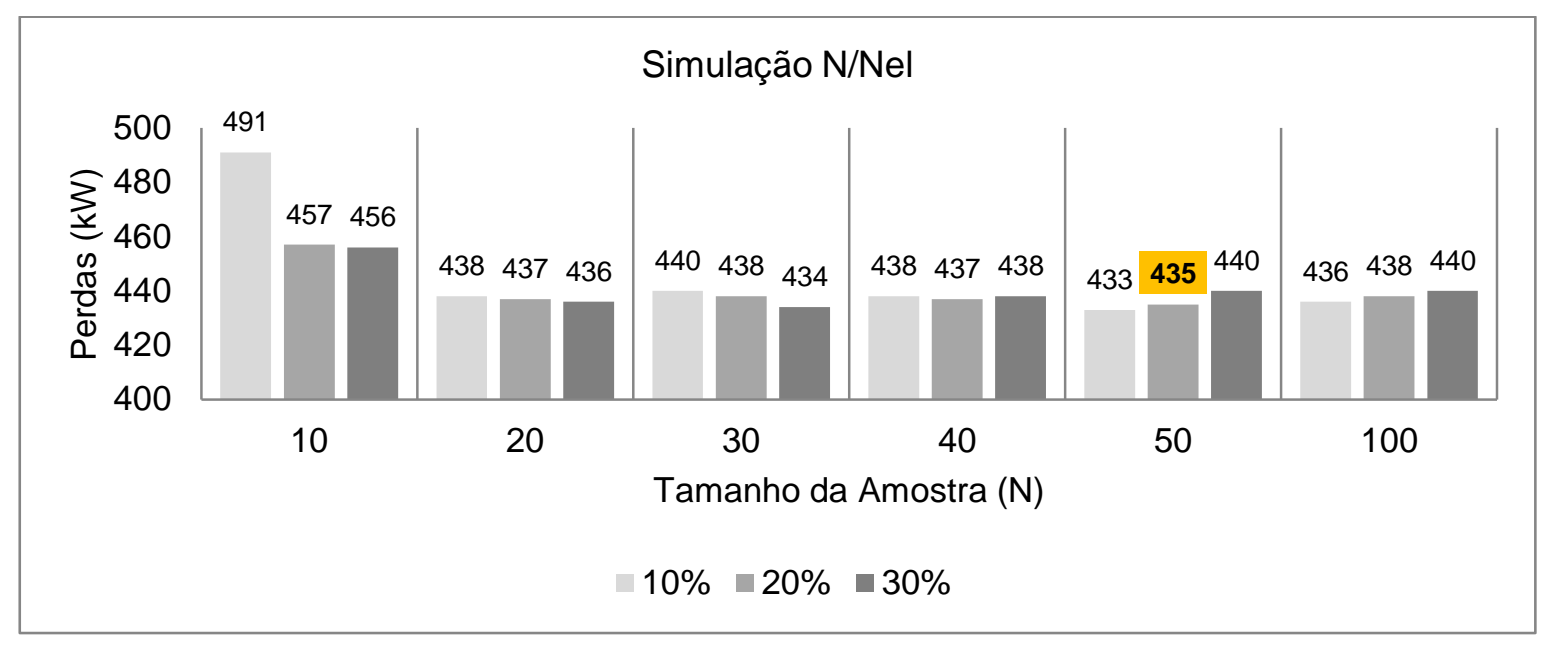

Figura 5.8 - Média de Perdas Elétricas por Elitização. 


\subsubsection{Simulação Geração Distribuída e Regulador de Tensão}

De acordo com a Figura 5.1, o sistema com 36 barras possui dois grupos geradores localizados, respectivamente, nas barras 2100 e 2200. Acrescentaram-se 8 reguladores de tensão nas barras 1200, 1300, 1051, 1041, 1021, 1091, 2100 e 2200 e simulou-se o sistema em dois pontos de operação (com geração distribuída e regulador de tensão; sem geração distribuída e regulador de tensão).

Resultados para as perdas elétricas estão na Tabela 5.17 e Figura 5.9. Como observado, quando sistema opera sem geração distribuída e regulador de tensão, as perdas elétricas são menores (416 kW). Interessante destacar que com e sem GD e RT, o comportamento do algoritmo é similar em ambas as simulações, provendo redução nas perdas elétricas de até $20 \%$ (ou 102kW). Nos dois casos, também, o valor do banco de capacitores C8 e C9 dimensionado é 0 kVAr. Uma justificativa para operar o sistema com GD e RT, seria a melhoria do perfil de tensão nas barras do sistema, houve um aumento médio de $4 \%$ na tensão, o que é mostrado na Tabela 5.18.

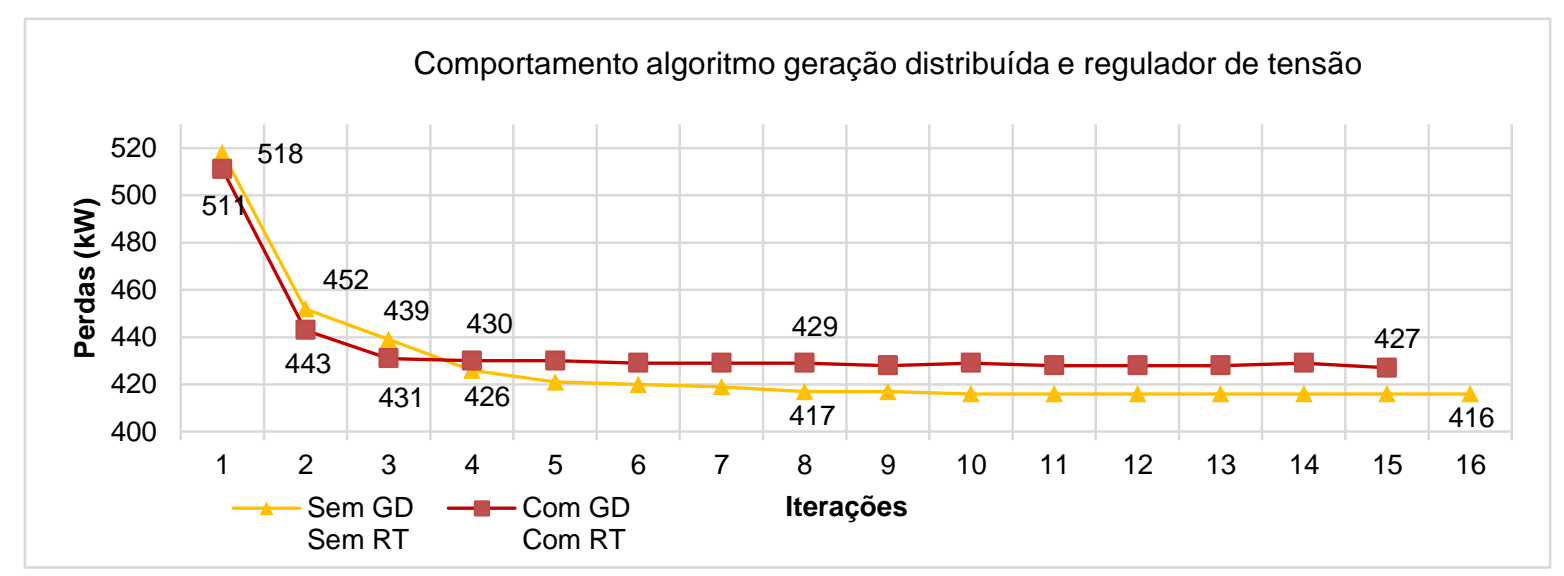

Figura 5.9 - Comportamento algoritmo geração distribuída e regulador de tensão. 
Tabela 5.17 - Simulação geração distribuída e reguladores de tensão.

\begin{tabular}{|c|c|c|c|c|c|c|c|c|c|c|c|c|c|c|}
\hline \multirow{2}{*}{ Simulação } & \multirow{2}{*}{ Iteração } & \multirow{2}{*}{ Perdas (kW) } & \multicolumn{12}{|c|}{ Bancos de Capacitores } \\
\hline & & & C1 & $\mathrm{C2}$ & C3 & C4 & $\mathrm{C5}$ & $\mathrm{CC}$ & C7 & $\mathrm{C8}$ & $\mathrm{Cg}$ & C10 & C11 & C12 \\
\hline \multirow{16}{*}{$\begin{array}{l}\text { Sem GD } \\
\text { Sem RT }\end{array}$} & 1 & 518 & \multirow{16}{*}{600} & \multirow{16}{*}{400} & \multirow{16}{*}{100} & \multirow{16}{*}{200} & \multirow{16}{*}{0} & \multirow{16}{*}{800} & \multirow{16}{*}{100} & \multirow{16}{*}{0} & \multirow{16}{*}{0} & \multirow{16}{*}{500} & \multirow{16}{*}{100} & \multirow{16}{*}{600} \\
\hline & 2 & 452 & & & & & & & & & & & & \\
\hline & 3 & 439 & & & & & & & & & & & & \\
\hline & 4 & 426 & & & & & & & & & & & & \\
\hline & 5 & 421 & & & & & & & & & & & & \\
\hline & 6 & 420 & & & & & & & & & & & & \\
\hline & 7 & 419 & & & & & & & & & & & & \\
\hline & 8 & 417 & & & & & & & & & & & & \\
\hline & 9 & 417 & & & & & & & & & & & & \\
\hline & 10 & 416 & & & & & & & & & & & & \\
\hline & 11 & 416 & & & & & & & & & & & & \\
\hline & 12 & 416 & & & & & & & & & & & & \\
\hline & 13 & 416 & & & & & & & & & & & & \\
\hline & 14 & 416 & & & & & & & & & & & & \\
\hline & 15 & 416 & & & & & & & & & & & & \\
\hline & 16 & 416 & & & & & & & & & & & & \\
\hline \multirow{15}{*}{$\begin{array}{l}\text { Com GD } \\
\text { Com RT }\end{array}$} & 1 & 511 & \multirow{15}{*}{800} & \multirow{15}{*}{700} & \multirow{15}{*}{900} & \multirow{15}{*}{400} & \multirow{15}{*}{1100} & \multirow{15}{*}{700} & \multirow{15}{*}{400} & & & & & \\
\hline & 2 & 443 & & & & & & & & & & & & \\
\hline & 3 & 431 & & & & & & & & & & & & \\
\hline & 4 & 430 & & & & & & & & & & & & \\
\hline & 5 & 430 & & & & & & & & & & & & \\
\hline & 6 & 429 & & & & & & & & & & & & \\
\hline & 7 & 429 & & & & & & & & & & & & \\
\hline & 8 & 429 & & & & & & & & 0 & 0 & 1200 & 400 & 900 \\
\hline & 9 & 428 & & & & & & & & & & & & \\
\hline & 10 & 429 & & & & & & & & & & & & \\
\hline & 11 & 428 & & & & & & & & & & & & \\
\hline & 12 & 428 & & & & & & & & & & & & \\
\hline & 13 & 428 & & & & & & & & & & & & \\
\hline & 14 & 429 & & & & & & & & & & & & \\
\hline & 15 & 427 & & & & & & & & & & & & \\
\hline
\end{tabular}


Tabela 5.18 - Perfil de tensão sem (V1) e com (V1') geração distribuída e reguladores de tensão.

\begin{tabular}{|c|c|c|c|}
\hline Barra & V1 (pu) & V1' (pu) & V1'/V1 \\
\hline 1000 & 0,9921 & 1,001 & $1 \%$ \\
\hline 1300 & 0,9894 & 1,019 & $3 \%$ \\
\hline 1200 & 0,9857 & 1,014 & $3 \%$ \\
\hline 1061 & 0,9803 & 1,014 & $3 \%$ \\
\hline 1062 & 0,9657 & 1,002 & $4 \%$ \\
\hline 2200 & 0,9606 & 0,9986 & $4 \%$ \\
\hline 1032 & 0,9685 & 1,004 & $4 \%$ \\
\hline 1931 & 0,9725 & 1,007 & $4 \%$ \\
\hline 1031 & 0,9806 & 1,012 & $3 \%$ \\
\hline 2100 & 0,955 & 0,9923 & $4 \%$ \\
\hline 1073 & 0,9646 & 1,003 & $4 \%$ \\
\hline 1072 & 0,9692 & 1,004 & $4 \%$ \\
\hline 1071 & 0,975 & 1,008 & $3 \%$ \\
\hline 1971 & 0,9784 & 1,01 & $3 \%$ \\
\hline 1081 & 0,9605 & 0,9959 & $4 \%$ \\
\hline 1051 & 0,9521 & 0,9916 & $4 \%$ \\
\hline 1054 & 0,9504 & 0,9899 & $4 \%$ \\
\hline 1052 & 0,9515 & 0,991 & $4 \%$ \\
\hline 1053 & 0,9514 & 0,9909 & $4 \%$ \\
\hline 1041 & 0,9434 & 0,9805 & $4 \%$ \\
\hline 1941 & 0,9368 & 0,9738 & $4 \%$ \\
\hline 1042 & 0,9249 & 0,9616 & $4 \%$ \\
\hline 1043 & 0,9189 & 0,9554 & $4 \%$ \\
\hline 1021 & 0,9593 & 0,9975 & $4 \%$ \\
\hline 1921 & 0,9486 & 0,9882 & $4 \%$ \\
\hline 1022 & 0,9462 & 0,9861 & $4 \%$ \\
\hline 1023 & 0,9406 & 0,9806 & $4 \%$ \\
\hline 1922 & 0,9449 & 0,9851 & $4 \%$ \\
\hline 1024 & 0,9364 & 0,9767 & $4 \%$ \\
\hline 1091 & 0,9543 & 0,9951 & $4 \%$ \\
\hline 1991 & 0,9532 & 0,9945 & $4 \%$ \\
\hline 1092 & 0,9491 & 0,9916 & $4 \%$ \\
\hline 1093 & 0,944 & 0,9866 & $5 \%$ \\
\hline
\end{tabular}




\subsubsection{Sistema com curva de carga de 10 pontos}

De acordo com as sessões anteriores, os valores escolhidos para número da amostra inicial $\mathrm{N}$ e amostra de elite $\mathrm{Nel}$, são respectivamente, 50 e 10, isto é, uma taxa de elitização de $20 \%$. A justificativa para tal escolha é porque as perdas elétricas são menores nesta configuração. Foi mostrada também, a diferença dos resultados quando o sistema opera na presença e ausência de geradores distribuídos e reguladores de tensão. Na primeira opção, as perdas elétricas são maiores, porém a tensão nas barras do sistema apresentam valores mais próximos de 1 pu, o que é invertido no segundo ponto de operação, isto é, perdas menores e valores mais distantes de 1 pu são obtidos, quando o sistema de 36 barras é simulado sem GD e RT.

Partindo deste entendimento - taxa de elitização de $20 \%$ ( $N$ igual a 50 e Nel igual a 10) e geradores distribuídos e reguladores de tensão presentes no sistema construiu-se 22 curvas, com dados fictícios, para as 22 cargas trifásicas e balanceadas.

$\mathrm{Na}$ Tabela 5.19 , há os valores de potência ativa $(\mathrm{kW})$ e potência reativa (kVAr) para cada carregamento. Considera-se que $10 \%$ é o carregamento leve da linha e $100 \%$ se aplica ao carregamento de plena carga. Para cada nível de carregamento, simulou-se o sistema, obtendo a configuração dos bancos de capacitores, perdas elétricas e tensão em pu nas barras. Mais um vez, a interface OpenDSS-Python se mostrou prática e simples quanto ao manuseio dos dados adquiridos e implementação dos ajustes mencionados. 
Tabela 5.19 - Curva de carga de 10 pontos por barra do sistema com valores percentuais do nível de carregamento.

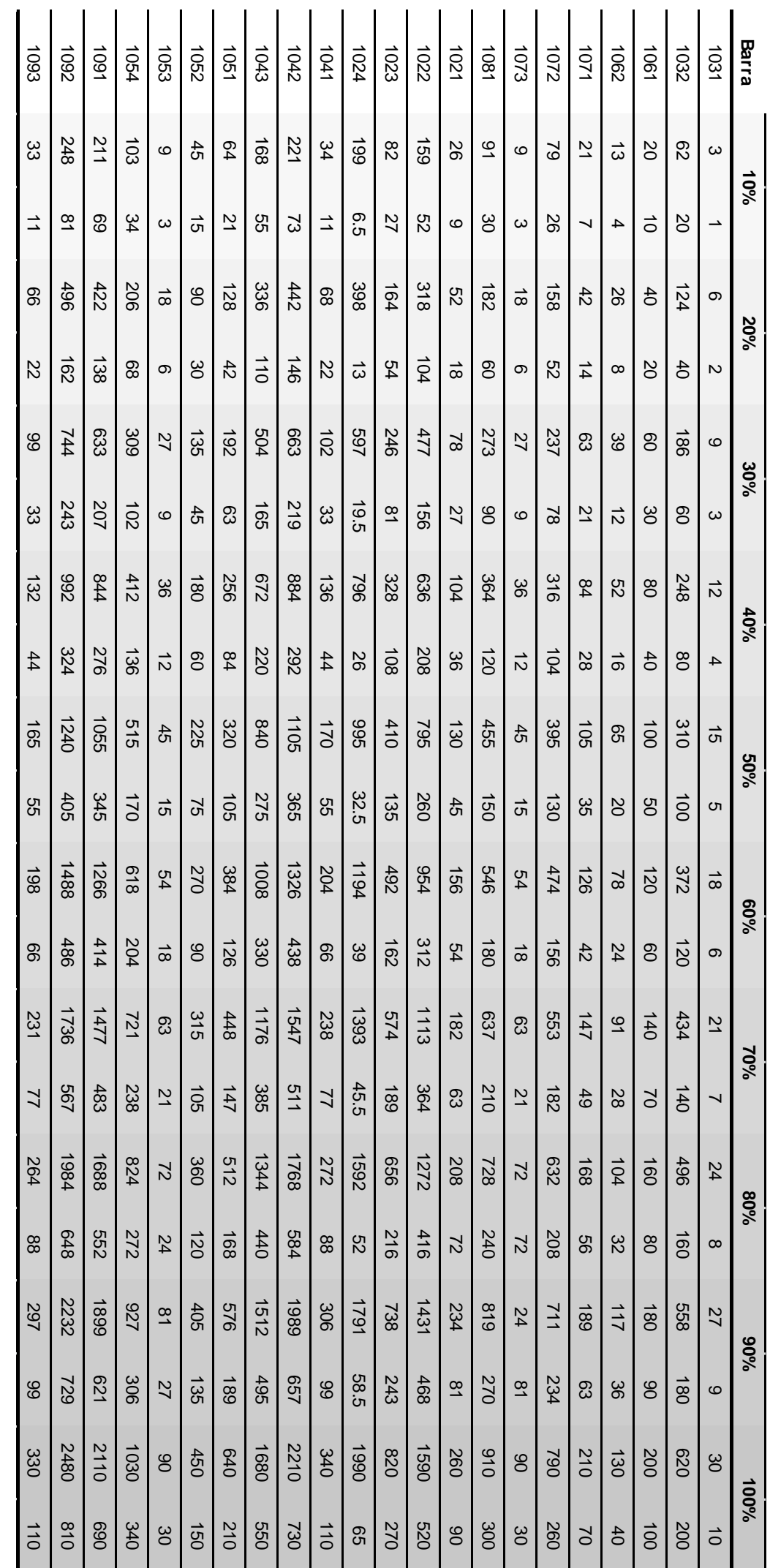


Na Figura 5.10, há a sintetização das perdas elétricas por nível de carregamento da linha. Quando carregamento está entre 10\% e 50\%, as perdas ótimas foram as mesmas, $411 \mathrm{~kW}$. Temos diferentes valores entre $60 \%$ e $100 \%$, sendo que neste último, as perdas elétricas foram as maiores registradas, $427 \mathrm{~kW}$. Destaca-se que em todos os níveis de carregamento houve o ajuste, pelo algoritmo de otimização, da configuração dos bancos de capacitores, o que representou redução média de $20 \%$ nas perdas elétricas do sistema.

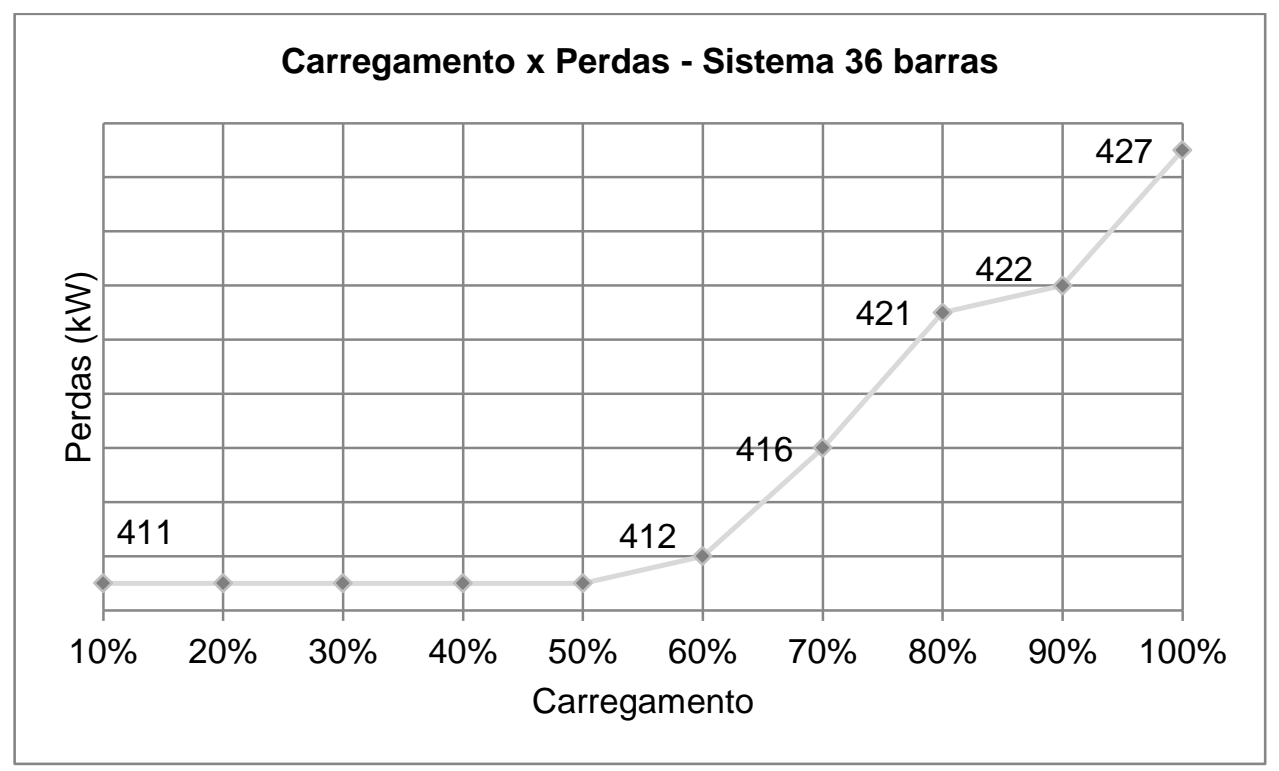

Figura 5.10 - Carregamento x Perdas - Sistema 36 barras.

Além disto, obteve-se, para cada nível de carregamento, a tensão nas barras do sistema. Na Tabela 5.20 e Figura 5.11 isto pode ser observado. A menor tensão em pu, de acordo com a Figura 5.11, é registrada na barra 1043 quando o mesmo se encontra a $30 \%$ de sua plena carga, sendo o valor igual a 0,9120 pu. Em plena carga, $100 \%$, o valor de tensão registrada nesta mesma barra é de 0,9554. Em contrapartida, a barra com maior tensão é a 1300, com valor em pu de 1,019. 
Tabela 5.20 - Tensão (pu) nas barras por carregamento - Sistema 36 barras.

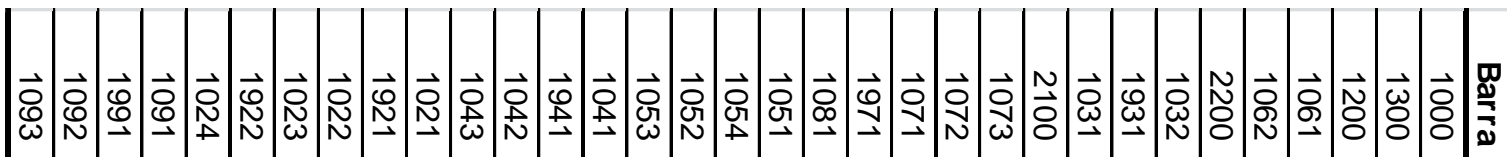

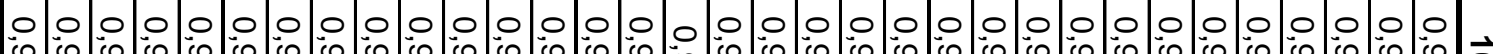

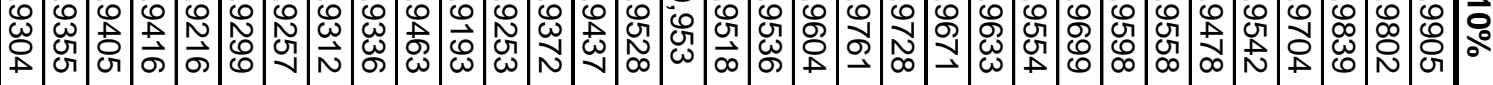

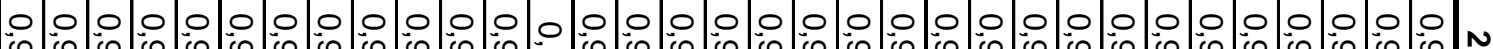

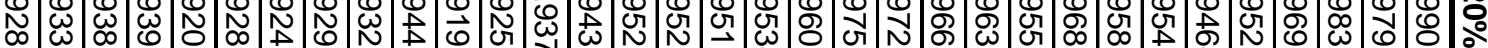

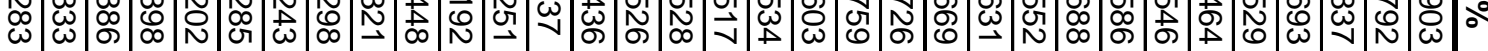

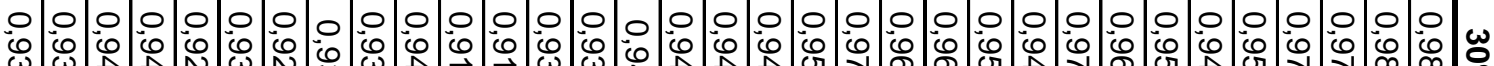

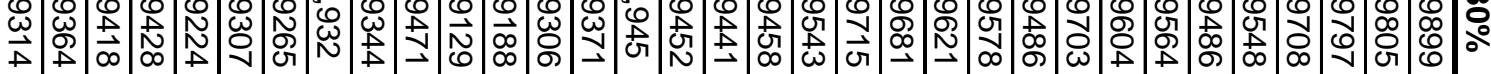

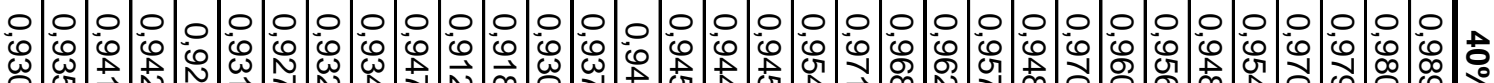

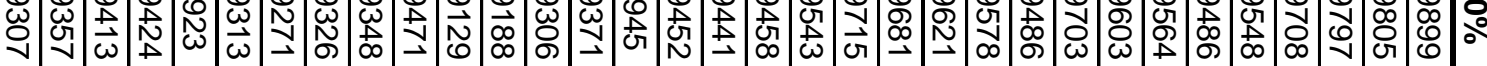

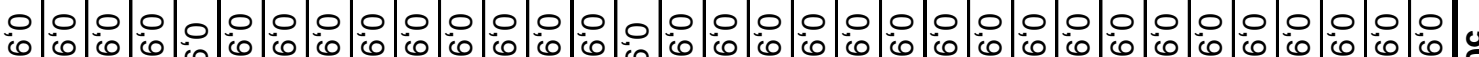

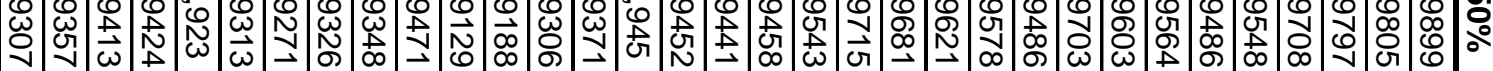

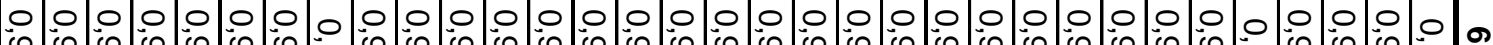

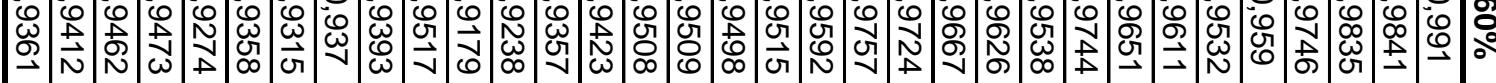

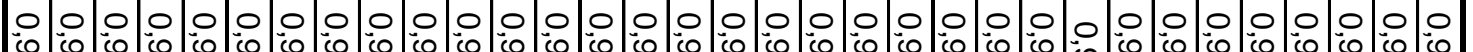

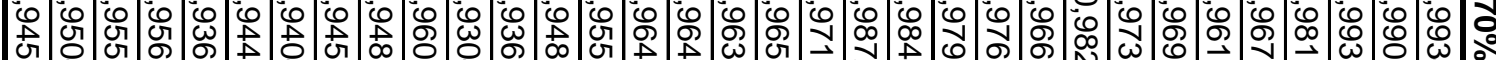

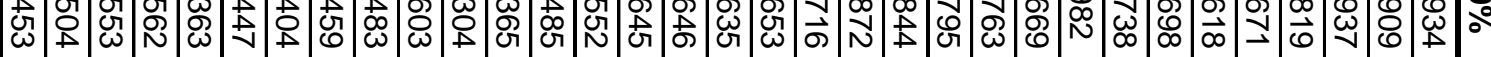

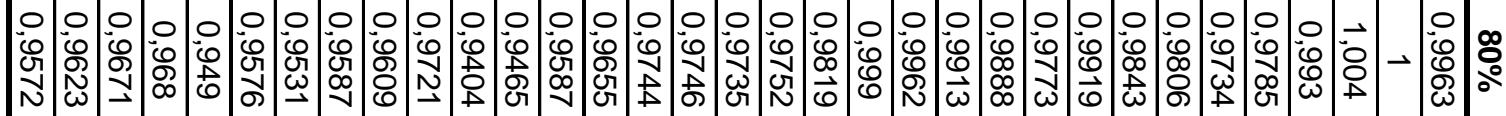

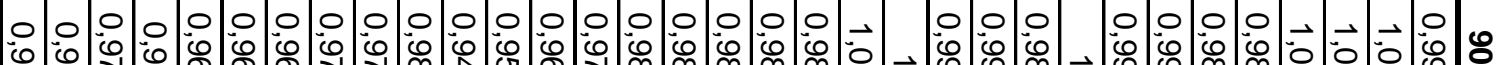

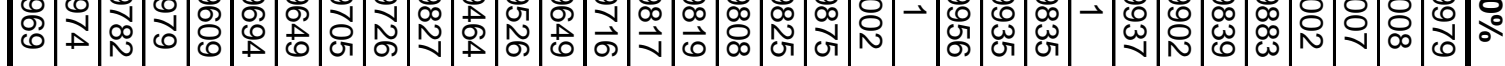

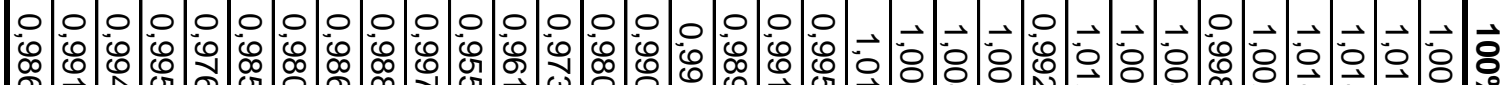

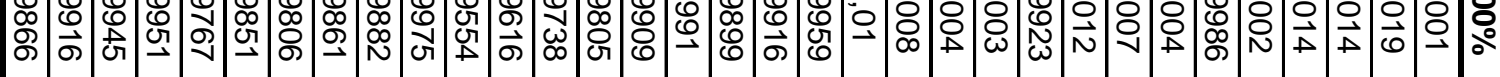




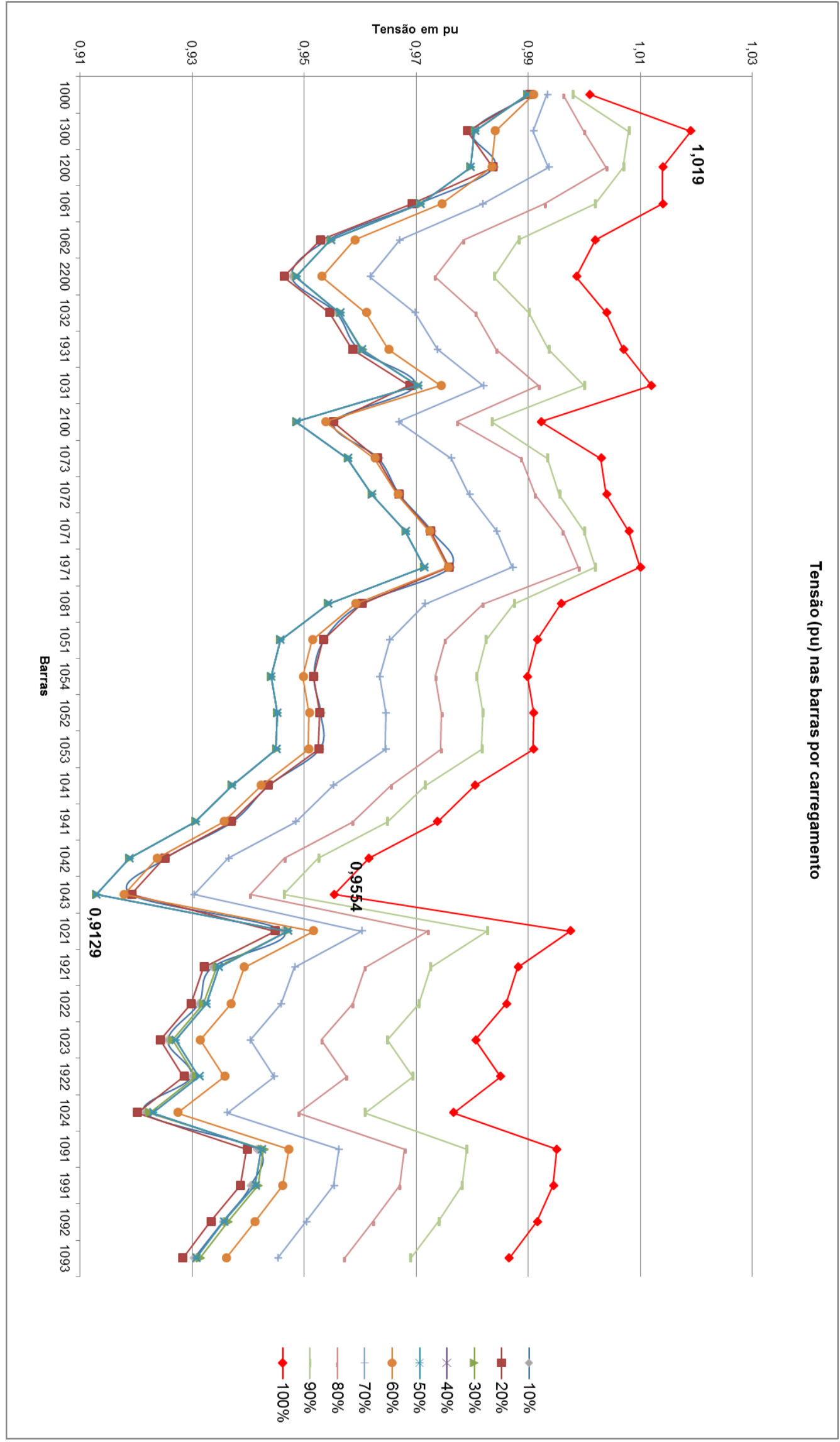

Figura 5.11 - Tensão (pu) nas barras por carregamento - Sistema 36 barras. 
A configuração dos bancos de capacitores por carregamento está na Tabela 5.21. Interessante notar que para níveis menores de carregamento, a configuração dos BC é pouco alterada, o que não ocorre com carregamento entre $60 \%$ e $100 \%$. Além disto, de acordo com a Figura 5.12, a potência reativa total dos bancos de capacitores decresce no trecho 10\%-30\% com a manutenção das perdas elétricas de $411 \mathrm{~kW}$, se mantém constante no trecho $30 \%-50 \%$ e é ascendente no carregamento de $60 \%$ ao $100 \%$, com aumento das perdas.

Estes resultados mostram uma sensibilidade maior do algoritmo de otimização para níveis elevados de carregamento e um comportamento não convencional quando o sistema está com menor demanda. Para correção desta não conformidade, seria importante realizar ajustes manuais na configuração dos bancos de capacitores. Por fim, em todos os níveis de carregamento, a potência reativa registrada dos $\mathrm{BC}$ C8 e C9, é 0 kVAr, resultado já encontrado em outras sessõos.

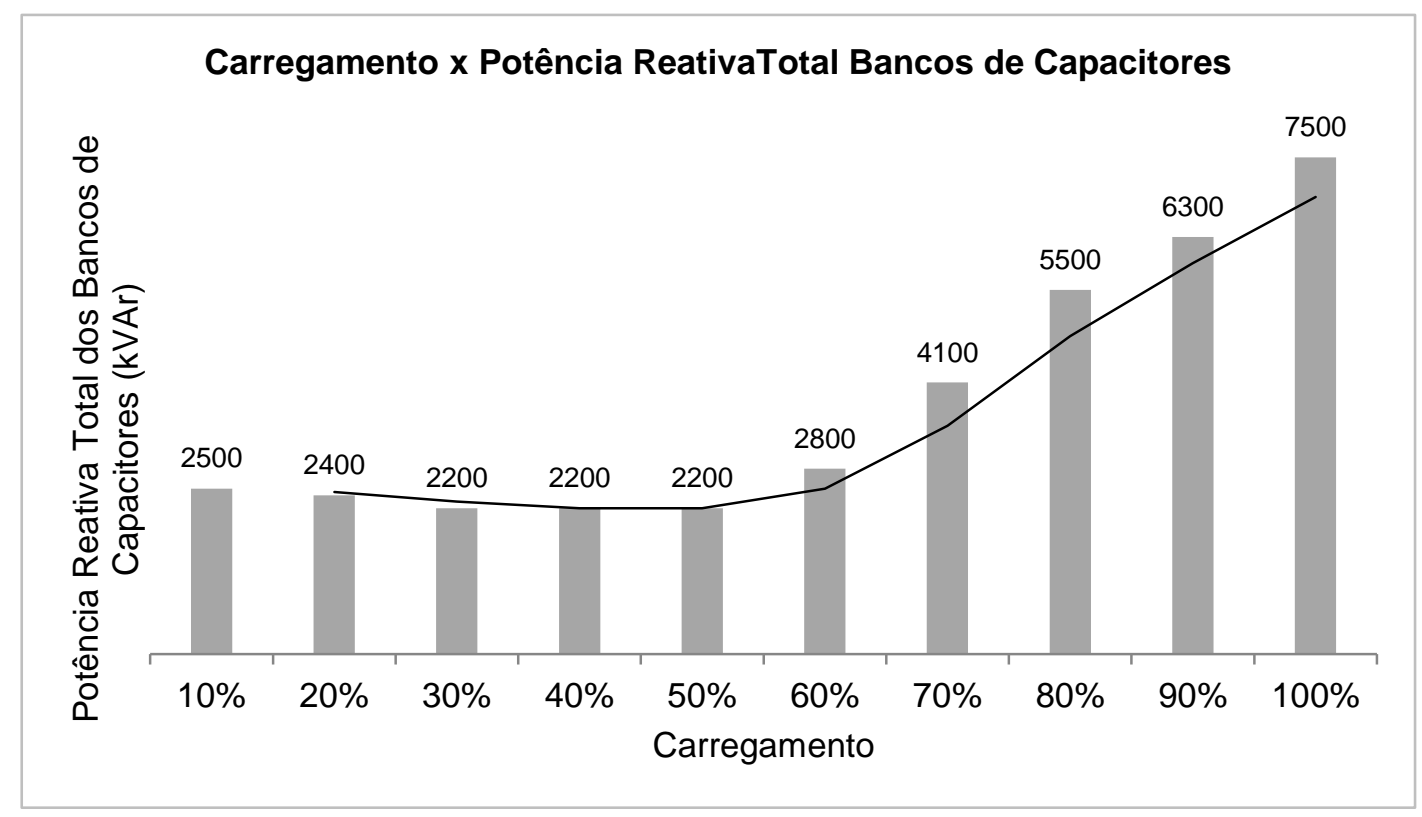

Figura 5.12 - Carregamento x Potência Reativa Total dos Bancos de Capacitores - Sistema 36 barras. 
Tabela 5.21 - Bancos de capacitores por carregamento - Sistema 36 barras.

\begin{tabular}{|c|c|c|c|c|c|c|c|c|c|c|}
\hline $\begin{array}{l}\vec{\circ} \\
\text { o }\end{array}$ & $\begin{array}{l}0 \\
:\end{array}$ & $\stackrel{\infty}{\circ}$ & ๙े & : & $\begin{array}{l}\text { जo } \\
\text { 응 }\end{array}$ & $\begin{array}{l}\stackrel{t}{\circ} \\
\text { ᄋ }\end{array}$ & $\begin{array}{l}\omega \\
\stackrel{\circ}{\circ}\end{array}$ & $\begin{array}{l}\text { No } \\
\text { o }\end{array}$ & $\begin{array}{l}\overrightarrow{0} \\
\stackrel{\circ}{\circ}\end{array}$ & 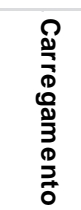 \\
\hline N & 怘 & ث્త & $\vec{\sigma}$ & $\frac{\vec{N}}{N}$ & $\stackrel{ \pm}{ \pm}$ & $\stackrel{ \pm}{\Xi}$ & $\stackrel{\triangleq}{\Xi}$ & $\stackrel{\triangleq}{\Xi}$ & $\stackrel{ \pm}{ \pm}$ & 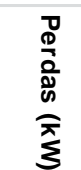 \\
\hline ঃ̊ & ઠે & ৪ & 8 & ڤ̆ & $\overrightarrow{8}$ & $\overrightarrow{8}$ & $\overrightarrow{8}$ & $\overrightarrow{8}$ & $\overrightarrow{8}$ & S \\
\hline ઠั & 8े & \& & ั & $\vec{\circ}$ & $\overrightarrow{8}$ & $\overrightarrow{8}$ & $\overrightarrow{8}$ & $\overrightarrow{8}$ & $\overrightarrow{8}$ & $\mathcal{N}$ \\
\hline \& & ઠे & ঃ̊ & 흐 & $\overrightarrow{8}$ & $\overrightarrow{8}$ & $\overrightarrow{8}$ & $\overrightarrow{8}$ & $\overrightarrow{8}$ & $\overrightarrow{8}$ & $\S$ \\
\hline 호 & $\stackrel{े}{\circ}$ & ั & ঃे & $\tilde{8}$ & $\overrightarrow{8}$ & $\overrightarrow{8}$ & $\overrightarrow{8}$ & $\overrightarrow{8}$ & $\overrightarrow{8}$ & $\$$ \\
\hline$\vec{\Delta}$ & ঃ̊ & 8 & $\vec{\circ}$ & $\vec{\circ}$ & $\overrightarrow{8}$ & $\overrightarrow{8}$ & $\overrightarrow{8}$ & $\overrightarrow{8}$ & $\overrightarrow{8}$ & \& \\
\hline ชั & 8 & 몽 & 吝 & $\stackrel{\omega}{\sigma}$ & $\stackrel{\omega}{\sigma}$ & $\stackrel{\omega}{\circ}$ & $\stackrel{\omega}{\&}$ & $\stackrel{\omega}{\sigma}$ & $\stackrel{\omega}{\&}$ & ภ \\
\hline 总 & ㅁㅇ & ฉे & $\tilde{8}$ & $\tilde{O}$ & $\tilde{8}$ & $\tilde{8}$ & $\overrightarrow{8}$ & $\overrightarrow{8}$ & $\overrightarrow{8}$ & 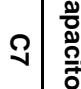 \\
\hline 0 & 0 & 0 & 0 & 0 & 0 & 0 & 0 & 0 & 0 & \& \\
\hline 0 & 0 & 0 & 0 & 0 & ○ & ○ & ○ & 0 & ○ & 8 \\
\hline $\overrightarrow{\widetilde{ઠ}}$ & $\overrightarrow{\mathrm{o}}$ & ઠे & \& & ઠे & 응 & 잉 & 잉 & \& & $\stackrel{8}{8}$ & $\stackrel{ᄋ}{0}$ \\
\hline sे & 응 & 8 & 8. & 8 & ठे & ઠे & ઠิ & 잉 & 잉 & $\stackrel{?}{\Xi}$ \\
\hline \& & 응 & $\stackrel{\omega}{\circ}$ & $\stackrel{\omega}{\circ}$ & ชั & 0 & 0 & $\overrightarrow{8}$ & $\overrightarrow{8}$ & : & $\stackrel{?}{N}$ \\
\hline$\infty$ & 0 & 0 & $v$ & or & 0 & - & $N$ & - & & 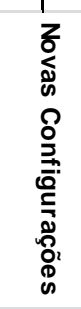 \\
\hline
\end{tabular}




\subsection{Sistema IEEE 13 barras desbalanceado}

Os próximos resultados se basearam nos dados do sistema IEEE 13 barras, mostrado na Figura 5.13, que se caracteriza por ser trifásico, desbalanceado, tensão fase-fase da subestação de 115 kV e possuir 15 cargas espalhadas ao longo de sua topologia. No mesmo, não há transformadores e geradores distribuídos, apenas um regulador de tensão na barra RG60 e dois bancos de capacitores, C1 trifásico de 600 kVAr na barra 675 e C2 monofásico de 100 kVAr na barra 611 fase C.

Simulou-se o sistema para curva de carga de 10 pontos (10\% carga leve e 100\% plena carga), obteve-se a perdas elétricas, configuração dos bancos de capacitores e tensão fase-neutro nas barras.

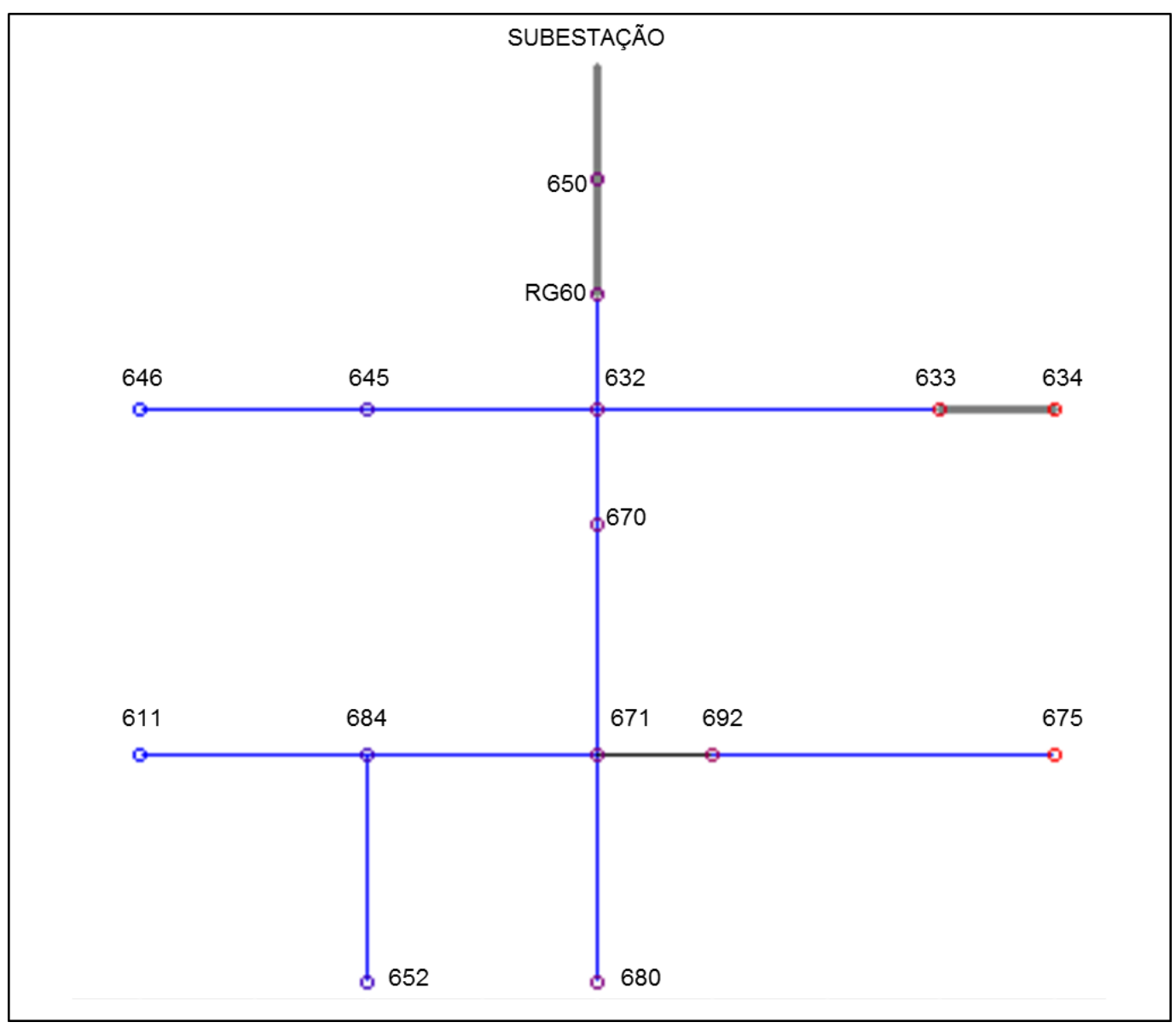

Figura 5.13- Sistema IEEE 13 barras. 
Ajustou-se os parâmetros $\mathrm{N}$, tamanho da amostra, e Nel, amostra de elite, do algoritmo de otimização para 20 e 5, respectivamente, com taxa de elitização de $25 \%$. Esta necessidade de um novo setup, foi devido ao comportamento inadequado do algoritmo com os parâmetros $\mathrm{N}$ e Nel configurados anteriormente para o sistema 35 barras. Isto é, tal necessidade identifica que o algoritmo é sensível ao tamanho do sistema e quantidade de variáveis controladas.

Na Figura 5.14 temos os valores das perdas elétricas por carregamento. No trecho $10 \%-80 \%$, registrou-se $104 \mathrm{~kW}$, enquanto que no trecho $90 \%-100 \%$, as perdas tiveram um aumento de $1 \mathrm{~kW}$.

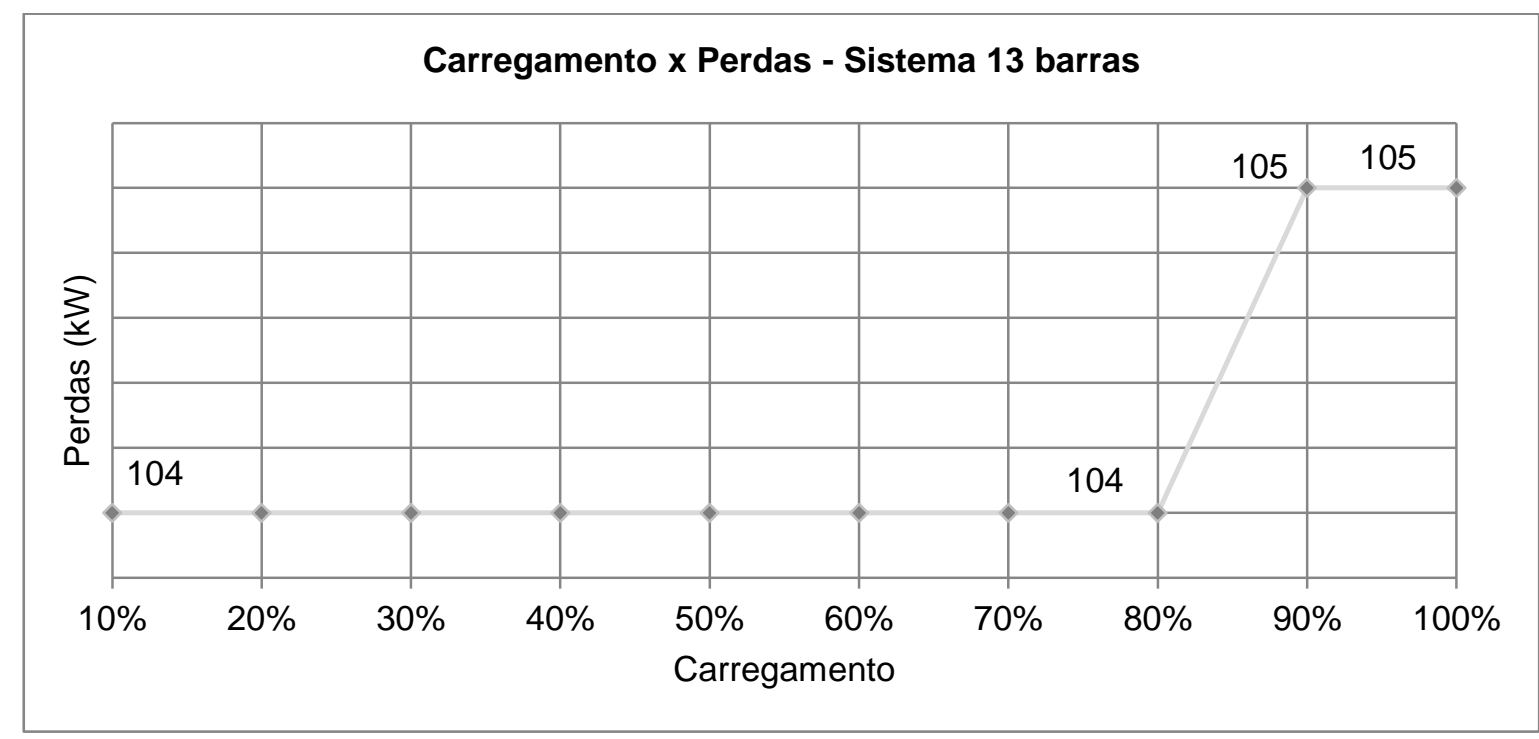

Figura 5.14 - Carregamento x Perdas - Sistema 13 barras.

A Tabela 5.22 mostra a configuração dos bancos C1 e C2 para cada carregamento. Assim como nas perdas, não houve alteração nos valores entre $10 \%$ e $80 \%$. Apenas o banco C1 ajustou-se para 800 kVAr tanto no carregamento de $90 \%$ quanto no de 100\%. A potência reativa total dos bancos de capacitores é apresentada na Figura 5.15. Para os carregamento entre 10\% e 80\%, $1400 \mathrm{kVAr}$ (104 kW de perdas), e para os carregamentos 90\% e 100\%, 1300 kVAr (105 kW de perdas). 
Tabela 5.22 - Bancos de capacitores por carregamento - Sistema 13 barras.

\begin{tabular}{|c|c|c|c|c}
\hline \multirow{2}{*}{ Carregamento } & \multirow{2}{*}{ Perdas (kW) } & \multicolumn{2}{c|}{ Bancos de Capacitores } & \multirow{2}{*}{ Novas Configurações } \\
\cline { 3 - 5 } & & $\mathbf{C 1}$ & $\mathbf{C 2}$ & \\
\hline $10 \%$ & 104 & 900 & 500 & 0 \\
\hline $30 \%$ & 104 & 900 & 500 & 0 \\
\hline $40 \%$ & 104 & 900 & 500 & 0 \\
\hline $50 \%$ & 104 & 900 & 500 & 0 \\
\hline $60 \%$ & 104 & 900 & 500 & 0 \\
\hline $70 \%$ & 104 & 900 & 500 & 0 \\
\hline $80 \%$ & 104 & 900 & 500 & 1 \\
\hline $90 \%$ & 105 & 800 & 500 & 0 \\
\hline $100 \%$ & 105 & 800 & 500 & 0 \\
\hline
\end{tabular}

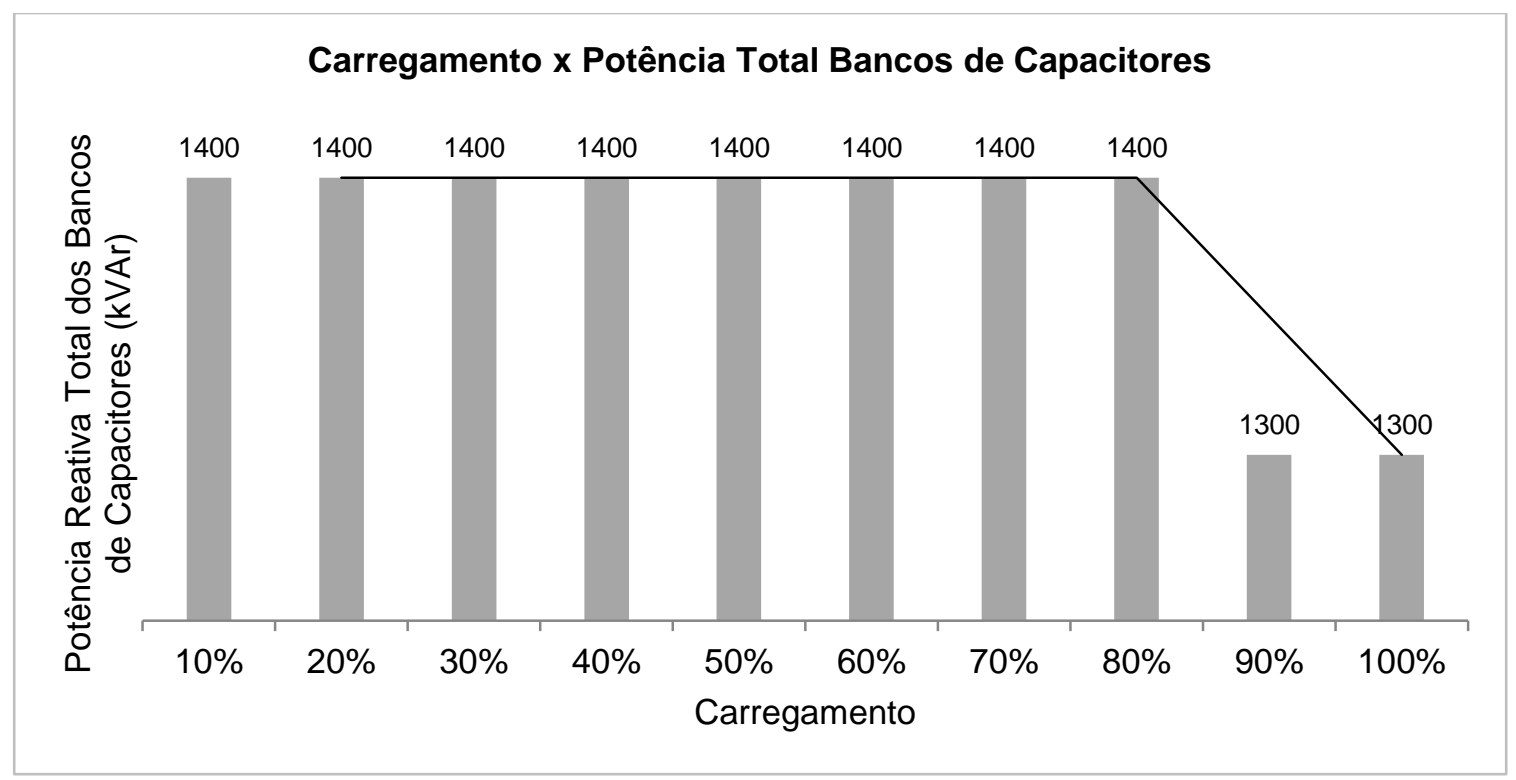

Figura 5.15 - Carregamento x Potência Total Bancos de Capacitores - Sistema 13 barras. 
A tensão fase-neutro, ângulo de fase, tensão fase-fase e ângulo entre fases nas barras para carregamento $10 \%, 50 \%$ e $100 \%$ se encontram na Tabela 5.23 . 0 nível de carregamento pouco interfere no fluxo de carga do sistema e não há violação dos limites de operação 0,93 e 1,05 pu em todos casos.

Percebe-se o desbalanceamento do sistema pela diferença entre os módulos das tensões de uma mesma barra. Isto fica melhor explicado, analisando a Figura 5.16. Nesta, todas as tensões fase-neutro em pu da fase $a, b$ e c são registradas. O desbalanceamento de tensão é mais crítico na barra 675 , onde se observa $5 \%$ entre fase a e b, $1 \%$ entre fase b e c e $4 \%$ entre fase a e c. O ângulo entre as fases é $120^{\circ}$.

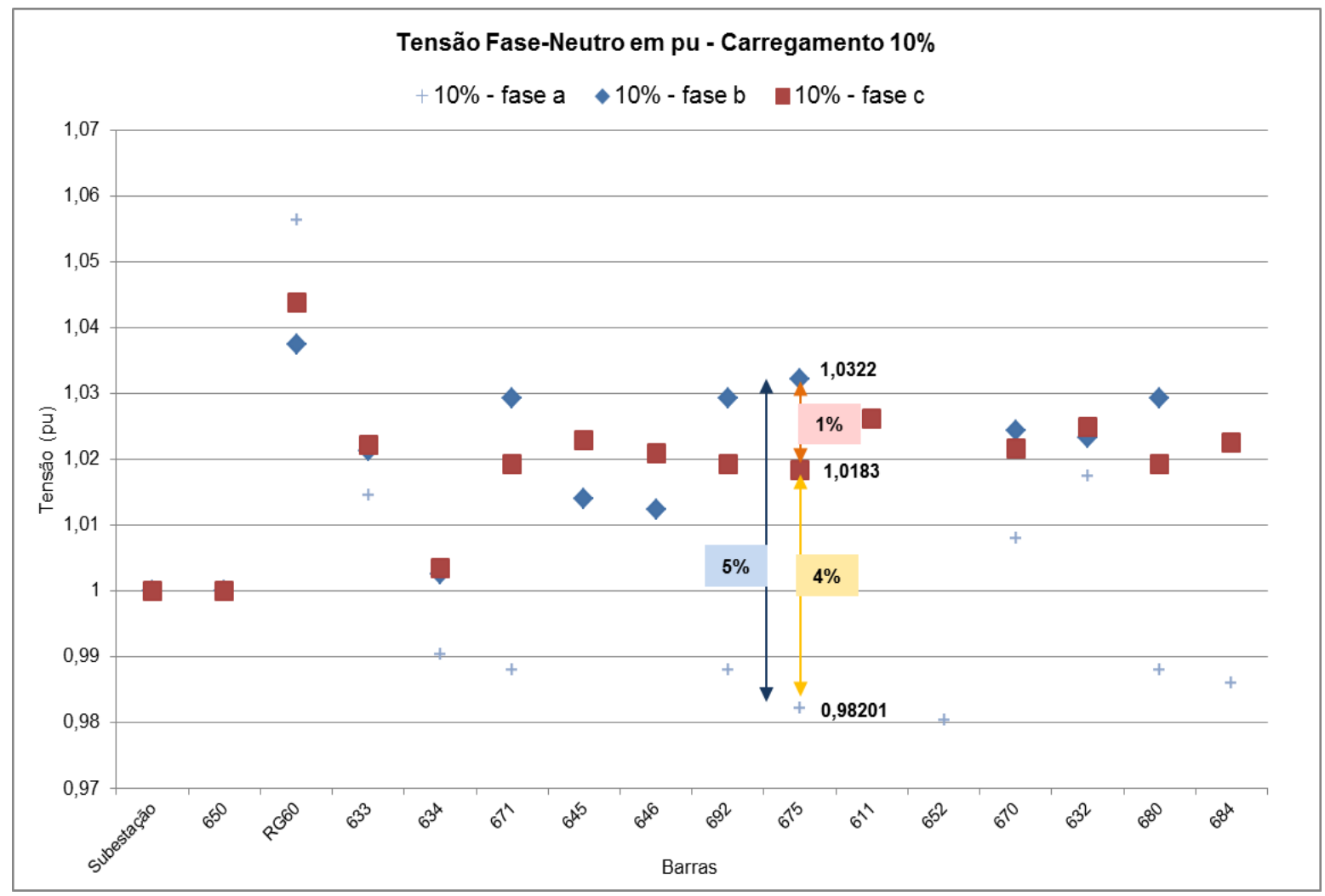

Figura 5.16 - Tensão Fase-Neutro em pu - Carregamento 10\% - Sistema 13 barras. 
Tabela 5.23 - Tensão (pu) nas barras por carregamento - Sistema 13 barras.

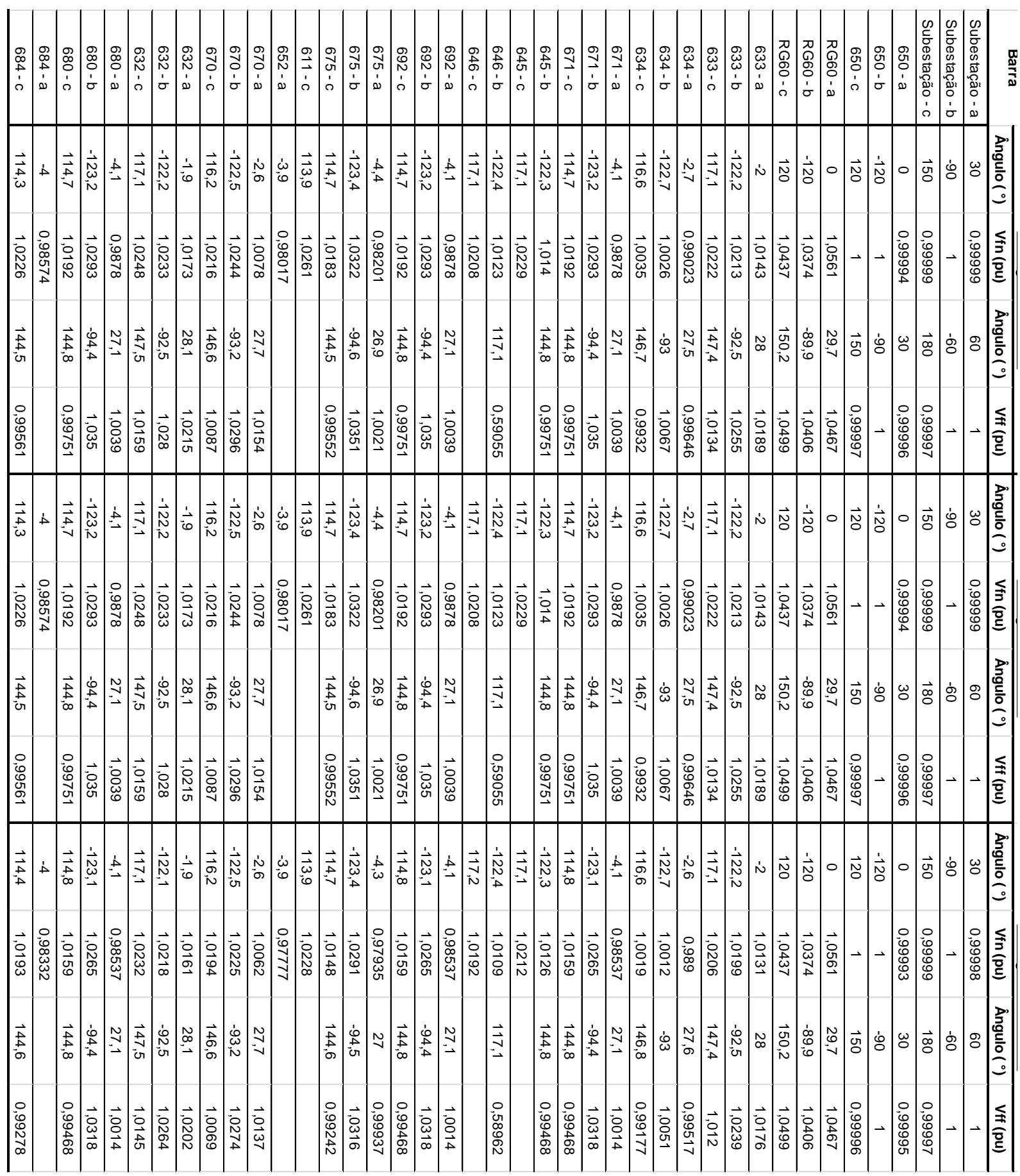




\subsection{Sistema IEEE 123 barras desbalanceado}

Com o propósito de se estudar o comportamento do algoritmo de otimização para sistemas maiores, implementou-se no OpenDSS o sistema IEEE 123 barras. Sua topologia pode ser observada na Figura 5.17. Este sistema é trifásico e desbalanceado, possui 114 cargas trifásicas distribuídas ao longo da rede. A subestação de 4,16 kV se encontra na barra 150. Bancos de capacitores de 600 kVAr cada estão presentes nas barras 83 (C1), 88 (C2), 90 (C3) e 92 (C4). Além disto, há quatro reguladores de tensão localizados nas barras $150 \mathrm{R}, 9 \mathrm{R}, 25 \mathrm{R}$ e 160R.

Simulou-se o sistema, obtendo tensão nas barras, comportamento do algoritmo, perdas elétricas e configuração dos bancos de capacitores.

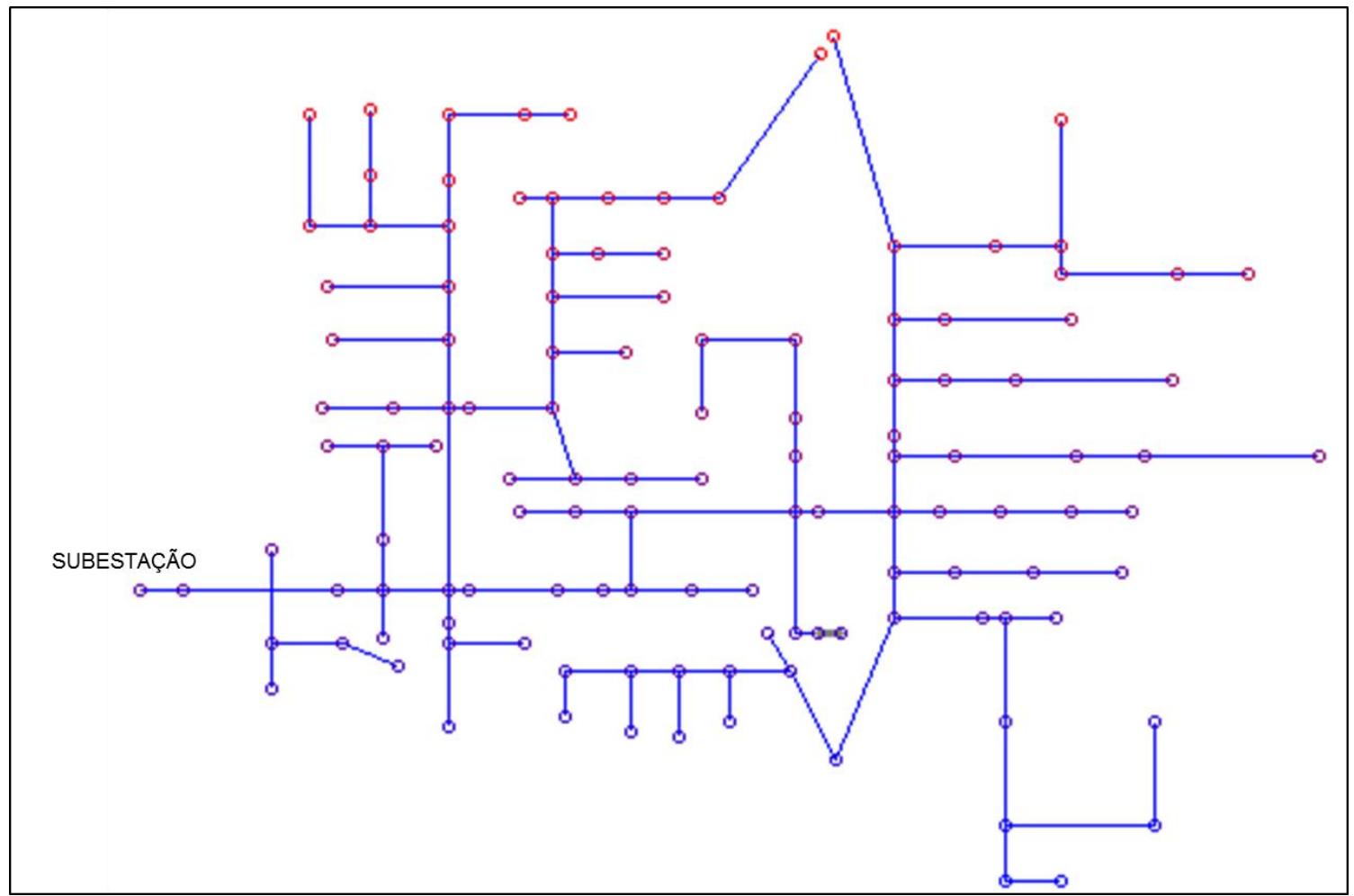

Figura 5.17- Sistema IEEE 123 barras. 
Com taxa de elitização de $20 \%$, ou seja, N, tamanho da amostra inicial, igual a 50 e Nel, tamanho da amostra de elite, igual a 10, o comportamento do algoritmo de otimização é mostrado na Figura 5.18. O algoritmo convergiu com dez iterações, registrando $258 \mathrm{~kW}$ de perdas iniciais e convergindo para $97 \mathrm{~kW}$ de perdas elétricas totais do sistema. Nesta situação, a potência reativa dos bancos de capacitores foi de 500 kVAr (C1), 300 kVAr (C2), 200 kVAr (C3) e 300 kVAr (C4). Nota-se que o algoritmo de otimização proporcionou redução de $62,40 \%$ nas perdas elétricas do sistema. Não houve pontos espúrios nesta simulação como evidenciado nos resultados anteriores, mas sempre um direcionamento para menores perdas em cada iteração. Os dados consideram o sistema operando em plena carga.

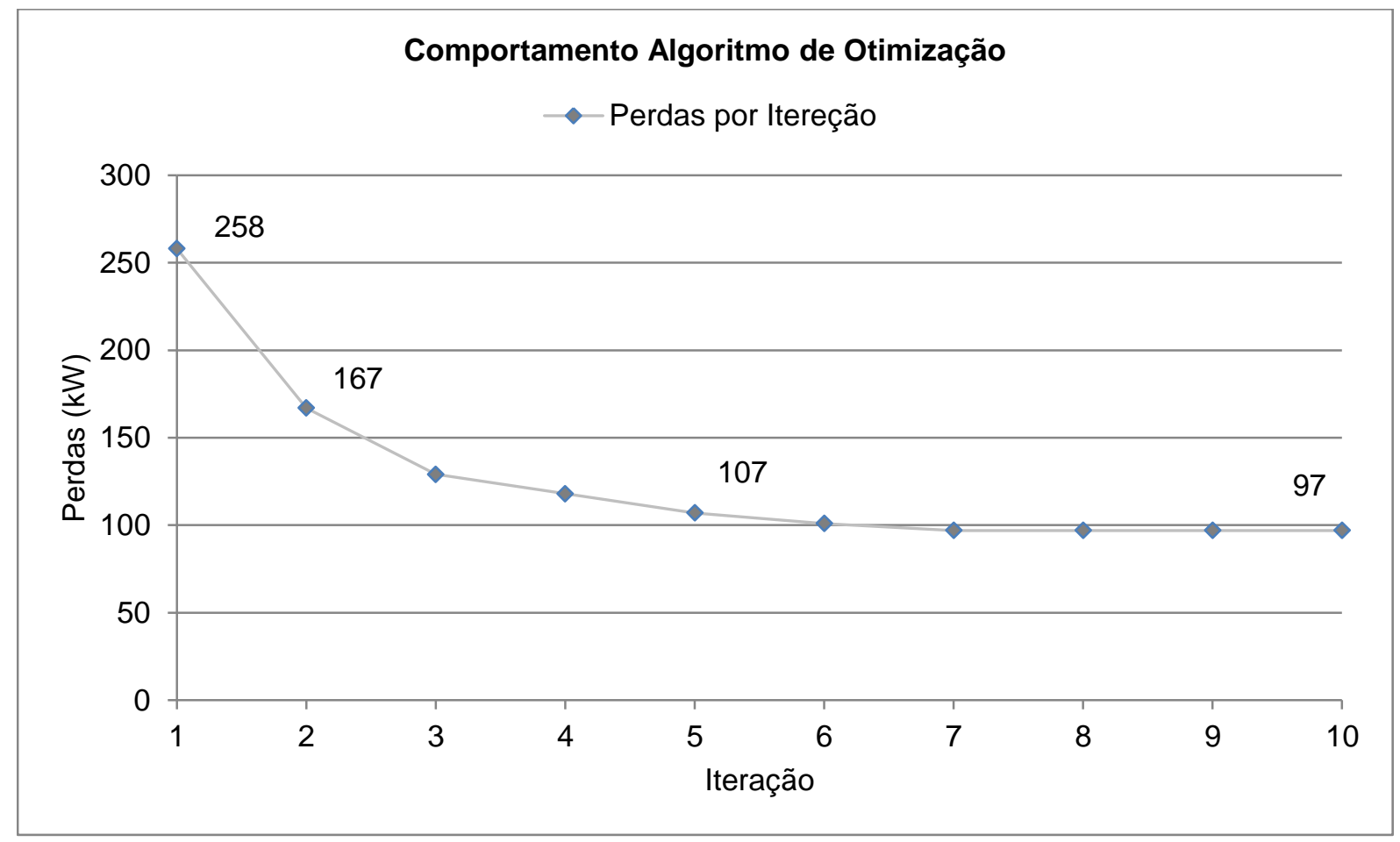

Figura 5.18 - Comportamento Algoritmo Otimização para Sistema IEEE 123 barras. 
Na Figura 5.19 é identificado por cores as tensões nas barras do sistema. Em azul, barras com tensão acima de 1,02 pu. Em verde, barras com tensão entre 1,0 e 1,02 pu. Em vermelho, barras com tensão abaixo de 1,0 pu. Nas barras dos bancos de capacitores, os valores estão acima entre 1,0 pu e 1,02 pu. Os reguladores de tensão $25 \mathrm{R}$ e $160 \mathrm{R}$ registraram tensões abaixo de $1,0 \mathrm{pu}$. Na Tabela 5.24 estão as tensões fase-neutro e fase-fase de todas as barras do sistema.

Portanto, os resultados foram de acordo com o esperado, não havendo necessidade de ajuste nos parâmetros $\mathrm{N}$ e $\mathrm{Nel}$ (taxa de elitização). Mesmo para um sistema com quantidade maior de barras, o algoritmo de otimização convergiu em aproximadamente um minuto.

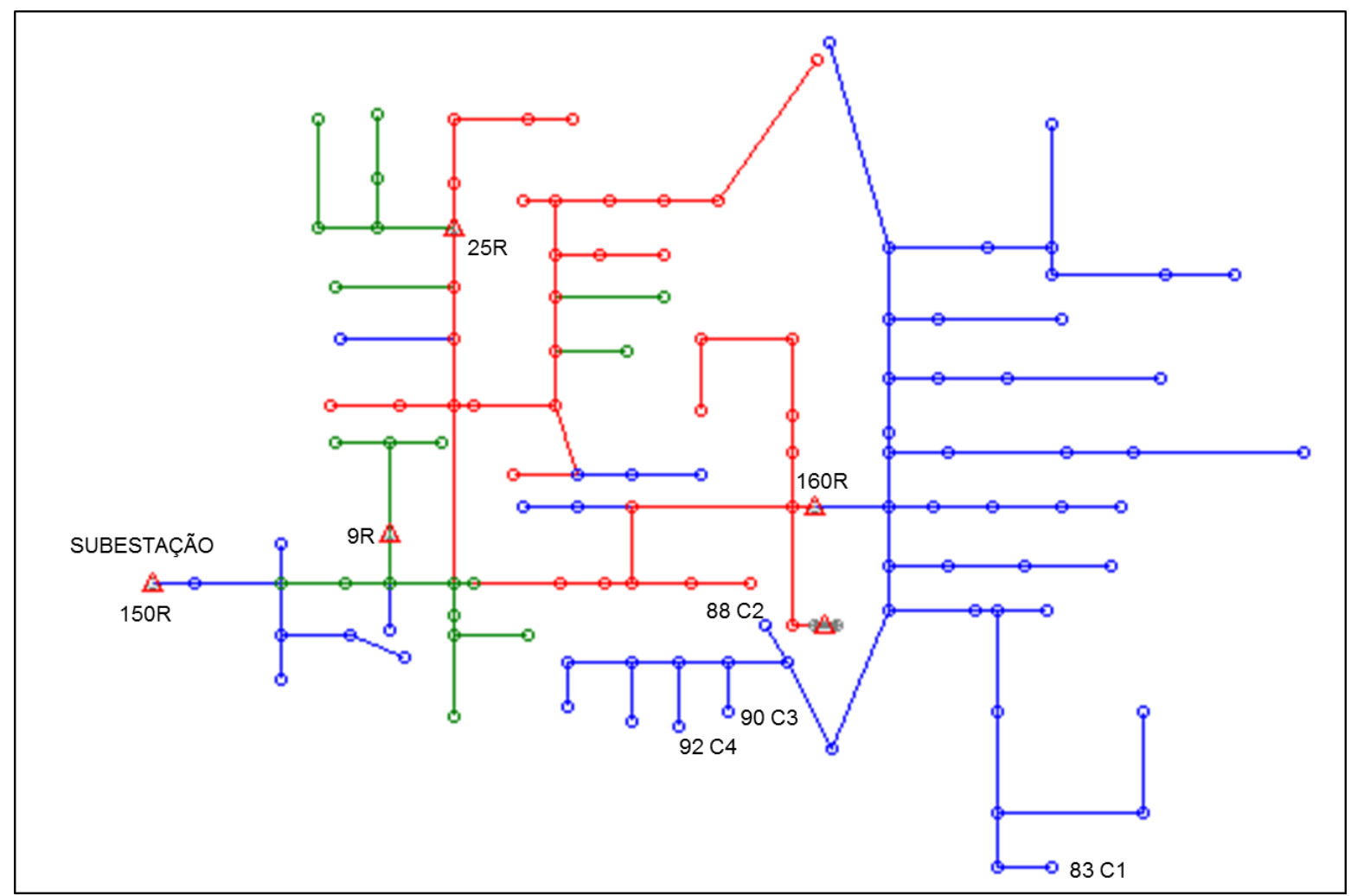

Figura 5.19 - Identificação das tensões nas barras. Azul: barras com tensão acima de 1,02 pu. Verde: barras com tensão entre 1,0 e 1,02 pu. Vermelho: barras com tensão abaixo de 1,0 pu. 
Tabela 5.24 - Tensão fase-neutro e fase-fase para o sistema 123 barras.

\begin{tabular}{|c|c|c|c|c|}
\hline Barra & Ângulo ( ${ }^{\circ}$ ) & Vfn (pu) & Ângulo ( ${ }^{\circ}$ ) & Vff (pu) \\
\hline SUBESTAÇÃO a & 0 & 0,99999 & 30 & 0,99999 \\
\hline SUBESTAÇÃO b & -120 & 1 & -90 & 1 \\
\hline SUBESTAÇÃO c & 120 & 1 & 150 & 1 \\
\hline $150 \mathrm{R}$ a & 0 & 1,0375 & 30 & 1,0375 \\
\hline 150R b & -120 & 1,0375 & -90 & 1,0375 \\
\hline 150R c & 120 & 1,0375 & 150 & 1,0375 \\
\hline $149 a$ & 0 & 1,0375 & 30 & 1,0375 \\
\hline $149 \mathrm{~b}$ & -120 & 1,0375 & -90 & 1,0375 \\
\hline $149 c$ & 120 & 1,0375 & 150 & 1,0375 \\
\hline $1 \mathrm{a}$ & $-0,7$ & 1,0275 & 29,6 & 1,0295 \\
\hline $1 \mathrm{~b}$ & $-120,3$ & 1,0353 & $-90,5$ & 1,0337 \\
\hline $1 \mathrm{c}$ & 119,5 & 1,0306 & 149,4 & 1,0302 \\
\hline $2 \mathrm{~b}$ & $-120,3$ & 1,0351 & & \\
\hline $3 c$ & 119,5 & 1,029 & & \\
\hline $7 \mathrm{a}$ & $-1,2$ & 1,0201 & 29,3 & 1,0238 \\
\hline $7 \mathrm{~b}$ & $-120,6$ & 1,0338 & $-90,8$ & 1,0312 \\
\hline $7 \mathrm{c}$ & 119,2 & 1,0264 & 148,9 & 1,0254 \\
\hline a c & 119,5 & 1,0284 & & \\
\hline $5 c$ & 119,5 & 1,0277 & & \\
\hline $6 \mathrm{c}$ & 119,5 & 1,027 & & \\
\hline $8 \mathrm{a}$ & $-1,5$ & 1,0153 & 29,2 & 1,02 \\
\hline $8 b$ & $-120,7$ & 1,0328 & -91 & 1,0295 \\
\hline $8 \mathrm{c}$ & 119 & 1,0236 & 148,6 & 1,0222 \\
\hline $12 b$ & $-120,7$ & 1,0325 & & \\
\hline $9 \mathrm{a}$ & $-1,6$ & 1,0138 & & \\
\hline $12 \mathrm{a}$ & -2 & 1,0092 & 28,9 & 1,0148 \\
\hline $12 b$ & -121 & 1,0308 & $-91,3$ & 1,027 \\
\hline $12 \mathrm{c}$ & 118,7 & 1,0195 & 148,2 & 1,0177 \\
\hline $9 \mathrm{R} a$ & $-1,6$ & 1,0075 & & \\
\hline $14 \mathrm{a}$ & $-1,6$ & 1,0058 & & \\
\hline $34 \mathrm{c}$ & 118,6 & 1,0185 & & \\
\hline $18 \mathrm{a}$ & $-2,4$ & 1,0002 & 28,6 & 1,0074 \\
\hline $18 \mathrm{~b}$ & $-121,2$ & 1,0267 & $-91,6$ & 1,0203 \\
\hline $18 \mathrm{c}$ & 118,6 & 1,0121 & 147,9 & 1,0112 \\
\hline $11 \mathrm{a}$ & $-1,6$ & 1,0052 & & \\
\hline $10 a$ & $-1,6$ & 1,0055 & & \\
\hline $15 \mathrm{c}$ & 118,6 & 1,0181 & & \\
\hline $16 \mathrm{c}$ & 118,6 & 1,0172 & & \\
\hline $17 c$ & 118,6 & 1,0177 & & \\
\hline
\end{tabular}




\begin{tabular}{|c|c|c|c|c|}
\hline Barra & Ângulo ( ${ }^{\circ}$ ) & Vfn (pu) & Ângulo ( ${ }^{\circ}$ ) & Vff (pu) \\
\hline $19 a$ & $-2,4$ & 0,99886 & & \\
\hline $21 \mathrm{a}$ & $-2,5$ & 0,99962 & 28,6 & 1,0069 \\
\hline $21 \mathrm{~b}$ & $-121,2$ & 1,0267 & $-91,6$ & 1,0198 \\
\hline $21 \mathrm{c}$ & 118,6 & 1,0109 & 147,9 & 1,0105 \\
\hline $20 \mathrm{a}$ & $-2,5$ & 0,99801 & & \\
\hline $22 \mathrm{~b}$ & $-121,3$ & 1,0253 & & \\
\hline $23 a$ & $-2,5$ & 0,9992 & 28,6 & 1,0065 \\
\hline $23 \mathrm{~b}$ & $-121,2$ & 1,0271 & $-91,6$ & 1,0196 \\
\hline $23 \mathrm{c}$ & 118,6 & 1,0098 & 147,9 & 1,0099 \\
\hline $24 \mathrm{c}$ & 118,5 & 1,0084 & & \\
\hline $25 \mathrm{a}$ & $-2,6$ & 0,99854 & 28,6 & 1,006 \\
\hline $25 \mathrm{~b}$ & $-121,2$ & 1,0276 & $-91,6$ & 1,0195 \\
\hline $25 \mathrm{c}$ & 118,6 & 1,0089 & 147,8 & 1,0094 \\
\hline $25 \mathrm{R} \mathrm{a}$ & $-2,6$ & 1,0048 & & \\
\hline $25 \mathrm{R} \mathrm{c}$ & 118,6 & 1,0026 & 148 & 1,0094 \\
\hline $26 \mathrm{a}$ & $-2,6$ & 1,0045 & & \\
\hline $26 \mathrm{c}$ & 118,6 & 1,0021 & 148 & 1,0091 \\
\hline $28 \mathrm{a}$ & $-2,6$ & 0,99817 & 28,6 & 1,0058 \\
\hline $28 \mathrm{~b}$ & $-121,2$ & 1,0278 & $-91,6$ & 1,0194 \\
\hline $28 \mathrm{c}$ & 118,6 & 1,0086 & 147,8 & 1,0092 \\
\hline $27 \mathrm{a}$ & $-2,6$ & 1,0042 & & \\
\hline $27 c$ & 118,6 & 1,0021 & 148 & 1,009 \\
\hline $31 \mathrm{c}$ & 118,5 & 1,0015 & & \\
\hline $33 \mathrm{a}$ & $-2,6$ & 1,0028 & & \\
\hline $29 a$ & $-2,6$ & 0,998 & 28,6 & 1,0057 \\
\hline $29 \mathrm{~b}$ & $-121,2$ & 1,028 & $-91,6$ & 1,0193 \\
\hline $29 \mathrm{c}$ & 118,6 & 1,0081 & 147,8 & 1,009 \\
\hline $30 a$ & $-2,6$ & 0,99826 & 28,6 & 1,0057 \\
\hline $30 \mathrm{~b}$ & $-121,2$ & 1,0279 & $-91,7$ & 1,0192 \\
\hline $30 \mathrm{c}$ & 118,5 & 1,0077 & 147,8 & 1,0088 \\
\hline $250 \mathrm{a}$ & $-2,6$ & 0,99826 & 28,6 & 1,0057 \\
\hline $250 \mathrm{~b}$ & $-121,2$ & 1,0279 & $-91,7$ & 1,0192 \\
\hline $250 \mathrm{c}$ & 118,5 & 1,0077 & 147,8 & 1,0088 \\
\hline $32 \mathrm{c}$ & 118,5 & 1,0011 & & \\
\hline $35 \mathrm{a}$ & $-2,5$ & 0,9974 & 28,5 & 1,0047 \\
\hline $35 \mathrm{~b}$ & $-121,3$ & 1,0241 & $-91,6$ & 1,0183 \\
\hline $35 c$ & 118,5 & 1,011 & 147,8 & 1,0094 \\
\hline $36 \mathrm{a}$ & $-2,5$ & 0,99646 & 28,5 & 1,0042 \\
\hline $36 \mathrm{~b}$ & $-121,4$ & 1,0237 & & \\
\hline
\end{tabular}




\begin{tabular}{|c|c|c|c|c|}
\hline Barra & Ângulo ( ${ }^{\circ}$ ) & Vfn (pu) & Ângulo ( ${ }^{\circ}$ ) & Vff (pu) \\
\hline $40 \mathrm{a}$ & $-2,5$ & 0,99588 & 28,5 & 1,0035 \\
\hline $40 \mathrm{~b}$ & $-121,4$ & 1,023 & $-91,6$ & 1,0172 \\
\hline $40 \mathrm{c}$ & 118,5 & 1,01 & 147,8 & 1,0081 \\
\hline $37 \mathrm{a}$ & $-2,5$ & 0,99568 & & \\
\hline $38 \mathrm{~b}$ & $-121,4$ & 1,023 & & \\
\hline $39 \mathrm{~b}$ & $-121,4$ & 1,0226 & & \\
\hline $41 \mathrm{c}$ & 118,5 & 1,0096 & & \\
\hline $42 \mathrm{a}$ & $-2,6$ & 0,99428 & 28,5 & 1,0022 \\
\hline $42 \mathrm{~b}$ & $-121,4$ & 1,0219 & $-91,7$ & 1,0162 \\
\hline $42 c$ & 118,5 & 1,0091 & 147,7 & 1,0068 \\
\hline $43 \mathrm{~b}$ & $-121,4$ & 1,0205 & & \\
\hline $44 \mathrm{a}$ & $-2,6$ & 0,99319 & 28,5 & 1,0013 \\
\hline $44 \mathrm{~b}$ & $-121,4$ & 1,0212 & $-91,7$ & 1,0154 \\
\hline $44 \mathrm{c}$ & 118,4 & 1,0083 & 147,7 & 1,0058 \\
\hline $45 a$ & $-2,6$ & 0,99266 & & \\
\hline $47 \mathrm{a}$ & $-2,6$ & 0,99215 & 28,4 & 1,0003 \\
\hline $47 \mathrm{~b}$ & $-121,5$ & 1,0201 & $-91,8$ & 1,0145 \\
\hline $47 c$ & 118,4 & 1,0073 & 147,6 & 1,0047 \\
\hline $46 \mathrm{a}$ & $-2,6$ & 0,99226 & & \\
\hline $48 \mathrm{a}$ & $-2,6$ & 0,99187 & 28,4 & 1 \\
\hline $48 \mathrm{~b}$ & $-121,5$ & 1,0198 & $-91,8$ & 1,0142 \\
\hline $48 c$ & 118,4 & 1,007 & 147,6 & 1,0044 \\
\hline $49 a$ & $-2,6$ & 0,99187 & 28,4 & 0,9999 \\
\hline $49 \mathrm{~b}$ & $-121,5$ & 1,0196 & $-91,8$ & 1,0141 \\
\hline $49 c$ & 118,4 & 1,007 & 147,6 & 1,0043 \\
\hline $50 \mathrm{a}$ & $-2,6$ & 0,99185 & 28,4 & 0,9998 \\
\hline $50 \mathrm{~b}$ & $-121,5$ & 1,0196 & $-91,8$ & 1,0141 \\
\hline $50 \mathrm{c}$ & 118,3 & 1,0066 & 147,6 & 1,0041 \\
\hline $51 \mathrm{a}$ & $-2,6$ & 0,99169 & 28,4 & 0,99973 \\
\hline $51 \mathrm{~b}$ & $-121,5$ & 1,0197 & $-91,8$ & 1,0141 \\
\hline $51 \mathrm{c}$ & 118,3 & 1,0066 & 147,6 & 1,0041 \\
\hline $151 \mathrm{a}$ & $-2,6$ & 0,99169 & 28,4 & 0,99973 \\
\hline $151 \mathrm{~b}$ & $-121,5$ & 1,0197 & $-91,8$ & 1,0141 \\
\hline $151 \mathrm{c}$ & 118,3 & 1,0066 & 147,6 & 1,0041 \\
\hline $52 \mathrm{a}$ & $-2,4$ & 1,0058 & 28,6 & 1,0117 \\
\hline $52 \mathrm{~b}$ & $-121,2$ & 1,0299 & $-91,6$ & 1,0263 \\
\hline $52 \mathrm{c}$ & 118,3 & 1,0183 & 147,8 & 1,0158 \\
\hline $53 a$ & $-2,6$ & 1,0043 & 28,4 & 1,0103 \\
\hline $53 \mathrm{~b}$ & $-121,3$ & 1,0292 & $-91,8$ & 1,026 \\
\hline
\end{tabular}




\begin{tabular}{|c|c|c|c|c|}
\hline Barra & Ângulo ( ${ }^{\circ}$ ) & Vfn (pu) & Ângulo $\left({ }^{\circ}\right)$ & Vff (pu) \\
\hline $53 \mathrm{c}$ & 118,2 & 1,0177 & 147,6 & 1,0149 \\
\hline $54 a$ & $-2,7$ & 1,0036 & 28,3 & 1,0095 \\
\hline $54 \mathrm{~b}$ & $-121,4$ & 1,0288 & $-91,9$ & 1,0258 \\
\hline $54 \mathrm{c}$ & 118,1 & 1,0174 & 147,4 & 1,0144 \\
\hline $55 \mathrm{a}$ & $-2,7$ & 1,0034 & 28,3 & 1,0094 \\
\hline $55 \mathrm{~b}$ & $-121,4$ & 1,0287 & $-91,9$ & 1,0257 \\
\hline $55 \mathrm{c}$ & 118,1 & 1,0175 & 147,4 & 1,0144 \\
\hline $57 a$ & -3 & 1,0027 & 28 & 1,0074 \\
\hline $57 \mathrm{~b}$ & $-121,7$ & 1,0263 & $-92,1$ & 1,0244 \\
\hline $57 c$ & 117,8 & 1,0165 & 147,1 & 1,0137 \\
\hline $56 \mathrm{a}$ & $-2,7$ & 1,0034 & 28,3 & 1,0094 \\
\hline $56 \mathrm{~b}$ & $-121,4$ & 1,0285 & $-91,9$ & 1,0257 \\
\hline $56 \mathrm{c}$ & 118,1 & 1,0176 & 147,4 & 1,0144 \\
\hline $58 \mathrm{~b}$ & $-121,7$ & 1,0256 & & \\
\hline $60 \mathrm{a}$ & $-3,8$ & 1,0011 & 27,4 & 1,003 \\
\hline $60 \mathrm{~b}$ & $-122,1$ & 1,022 & $-92,6$ & 1,0218 \\
\hline $60 c$ & 117,2 & 1,014 & 146,5 & 1,0122 \\
\hline $59 \mathrm{~b}$ & $-121,7$ & 1,0253 & & \\
\hline $61 \mathrm{a}$ & $-3,8$ & 1,0011 & 27,4 & 1,003 \\
\hline $61 \mathrm{~b}$ & $-122,1$ & 1,022 & $-92,6$ & 1,0218 \\
\hline $61 c$ & 117,2 & 1,014 & 146,5 & 1,0122 \\
\hline $62 \mathrm{a}$ & $-3,8$ & 1,0003 & 27,4 & 1,002 \\
\hline $62 \mathrm{a}$ & $-122,1$ & 1,0209 & $-92,6$ & 1,0204 \\
\hline $62 \mathrm{c}$ & 117,1 & 1,0119 & 146,5 & 1,0107 \\
\hline $63 \mathrm{a}$ & $-3,7$ & 0,9997 & 27,4 & 1,0013 \\
\hline $63 \mathrm{~b}$ & $-122,1$ & 1,02 & $-92,6$ & 1,0195 \\
\hline $63 c$ & 117,1 & 1,0109 & 146,5 & 1,0098 \\
\hline $64 \mathrm{a}$ & $-3,7$ & 0,99936 & 27,4 & 1,0001 \\
\hline $64 \mathrm{~b}$ & -122 & 1,0182 & $-92,6$ & 1,0178 \\
\hline $64 \mathrm{c}$ & 117,1 & 1,0088 & 146,5 & 1,0082 \\
\hline $65 a$ & $-3,7$ & 0,99865 & 27,5 & 0,99932 \\
\hline $65 \mathrm{~b}$ & -122 & 1,0178 & $-92,6$ & 1,0164 \\
\hline $65 c$ & 117,1 & 1,0058 & 146,6 & 1,0064 \\
\hline $66 \mathrm{a}$ & $-3,8$ & 0,99888 & 27,5 & 0,99929 \\
\hline $66 \mathrm{~b}$ & -122 & 1,0181 & $-92,7$ & 1,0159 \\
\hline $66 \mathrm{c}$ & 117,1 & 1,0043 & 146,6 & 1,0059 \\
\hline $67 \mathrm{a}$ & -4 & 1,0388 & 26,9 & 1,0306 \\
\hline $67 \mathrm{~b}$ & $-122,3$ & 1,0408 & $-92,8$ & 1,0406 \\
\hline $67 c$ & 116,9 & 1,0324 & 146,6 & 1,0406 \\
\hline
\end{tabular}




\begin{tabular}{|c|c|c|c|c|}
\hline Barra & Ângulo $\left({ }^{\circ}\right)$ & Vfn (pu) & Ângulo $\left({ }^{\circ}\right)$ & Vff (pu) \\
\hline $68 \mathrm{a}$ & $-4,1$ & 1,0373 & & \\
\hline $72 \mathrm{a}$ & $-4,1$ & 1,0409 & 26,7 & 1,0314 \\
\hline 72 b & $-122,4$ & 1,0402 & $-92,9$ & 1,0411 \\
\hline $72 \mathrm{c}$ & 116,8 & 1,0335 & 146,4 & 1,0419 \\
\hline $97 \mathrm{a}$ & $-4,1$ & 1,0378 & 26,8 & 1,0297 \\
\hline $97 \mathrm{~b}$ & $-122,3$ & 1,0403 & $-92,8$ & 1,04 \\
\hline $97 \mathrm{c}$ & 116,9 & 1,0317 & 146,5 & 1,0399 \\
\hline $69 \mathrm{a}$ & $-4,1$ & 1,0356 & & \\
\hline $70 \mathrm{a}$ & $-4,1$ & 1,0343 & & \\
\hline $70 \mathrm{a}$ & $-4,1$ & 1,0336 & & \\
\hline $73 \mathrm{c}$ & 116,7 & 1,0313 & & \\
\hline $76 \mathrm{a}$ & $-4,2$ & 1,0421 & 26,6 & 1,032 \\
\hline $76 \mathrm{~b}$ & $-122,5$ & 1,0399 & -93 & 1,0416 \\
\hline $76 \mathrm{c}$ & 116,7 & 1,035 & 146,3 & 1,0432 \\
\hline $74 \mathrm{c}$ & 116,7 & 1,0295 & & \\
\hline $75 c$ & 116,7 & 1,0285 & & \\
\hline $77 \mathrm{a}$ & $-4,3$ & 1,043 & 26,5 & 1,0329 \\
\hline $77 \mathrm{~b}$ & $-122,6$ & 1,0407 & $-93,1$ & 1,0424 \\
\hline $77 \mathrm{c}$ & 116,6 & 1,0356 & 146,3 & 1,0439 \\
\hline $86 \mathrm{a}$ & $-4,3$ & 1,046 & 26,4 & 1,0345 \\
\hline $86 \mathrm{~b}$ & $-122,8$ & 1,0393 & $-93,1$ & 1,0437 \\
\hline $86 \mathrm{c}$ & 116,5 & 1,0402 & 146,2 & 1,0472 \\
\hline $78 \mathrm{a}$ & $-4,3$ & 1,0432 & 26,5 & 1,0332 \\
\hline $78 \mathrm{~b}$ & $-122,6$ & 1,0411 & $-93,1$ & 1,0426 \\
\hline $78 c$ & 116,6 & 1,0357 & 146,3 & 1,044 \\
\hline $79 a$ & $-4,3$ & 1,0429 & 26,5 & 1,033 \\
\hline $79 \mathrm{~b}$ & $-122,6$ & 1,0412 & $-93,1$ & 1,0426 \\
\hline $79 \mathrm{c}$ & 116,6 & 1,0357 & 146,3 & 1,044 \\
\hline $80 a$ & $-4,3$ & 1,045 & 26,5 & 1,0347 \\
\hline $80 \mathrm{~b}$ & $-122,7$ & 1,0424 & $-93,2$ & 1,0438 \\
\hline $80 \mathrm{c}$ & 116,5 & 1,0363 & 146,2 & 1,045 \\
\hline $81 \mathrm{a}$ & $-4,4$ & 1,0457 & 26,4 & 1,0353 \\
\hline $81 \mathrm{~b}$ & $-122,7$ & 1,0431 & $-93,2$ & 1,0443 \\
\hline $81 \mathrm{c}$ & 116,5 & 1,0364 & 146,2 & 1,0453 \\
\hline $82 \mathrm{a}$ & $-4,4$ & 1,0463 & 26,4 & 1,0361 \\
\hline $82 \mathrm{~b}$ & $-122,7$ & 1,0442 & $-93,2$ & 1,0452 \\
\hline $82 \mathrm{c}$ & 116,4 & 1,037 & 146,2 & 1,046 \\
\hline $84 \mathrm{c}$ & 116,4 & 1,0338 & & \\
\hline $83 a$ & $-4,4$ & 1,0474 & 26,4 & 1,0371 \\
\hline
\end{tabular}




\begin{tabular}{|c|c|c|c|c|}
\hline Barra & Ângulo ( ${ }^{\circ}$ ) & Vfn (pu) & Ângulo ( ${ }^{\circ}$ ) & Vff (pu) \\
\hline $83 \mathrm{~b}$ & $-122,7$ & 1,0452 & $-93,3$ & 1,0461 \\
\hline $83 c$ & 116,4 & 1,0376 & 146,1 & 1,0467 \\
\hline $85 c$ & 116,4 & 1,0326 & & \\
\hline $87 a$ & $-4,3$ & 1,0485 & 26,2 & 1,0362 \\
\hline $87 \mathrm{~b}$ & $-122,9$ & 1,0394 & $-93,2$ & 1,0453 \\
\hline $87 c$ & 116,3 & 1,0431 & 146,1 & 1,0495 \\
\hline $88 \mathrm{a}$ & $-4,5$ & 1,0505 & & \\
\hline $89 a$ & $-4,3$ & 1,0474 & 26,2 & 1,0367 \\
\hline $89 \mathrm{~b}$ & -123 & 1,0398 & $-93,2$ & 1,0465 \\
\hline $89 \mathrm{c}$ & 116,3 & 1,0459 & 146 & 1,0498 \\
\hline $90 \mathrm{~b}$ & $-123,1$ & 1,0414 & & \\
\hline $91 \mathrm{a}$ & $-4,2$ & 1,047 & 26,2 & 1,0365 \\
\hline $91 \mathrm{~b}$ & -123 & 1,0388 & $-93,3$ & 1,0472 \\
\hline $91 \mathrm{c}$ & 116,2 & 1,0481 & 146 & 1,0501 \\
\hline $92 \mathrm{c}$ & 116 & 1,0516 & & \\
\hline $93 \mathrm{a}$ & $-4,2$ & 1,0466 & 26,2 & 1,0363 \\
\hline $93 \mathrm{~b}$ & $-123,1$ & 1,0386 & $-93,3$ & 1,0471 \\
\hline $93 \mathrm{c}$ & 116,2 & 1,0482 & 146 & 1,05 \\
\hline $94 \mathrm{a}$ & $-4,3$ & 1,046 & & \\
\hline $95 a$ & $-4,2$ & 1,0466 & 26,2 & 1,0363 \\
\hline $95 \mathrm{~b}$ & $-123,1$ & 1,0383 & $-93,3$ & 1,0469 \\
\hline $95 \mathrm{c}$ & 116,2 & 1,0484 & 146 & 1,05 \\
\hline $96 \mathrm{~b}$ & $-123,1$ & 1,038 & & \\
\hline $98 \mathrm{a}$ & $-4,1$ & 1,0376 & 26,8 & 1,0295 \\
\hline $98 \mathrm{~b}$ & $-122,3$ & 1,04 & $-92,8$ & 1,0397 \\
\hline $98 \mathrm{c}$ & 116,9 & 1,0315 & 146,5 & 1,0397 \\
\hline $99 \mathrm{a}$ & $-4,1$ & 1,0379 & 26,8 & 1,0294 \\
\hline $99 \mathrm{~b}$ & $-122,3$ & 1,0392 & $-92,9$ & 1,0393 \\
\hline $99 \mathrm{c}$ & 116,9 & 1,0311 & 146,5 & 1,0394 \\
\hline $100 \mathrm{a}$ & $-4,1$ & 1,0381 & 26,8 & 1,0293 \\
\hline $100 \mathrm{~b}$ & $-122,3$ & 1,0392 & $-92,9$ & 1,0392 \\
\hline $100 \mathrm{c}$ & 116,8 & 1,0307 & 146,5 & 1,0392 \\
\hline $450 \mathrm{a}$ & $-4,1$ & 1,0381 & 26,8 & 1,0293 \\
\hline $450 \mathrm{~b}$ & $-122,3$ & 1,0392 & $-92,9$ & 1,0392 \\
\hline $450 \mathrm{~b}$ & 116,8 & 1,0307 & 146,5 & 1,0392 \\
\hline $197 \mathrm{a}$ & $-4,1$ & 1,0378 & 26,8 & 1,0297 \\
\hline $197 \mathrm{~b}$ & $-122,3$ & 1,0403 & $-92,8$ & 1,04 \\
\hline $197 \mathrm{c}$ & 116,9 & 1,0317 & 146,5 & 1,0399 \\
\hline $101 \mathrm{a}$ & $-4,1$ & 1,037 & 26,8 & 1,0291 \\
\hline
\end{tabular}




\begin{tabular}{|c|c|c|c|c|}
\hline Barra & Ângulo $\left({ }^{\circ}\right)$ & Vfn (pu) & Ângulo $\left({ }^{\circ}\right)$ & Vff (pu) \\
\hline $101 \mathrm{~b}$ & $-122,3$ & 1,04 & $-92,9$ & 1,0395 \\
\hline $101 \mathrm{c}$ & 116,9 & 1,0311 & 146,5 & 1,0394 \\
\hline $102 \mathrm{c}$ & 116,9 & 1,0297 & & \\
\hline $105 a$ & $-4,2$ & 1,0357 & 26,8 & 1,0283 \\
\hline $105 \mathrm{~b}$ & $-122,4$ & 1,0399 & $-92,9$ & 1,0392 \\
\hline $105 c$ & 116,9 & 1,0314 & 146,5 & 1,0392 \\
\hline $103 c$ & 116,8 & 1,028 & & \\
\hline $104 \mathrm{c}$ & 116,8 & 1,0262 & & \\
\hline $106 \mathrm{~b}$ & $-122,4$ & 1,0387 & & \\
\hline $108 \mathrm{a}$ & $-4,2$ & 1,0342 & 26,8 & 1,0276 \\
\hline $108 \mathrm{~b}$ & $-122,4$ & 1,0405 & $-92,9$ & 1,0392 \\
\hline $108 \mathrm{c}$ & 117 & 1,0313 & 146,4 & 1,0389 \\
\hline $107 \mathrm{~b}$ & $-122,4$ & 1,0373 & & \\
\hline $109 a$ & $-4,3$ & 1,0301 & & \\
\hline $300 \mathrm{a}$ & $-4,2$ & 1,0342 & 26,8 & 1,0276 \\
\hline $300 \mathrm{~b}$ & $-122,4$ & 1,0405 & $-92,9$ & 1,0392 \\
\hline $300 \mathrm{c}$ & 117 & 1,0313 & 146,4 & 1,0389 \\
\hline $110 \mathrm{a}$ & $-4,3$ & 1,0281 & & \\
\hline $111 \mathrm{a}$ & $-4,4$ & 1,0274 & & \\
\hline $112 \mathrm{a}$ & $-4,4$ & 1,0275 & & \\
\hline $113 a$ & $-4,4$ & 1,0254 & & \\
\hline $114 \mathrm{a}$ & $-4,4$ & 1,025 & & \\
\hline $135 a$ & $-2,4$ & 1,0002 & 28,6 & 1,0074 \\
\hline $135 \mathrm{~b}$ & $-121,2$ & 1,0267 & $-91,6$ & 1,0203 \\
\hline $135 c$ & 118,6 & 1,0121 & 147,9 & 1,0112 \\
\hline $152 \mathrm{a}$ & -2 & 1,0092 & 28,9 & 1,0148 \\
\hline $152 \mathrm{~b}$ & -121 & 1,0308 & $-91,3$ & 1,027 \\
\hline $152 \mathrm{c}$ & 118,7 & 1,0195 & 148,2 & 1,0177 \\
\hline $160 \mathrm{R}$ a & $-3,8$ & 1,0386 & 27,1 & 1,0311 \\
\hline $160 \mathrm{R} b$ & $-122,1$ & 1,0412 & $-92,6$ & 1,0409 \\
\hline $160 \mathrm{R} \mathrm{C}$ & 117,2 & 1,033 & 146,8 & 1,0406 \\
\hline $160 \mathrm{a}$ & $-3,8$ & 1,0011 & 27,4 & 1,003 \\
\hline $160 \mathrm{~b}$ & $-122,1$ & 1,022 & $-92,6$ & 1,0218 \\
\hline $160 \mathrm{c}$ & 117,2 & 1,014 & 146,5 & 1,0122 \\
\hline $615 a$ & $-3,8$ & 1,0011 & 27,4 & 1,003 \\
\hline $615 b$ & $-122,1$ & 1,022 & $-92,6$ & 1,0218 \\
\hline $615 c$ & 117,2 & 1,014 & 146,5 & 1,0122 \\
\hline $1000 a$ & $-2,6$ & 0,99169 & 28,4 & 0,99973 \\
\hline $1000 \mathrm{~b}$ & $-121,5$ & 1,0197 & $-91,8$ & 1,0141 \\
\hline
\end{tabular}




\begin{tabular}{c|cccc}
\hline \multicolumn{1}{c}{ Barra } & Ângulo $\left(^{\circ}\right)$ & Vfn (pu) & Ângulo $\left(^{\circ}\right)$ & Vff (pu) \\
\hline $1000 \mathrm{c}$ & 118,3 & 1,0066 & 147,6 & 1,0041 \\
\hline $944 \mathrm{a}$ & $-2,7$ & 1,0036 & & \\
\hline $610 \mathrm{a}$ & $-3,2$ & 1,0029 & 27,4 & 1,003 \\
\hline $610 \mathrm{~b}$ & $-122,3$ & 1,0125 & $-92,6$ & 1,0218 \\
\hline $610 \mathrm{c}$ & 116,8 & 1,0216 & 146,5 & 1,0122 \\
\hline
\end{tabular}




\section{Conclusões}

A análise dos dados mostrados no Capítulo 5 evidencia dois resultados positivos, independente das características do sistema elétrico simulado: a configuração ótima dos bancos de capacitores proporciona ao sistema menores perdas elétricas e melhoria na qualidade da tensão nas barras. No melhor caso, a perda total no sistema de 36 barras foi reduzida para mais de $70 \%$, quando este se encontra no período de menor demanda.

Resultados não esperados foram retratados na Figura 5.6, onde as perdas no período de menor demanda são maiores do que no de maior demanda. Isto indicou necessidade de se estudar mais profundamente os parâmetros da metaheurísitca entropia cruzada.

A Tabela 5.16 consolidou este estudo. Como foi observado, o melhor ajuste para o algoritmo se estabelece na taxa de elitização de $20 \%$, quando tamanho da amostra $\mathrm{N}$ é igual a 50 e amostra de elite Nel é igual a 10. Através desta alteração, os resultados não esperados foram eliminados, como foi mostrado na Figura 5.10 (perdas no período de menor demanda menores do que no de maior demanda). Ainda, estes parâmetros se mostraram sensíveis ao nível de carregamento da rede, tamanho do sistema simulado e quantidade de variáveis (no caso, quantidade de bancos de capacitores). Importante também destacar que o algoritmo não é sensível ao desbalanceamento do sistema, como simulado nos casos 16 e 123 barras. 
Portanto, os resultados alcançados mostram a importância da presença do algoritmo de otimização, representado pela metaheurística entropia cruzada, no dimensionamento de bancos de capacitores em projetos de sistemas de distribuição de energia elétrica.

A funcionalidade permitida pelo OpenDSS, através da interface COM Server, proporciona ao trabalho praticidade e flexibilidade no controle das variáveis de análise. Além disto, por ser uma ferramenta opensource com notoriedade nas fontes de apoio a programação, o software Python corrobora para sua escolha em futuros trabalhos de pesquisa.

A metaheurística Entropia Cruzada se mostrou aderente ao problema de minimização da função objetivo perdas e adaptável às variáveis de controle e tamanho do sistema. Estas características somadas ao OpenDSS, tornam a abordagem de solução uma relevante ferramenta para análise de sistemas de distribuição de energia elétrica. No entanto, é importante destacar que a escolha adequada dos parâmetros iniciais da metaheurística é fundamental para se obter resultados esperados.

Em trabalhos futuros propõe-se realizar a configuração dos parâmetros da metaheurística através de métodos de otimização para se automatizar esta etapa, isto é, a seleção dos parâmetros será com base em análise combinatório de critérios de desempenho dos sistemas de distribuição de energia elétrica, como perfil de tensão, limite de perdas elétricas, desbalanceamento de tensão, etc. Além disto, propõem-se, também, a simulação da abordagem de solução em sistemas maiores, como IEEE 1000 barras. 


\section{Referências Bibliográficas}

[1] Portal Associação Brasileira de Distribuidores de Energia Elétrica (ABRADEE) - A Distribuição de Energia. Disponível em: <http://www.abradee.com.br/setor-dedistribuicao/a-distribuicao-de-energia> Acesso em 2 de agosto de 2015.

[2]BEÊ, R. T. "Alocação de Bancos de Capacitores em Sistema de Distribuição de Energia Elétrica Utilizando Algoritmos Genéticos". Programa de Pós-Graduação em Engenharia Elétrica da Universidade Federal do Paraná, Março, 2007.

[3] PAULA, C. P. "Geração Distribuída e Cogeração no Setor Elétrico: Avaliação Sistêmica de um Plano de Inserção Incentivada". Tese (doutorado em energia Programa Interunidades de Pós-Graduação EP, FEA, IEE, IF) - Universidade de São Paulo, 2004.

[4] SUBRAHMANYAM, J. B. V. "Optimal Capacitor Placement in Unbalanced Radial Distribution Networks". Journal of Theoretical and Applied Information Technology, Vol. 6, No. 1, pp 106-105, 2009.

[5]PEREIRA, B. R., COSSI, M. A., MANTOVANI, J. R. S. "Alocação de Bancos de Capacitores em Sistemas de Distribuição de Energia Elétrica Utilizando Algoritmo Evolutivo Multi-Objetivo". Grupo de Pesquisa em Planejamento de Sistemas de Energia Elétrica, Departamento de Engenharia Elétrica, Faculdade de Engenharia de llha Solteira, Universidade Estadual Paulista - Unesp.

[6]BROOKS, C. L., LEE, R. E. "A Method and Its Aplication to Evaluate Automated Distribution Control". IEEE Transactions on Power Delivery, Vol. 3, No. 3, 1988. 
[7]ABDEL AZIZ, M. M., KHALIL, T. M., YOUSSEF, H. K. M. "Optimal Capacitor Placement on Radial Distribution Feeders in Presence of Nonlinear Loads using Binary Particple Swarm Optimization". $19^{\circ}$ Internation Conference on Elecitricity Distribution, pp 180, Vienna, 21-24 May, 2007.

[8]ZENG, Y., ZHANG, C. "Voltage and Reactive Power Control Method for Distribution Grid". Power and Energy Engineering Conference (APPEEC), IEEE PES Asia-Pacific, 2013.

[9] CIVANLAR, S., GRAINGER, J. J., YIN, H., LEE, S. S. H. "Distribution Feeder Reconfiguration for Loss Reduction". IEEE Transactions on Power Delivery, Vol. 3, No. 3, April 1988, pp. 1217.

[10] CHIS, M., JAYARAM, S., SALAMA, M. M. A. "Capacitor placement in distribution systems using heuristic search strategies". IEE Proc-Gener. Transm. Distrib., Vol. 144, No. 3, May 1997.

[11] GOPIYA NAIK, S., KHATOD, D. K., SHARMA, M. P. "Optimal allocation of combined DG and capacitor for real power loss minimization in distribution networks". Electrical Power and Energy Systems 53 (2013) 967-973.

[12] ABDEL-SALAM, T. S., CHIKHANI, A. Y., HACKAM, R. "A New Technique for Loss Reduction Using Compensating Capacitors Applied to Distribution Systems With Varying Load Condition". IEEE Transactions on Power Delivery, Vol. 9, No. 2, April 1994.

[13] BARAN, M. E., WU F. F. "Optimal Capacitor Placement on Radial Distribution Systems". IEEE Transactions on Power Delivery, Vol. 4, No. 1, January 1989, pp. 725.

[14] MATIN, J. A., GIL, A. J. "A new heuristic approach for distribution systems loss reduction". Electric Power Systems Research 78 (2008) 1953-1958. 
[15] MANTOVANI, J. R. S., ROMERO, R. "Introdução a Metaheurísticas”. Anais do 3ํㅡㄹ Congresso Temático de Dinâmica e Controle da SBMAC; 31-maio a 3-junho de 2004; UNESP - Campus de Ilha Solteira.

[16] CERMY, V. "Termodynamical Approach to theTraveling Salesman Problem: An E_cient Simulation Algorithm", Journal of Optimization Theory and Application, 45(1), pp. 41-51,1985.

[17] KIRKPATRICK, S.; GELATT, Jr. C.D.; VECCHI M. "Optimization by Simulated Annealing", Science, 220(4598), pp. 498-516, 1983.

[18] MICHALEWICZ, Z. "Genetic Algorithms + Data Structures = Evolution Programs". 3ed.

[19] ClOVER, F.; TAILARD, E.; WERRA, D. "A Users Guide to Tabu Search", Annals of Operations Research, Vol. 41, 1993.

[20] GLOVER, F.; LAGUNA, M. "Tabu Search", Kluwer Academic Publishers, 1997.

[21] BOER, P., KROESE D. P., MANNOR, S., RUBINSTEIN, R. Y. "A Tutorial on the Cross-Entropy Method". Annals of Operations Research 134, pg. 19-67, 2005, Springer Science + Business Media, Inc. Manufactured in The Netherlands.

[22] KIM, J., LEE, J., JOO, S. "Assessment of Conditional Value at Risk (CVaR) in Transmission Investment Using Cross Entropy Method". IEEE T\&D Asia 2009.

[23] KOTHARI, R., KROESE, D. P. "Optimal Generation Expansion Planning via The Cross-Entropy Method. Proceedings of the 2009 Winter Simulation Conference.

[24] JALOCON, C. L., NERVES, A. C. "Renewable Energy Portfolio Planning Using the Cross-Entropy Method". IEEE Transction 2013.

[25] CASTRO, J. F. C. "Dimensionamento da Reserva Operativa Considerando Restrições de Transmissão via Método da Entropia Cruzada". Dissertação de Mestrado, Universidade Federal de Itajubá. 
[26] SILVA, S. B. "Análise de operação de sistemas de distribuição utilizando o OpenDSS". Escola de Engenharia de São Carlos, Universidade de São Paulo USP.

[27] Portal Python. Diposnível em: <https://www.python.org/> Acesso em 2 de agosto de 2015.

[28] Portal Electric Power Research Institute (EPRI) - Smart Grid Center. Diposnível em: <http://smartgrid.epri.com/SimulationTool.aspx> Acesso em 2 de agosto de 2015.

[29] "Aprimoramento da Metodologia de Cálculo de Perdas na Distribuição PRODIST - Módulo 7: Cálculo de Perdas na Distribuição". Agência Nacional de Energia Elétrica - ANEEL, revisado em 11/07/2014. BOMPARD, E., CARPANETO, E., CHICCO, G., NAPOLI, R., PIGLIONE, F. "Computations and Users of the Energy Flows For the Distribution System Analysis Over Time Intervals". IEEE 10th Porto Power Tech Conference, Setembro 2001. 


\section{Apêndice}

\section{Software OpenDSS}

O OpenDSS é uma ferramenta de simulação de sistemas elétricos aplicável ao segmento de distribuição. Seu desenvolvimento data de 1997 quando era denominado apenas Distribution System Simulator - DSS. O DSS foi adquirido pela Eletric Power Research Institute - EPRI, que em 2008 lançou o OpenDSS sob uma licença de código aberto [24].

O OpenDSS possui código aberto e é uma plataforma opensource. Além disto, apresenta uma série de vantagens que potencializam sua escolha para este estudo. Algumas de suas vantagens e aplicações podem ser observadas nas Figuras A.1 e A.2, respectivamente.

\begin{tabular}{|c|}
\hline Código Aberto \\
\hline Customizável \\
\hline Expansivel \\
\hline OpenSource \\
\hline Material de apoio - Wiki \\
\hline Suporte Técnico \\
\hline
\end{tabular}

Figura A.1 - Vantagens do OpenDSS. 


\begin{tabular}{|c|}
\hline Fluxo de Carga \\
\hline Geração Distribuída \\
\hline Distorções Harmônicas \\
\hline Planejamento \\
\hline Qualidade de Energia \\
\hline Estimação de Estado \\
\hline Cálculo de Perdas \\
\hline
\end{tabular}

Figura A.2 - Aplicações do OpenDSS.

Com vista à permitir que os usuários possam desenvolver e executar novas soluções customizadas a partir de programas externos, o OpenDSS disponibiliza a interface Component Object Model (COM). A partir dessa interface o programa pode ser acionado de forma totalmente independente de qualquer banco de dados ou arquivo de texto fixo que defina um circuito [24]. Por exemplo, o programa pode ser inicializado a partir de uma ferramenta MS Office, ou se qualquer outro programa de análise que pode suportar COM. Os usuários geralmente acionam o OpenDSS por meio dos programas MATLAB, Python, $C, R$, dentre outros. Isto possibilita a utilização de recursos analíticos externos, bem como outras formas gráficas para exibição dos resultados. Esse aspecto é fundamental para a viabilidade da utilização do OpenDSS no cálculo de perdas na distribuição pela ANEEL, pois permite que o procedimento de cálculo seja realizado de modo iterativo em decorrência da contabilização das perdas técnicas devido às perdas não técnicas [24].

Para este trabalho, escolheu-se o Python $(x, y) 2.7$ como programa externo ao OpenDSS para efetuar os comandos e instruções. O Python é um software que possui praticidade, flexibilidade quanto a escolha do ambiente de desenvolvimento e sua plataforma também é opensource. 


\section{Comunicação Python-OpenDSS}

A comunicação OpenDSS com Python é realizada através da estrutura OpenDSSEngine.DLL registrada automaticamente no RegEdit do Windowns quando o OpenDSS.exe é instalado. Desta forma, apenas é necessário verificar se a interface está disponível entre os dois programas. Com dois simples comandos executados no Console do Python isto pode ser verificado, conforme observado na Figura A.3.

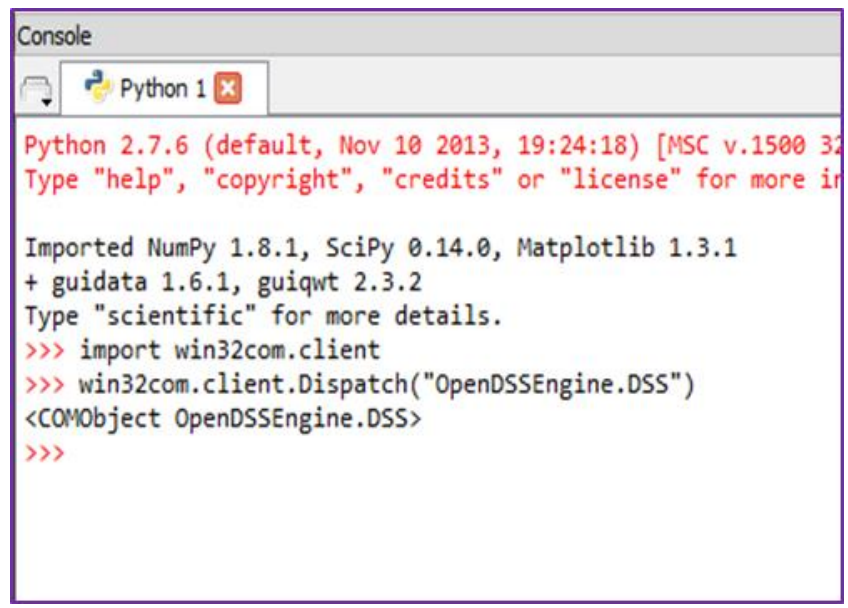

Figura A.3 - Verificação da Interface Python-OpenDSS.

Após esta validação, no ambiente de desenvolvimento do Python, neste estudo, no Spider, se configura a comunicação. Os comandos para isto são mostrados na Figura A.4. 


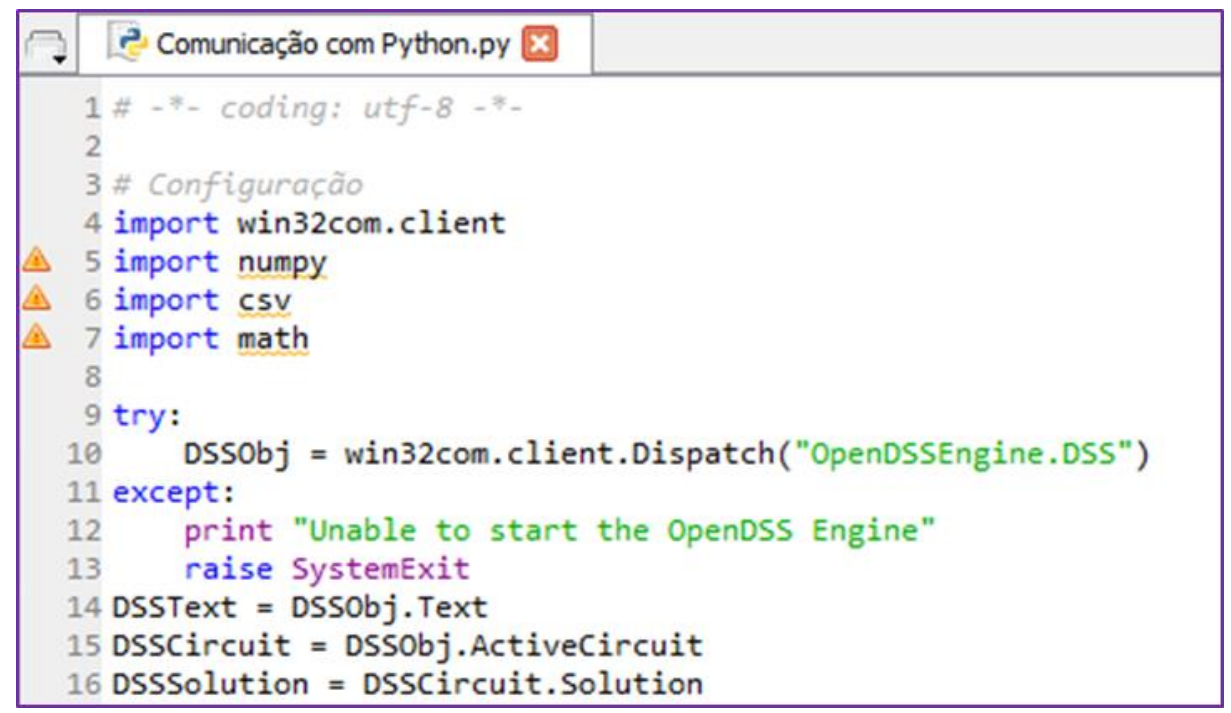

Figura A.4 - Configuração comunicação Python-OpenDSS. 